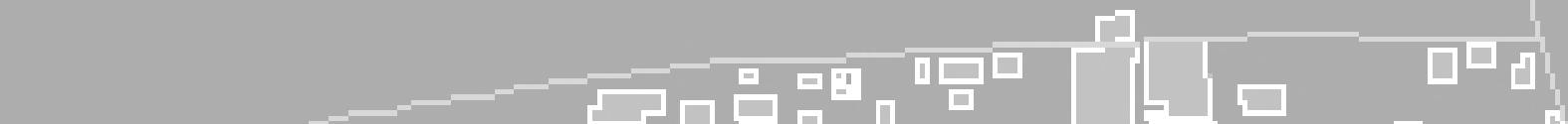 \\ Las Acequias de la Ciudad de México
}

Alejandro Jiménez Vaca

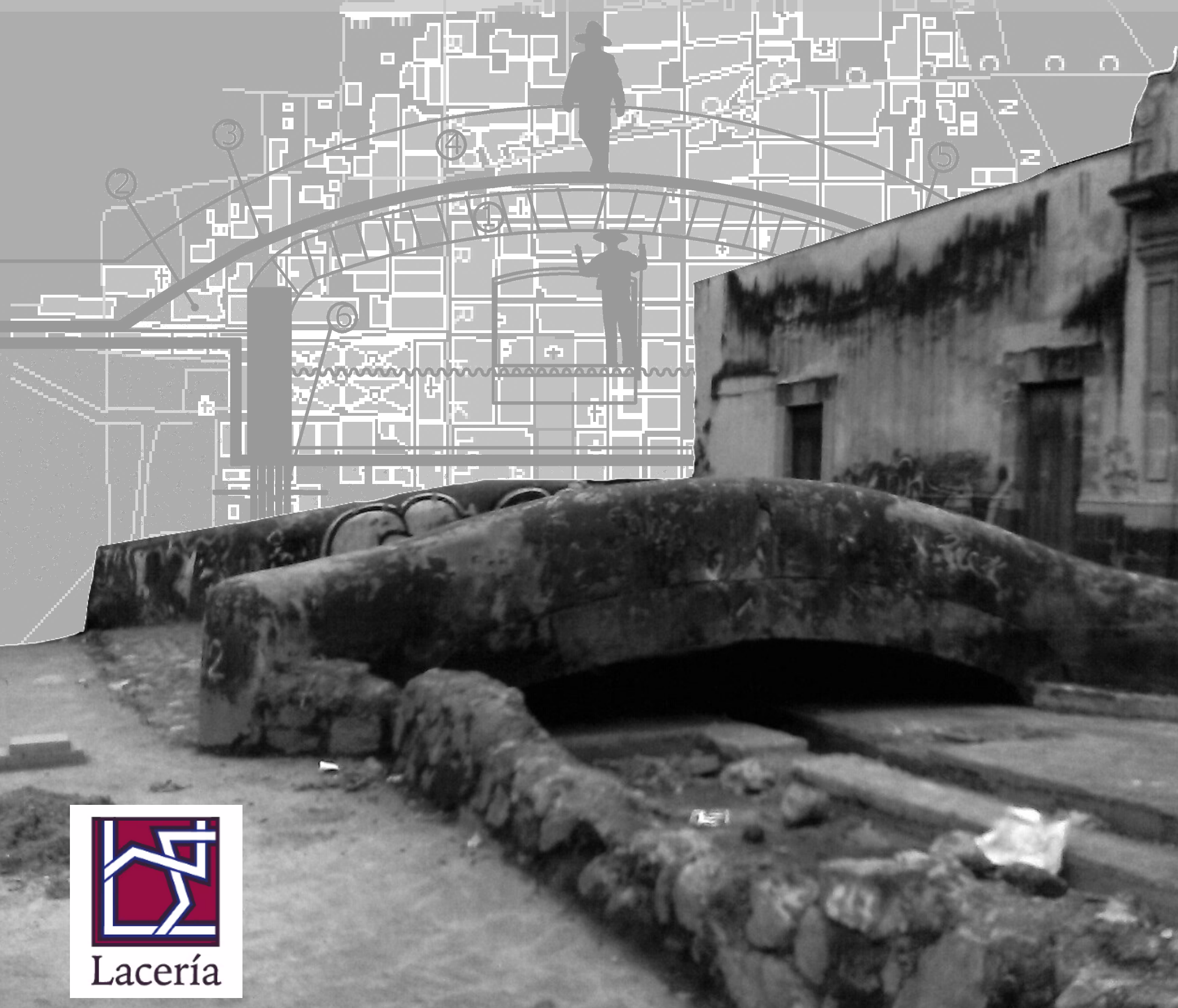




\section{Las Acequias de la Ciudad de México}

\section{Alejandro Jiménez Vaca}

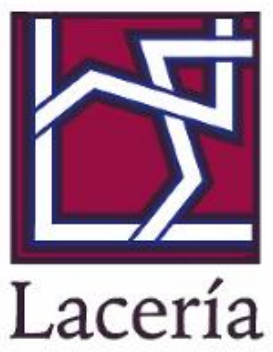


Jiménez Vaca, Alejandro.

Las Acequias de la Ciudad de México.

Primera edición, diciembre, 2020.

Grupo Lacería, Valladolid, España, 2020.

$128 \mathrm{pp}$.

ISBN digital: 978-84-123018-1-6 (PDF electronic eBook).

DOI: www.doi.org/10.37806/egl.2020.002

(C) 2020, Alejandro Jiménez Vaca.

(c) 2020, Editorial Grupo Lacería.

Revisión Técnica:

Pablo Francisco Gómez-Porter

Luis Carlos Cruz-Ramírez

Cerrada de Fresnos No. 44, Interior A503, Colonia Azcapotzalco.

C. P. 02120, Ciudad de México.

Alonso Pesquera 2, 4to, cp. 47002, Valladolid, España

(+34) 695423246

www.grupolaceria.com

editorinchief@grupolaceria.com

First edition, December, 2020.

Digital ISBN: 978-84-123018-1-6 (electronic eBook).

Este libro es un producto derivado del proyecto de investigación SIP 20202190,del Instituto Politécnico Nacional.

La presentación y disposición, en conjunto, es propiedad intelectual del autor. Bajo su consentimiento y en acuerdo con Editorial Lacería, pueden ser reproducidas o transmitidas, por cualquier sistema o método electrónico, incluyendo cualquier sistema de recuperación y almacenamiento de información, siempre y cuando se otorgue el crédito a los autores y a la editorial. La editorial no es responsable de la exactitud de la información contenida en este libro, por error u omisión.

Publicado y hecho en España y Ciudad de México.

Uploaded and made in Spain and Mexico City.

Disponible en la biblioteca virtual: www.grupolaceria.com/books/

Retrieved online on: www.grupolaceria.com/books/ 


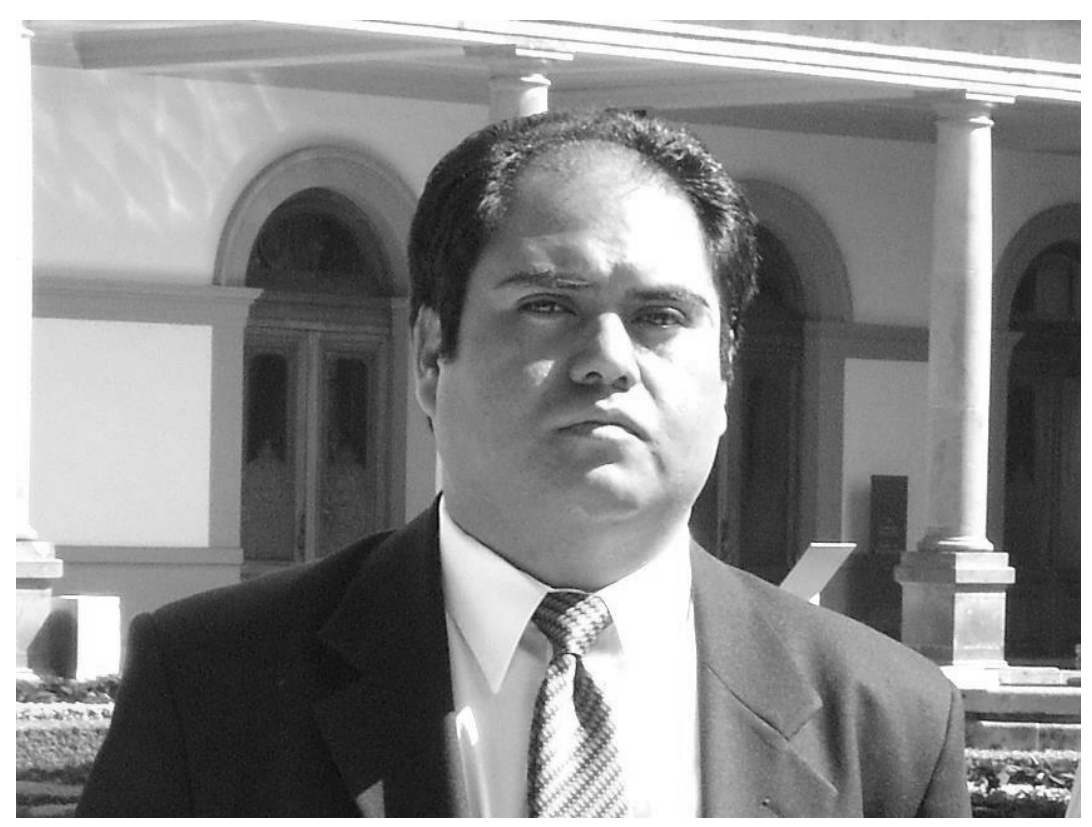

\section{Alejandro Jiménez Vaca}

Doctor en Arquitectura, Maestro en Arquitectura y Arquitecto por la UNAM. Actualmente es Coordinador Académico del Programa de Doctorado de la Sección de Estudios de Posgrado e Investigación (SEPI) de la Escuela Superior de Ingeniería Arquitectura (ESIA), Unidad Tecamachalco del IPN .Es profesor e investigador de la SEPI, ESIA, Unidad Tecamachalco del IPN desde el 2014, donde ha participado en diferentes investigaciones sobre Patrimonio Arquitectónico y Restauración Arquitectónica en temas como las acequias de la época virreinal. Ha impartido diversos cursos relacionados con el patrimonio arquitectónico, la teoría de la restauración arquitectónica y la historia de la arquitectura. Tiene diversas publicaciones referentes a la tecnología hidráulica virreinal, la lectura histórica arquitectónica y la ingeniería virreinal. Ha recibido diversas distinciones como la Medalla Alfonso Caso 2013, por los estudios más destacados del Doctorado en Arquitectura, Posgrado de Arquitectura, UNAM; la Medalla Alfonso Caso 2010, por los estudios más destacados de la Maestría en Arquitectura, Posgrado de Arquitectura, UNAM; y el Premio Nacional INAH, "Francisco de la Maza" 2011, en el área de la Conservación del Patrimonio Urbano Arquitectónico, a la mejor tesis de Maestría. Es miembro del Sistema Nacional de Investigadores del CONACyT en el Nivel 1. ORCID: 0000-0002-5519-9825 


\section{Índice.}

$\begin{array}{ll}\text { Introducción } & 6\end{array}$

PRIMERA PARTE. Las Acequias y la Ciudad. 9

1.- Las acequias: Definición y su función en la Ciudad de México 10

2.- Métodos Constructivos. 11

A.- Acequias Prehispánicas 11

B.- Acequias Europeas y Modernas.

C.- Alimentación de las Acequias en la Ciudad de México. 18

3.- Las acequias como condicionantes en la conformación de la traza urbana de la Ciudad de México. 20

$\begin{array}{ll}\text { A.- Las Calles. } & 20\end{array}$

B.- Las Plazas.

C.- Los Paseos.

4.- Las Acequias en el siglo XVIII. 24

5.- Las acequias como infraestructura urbana. 33

6.- Infraestructura complementaria de las acequias. 34

$\begin{array}{ll}\text { A.- Puentes. } & 34\end{array}$

$\begin{array}{ll}\text { B.- Compuertas. } & 37\end{array}$

7.- Las acequias en la producción. 41

8.- Las acequias en la vida diaria y su influencia en la arquitectura. 42

9.- Mantenimiento de las acequias.

10.- Las reformas borbónicas, desuso, cegamiento y construcción de nuevas acequias. 53

11.- La Acequia Maestra. 56

SEGUNDA PARTE. Las Casas Con Acequia. 63

1.- Definición de Arquitectura habitacional y tipologías en el siglo XVIII. 64

2.- Definición de Casa con Acequia y tipologías. 66

a.- Casa con acequia exenta. 66

b.- Casa con acequia que cruza el frente del inmueble. 67

c.- Casa con acequia que cruza la parte posterior del inmueble. 68

d.- Casa con acequia en la parte interior del inmueble. 69

3.- Núcleos de Casas con Acequia. 69

La Casa de Mesones 91-93, una casa con acequia. 92

Antecedentes históricos de la casa de Mesones 91-93 92

Colindancias y el entorno Urbano. 96

Análisis espacial. $\quad 97$

$\begin{array}{lr}\text { Conclusiones. } & 101\end{array}$

Anexos.

ANEXO 1. PLANO DE LA CIUDAD DE MÉXICO CON LOS 480 INMUEBLES DEL SIGLO XVIII CON USO 106 DE VIVIENDA Y CASAS CON ACEQUIA DEL SIGLO XVIII.

ANEXO 2. Plano de puentes en la ciudad de México. 109

ANEXO 3. OBRAS HIDRÁULICAS EN LA CUENCA DE MÉXICO EN EL SIGLO XVIII. 117

$\begin{array}{ll}\text { GLOSARIO } & 121\end{array}$

$\begin{array}{lr}\text { Fuentes de Información. } & 125\end{array}$ 


\section{INTRODUCCIÓN}

La aparente rectitud y orden que pareciera prevalecer en la traza urbana de las calles del Centro Histórico de la Ciudad de México, se ve ocasionalmente interrumpida por ligeras curvaturas; en algunos casos éstas se muestran de forma muy notoria pues se puede observar, cuando se transita por las calles, que estas irregularidades sin ninguna importancia aparente responden al pasado lacustre de la ciudad; urbe que era regida por el medio físico en el que se encontraba inmersa, correspondiendo la traza de estas calles con las antiguas vialidades acuáticas del México Prehispánico y Virreinal, canales que fueron conocidos con el nombre de acequias (las cuales, al cegarse, fueron ocupadas como vías de comunicación terrestre; aunque hay algunas que escapan a la vista del transeúnte de éta atareada ciudad).

En las crónicas del capitán conquistador proveniente de Extremadura, don Hernando Cortés ${ }^{1}$, así como en las del soldado español Bernal Díaz del Castillo, se da cuenta de lo bien trazada que estaban las calles de México-Tenochtitlán, enfatizando lo amplio y la buena hechura de las calzadas prehispánicas, así como lo recto de su trazo. El soldado Alonso García Bravo, quien por sus aportes en la edificación de sencillas construcciones militares en la guerra de conquista asumió el cargo de Primer Gran Alarife de la Ciudad ${ }^{2}$, trazó la nueva ciudad en base a los ideales renacentistas de la retícula del damero de ajedrez, sobreponiendo las manzanas de los solares a la antigua urbe. La traza de las nuevas calles, sin embargo, no pudo ser perfectamente recta en todos los casos, ya que las antiguas vialidades acuáticas impedían que esta planeación se llevara conforme a lo

\footnotetext{
1 “...son las calles de ella digo las principales muy anchas y muy derechas y algunas de éstas y todas las demás con la mitad de tierra y por la otra mitad de agua, por la cual andan sus canoas todas las calles de trecho a trecho están abiertas por donde atraviesa el agua de las unas a las otras; y en todas estas aberturas que son muy anchas hay puentes... por todas ellas pueden pasar diez a caballo juntos a la par, las calzadas son anchas como dos lanzas muy bien obradas..." CORTÉS, Hernán, Cartas de Relación, Editorial Porrúa, México 1979 p 62. VALERO DE GARCíA LASCURÁIN, Ana Rita La ciudad de México-Tenochtitlán su primera traza 1524-1534, Editorial Jus, México, 1992 p. 49.

${ }^{2}$ TOUSSAINT, Manuel, Planos de la Ciudad de México, Siglos XVI y XVII, UNAM, México, 1990, p 21 y 22.
} 
previsto por lo que, en algunos casos, la trayectoria siguió el trazo de las acequias; la apariencia del damero se percibía en el exterior de las calles, no así en algunas manzanas en las que algunas acequias quedaron en el interior de los solares, lo que provocó que los edificios tuvieran que adoptar soluciones únicas respecto a otras edificaciones que no se encontraban en esta situación.

Para establecer las razones de las características de este tipo de inmuebles, en el texto sucesivo se analizarán los cambios de las acequias, atendiendo las diferencias entre las acequias prehispánicas, las europeas y las que se construyen en la actualidad, definiendo los usos para los que se destinaron y sus métodos constructivos; del mismo modo, se verán los elementos que son indispensables para su funcionamiento, como puentes, compuertas y sifones, además de la relación inherente entre ellas y la cuenca.

El desuso de las acequias dentro de la ciudad, vinculado al descendimiento del nivel de los lagos, así como al descuido y suciedad en que éstos habían caído, permitió replantear por parte de los arquitectos de la llustración la utilidad de las acequias como método de irrigación agrícola, como vía de comunicación acuática y como protección de la misma ciudad, ratificando este elemento como un método muy valioso para la urbanización de la ciudad de finales del siglo XVIII y del siglo XIX. En el texto se analizará, por lo tanto, la utilización de las acequias durante este período, así como su reivindicación como un componente muy importante en la planeación urbana.

Se plantea también una localización hipotética de las acequias en un plano actual, a partir del análisis de varios planos de la Ciudad de México que permiten tener una visión del trayecto de las mismas, comenzando desde el plano de Upsala, de 1555, que da cuenta de la forma de las acequias en el siglo XVI, la perspectiva de Juan Gómez de Trasmonte de 1628, y el plano de Johannes Vingboons de 1665 (basado en la perspectiva de Trasmonte); documentos que dan cuenta de las acequias antes de la inundación de 1629. Se utilizan a su vez el plano de Pedro de Arrieta y los Maestros de la Arquitectura de 1737 (que permite ver la red de acequias antes del cierre perimetral de la ciudad mediante la Acequia Maestra), el plano de José Antonio Alzate de 1772 (que permite ver la ubicación 
de la acequia de San Pedro y San Pablo, la cual no es posible ver en otros planos), el Plano de Juan Manuel de Villavicencio de 1782 (donde se aprecian las acequias con gran parte del trazo de los canales que existían antes de su cegamiento), a la vez que se distingue el trayecto de la acequia perimetral en el plano de Diego García Conde de 1793 (donde se puede observar la Acequia de Resguardo, las garitas que rodeaban la ciudad y el centro de la urbe ya sin las acequias que se habían cegado). Simultáneamente, se pueden observar los Paseos de Azanza y de Revillagigedo, sumados a las avenidas de la Piedad y de la calzada de Guadalupe.

Por otra parte, se presenta como anexo un plano de ubicación de puentes, el cual fue indispensable para ubicar el trayecto de las acequias, ya que varios autores hacen referencia a los puentes para indicar su recorrido. Se realizó, así mismo, una identificación de los nombres y la localización de los puentes respecto al nombre original de las calles y el actual de las mismas; para poder realizar esto se analizaron los siguientes planos: el de Pedro de Arrieta y los Maestros de la Arquitectura, de 1737; el de Juan Manuel de Villavicencio, de 1782; el de Diego García Conde, de 1793; y el plano de Antonio García Cubas de 1881, éste último permitió ubicar por el nombre de las calles el Puente de las Guerras, el Puente del Zacate, el Puente de Solano y el Puente de la Soledad.

Finalmente, después de la localización de las acequias en un plano actual, éste permitió la identificación de las casas que se encontraban en su trayecto, adoptando, para este tipo de edificaciones, el término de casas con acequia. Se analizaron en este tipo de construcciones los rastros de los canales en su traza arquitectónica, así como las diversas fases de cegamiento de las que fueron objeto. De la misma manera, se determinaron los elementos arquitectónicos que le dan a este tipo de inmuebles peculiaridades únicas respecto a otras construcciones. 


\section{PRIMERA PARTE \\ Las Acequias y la Ciudad}




\section{1.- Las acequias: Definición y su función en la Ciudad de México.}

Los antiguos apantles o canales mexicas ${ }^{3}$ fueron renombrados por los españoles como acequias, palabra que heredaron de la cultura musulmana, y que tiene su base etimológica en la palabra as-saqiya o zaquia, que quiere decir "la que da de beber" o "la reguera"4. En lo que respecta a la utilización de este vocablo en lengua castellana y en términos arquitectónicos, las acequias son descritas por algunos autores como canales para irrigación agrícola ${ }^{5}$ o simplemente como zanjas que conducen agua ${ }^{6}$. Las acequias en la Ciudad de México, a consecuencia de su origen prehispánico diferían ligeramente de esta definición, desempeñando diversas funciones, la principal de ellas era servir como vías de desfogue de las corrientes del lago que eran provocadas por los ríos de los cuales se alimentaba, corrientes que prevalecieron desde tiempos anteriores a la fundación de México-Tenochtitlán y durante toda la existencia de la misma, así como en la ciudad novohispana. Esto hizo que las acequias se fueran conformando de forma distinta a como se hacían tradicionalmente en las ciudades europeas, en las cuales se excavaba el terreno para construir un canal que dirigía el agua de algún río cercano hacia algún campo de cultivo de un poblado, teniendo las acequias una doble función: la de irrigar tanto como la de recolectar el exceso de agua en los sembradíos. La solución inicial adoptada por los mexicas fue construir chinampas ${ }^{7}$ para ganarle terreno al lago, aunque respetando sus corrientes; dichas corrientes limitadas por chinampas se convirtieron en acequias, las cuales fueron de suficiente anchura para poder navegar por ellas varios acallis

\footnotetext{
${ }^{3}$ SIERRA, Carlos Justo, Breve Historia de la Navegación en la Ciudad de México, Departamento del Distrito Federal, 1973, p. 55.

${ }^{4}$ REAL ACADEMIA ESPAÑOLA, Diccionario de Autoridades, Editorial Gredos, Madrid, España, 2002.

${ }^{5}$ CAMACHO CARDONA, Mario, Diccionario de Arquitectura y Urbanismo, Editorial Trillas, México, 1998. $\mathrm{p} 12$.

${ }^{6}$ GONZÁLEZ LICÓN, Héctor Javier, Glosario de Términos Técnico Arquitectónicos, Universidad Michoacana de San Nicolas de Hidalgo, 1994, p11.

${ }^{7}$ Chinampa: del náhuatl chinámitl que quiere decir reja o seto de cañas. Armazón hecho con cuerdas de ixtle y con troncos delgados de árbol sobre los cuales se ponían transversalmente cañas más delgadas y una capa gruesa de tierra vegetal. VALERO DE GARCÍA LASCURÁIN, Ana Rita, La ciudad de México-Tenochtitlán, su primera traza 1524-1534, Editorial Jus, México, 1992 p. 47.
} 
o canoas. Tal solución tuvo que ser respetada por la sociedad virreinal, pues las inundaciones con las que continuamente se vieron afectados los habitantes de esa época hizo que adoptaran esta solución como propia, sumándose a ello el romanticismo idílico de vivir en una ciudad en medio de un lago.

\section{2.- Métodos Constructivos}

\section{A.- Acequias Prehispánicas}

Al igual que las acequias europeas, en múltiples zonas del altiplano mexicano, así como en las riberas de la cuenca de México, las acequias eran una parte del variado repertorio de métodos de cultivo que se utilizaban en la producción agrícola; fundamentalmente el método constructivo en lugares de tierra firme se basaba en el siguiente procedimiento: se excavaba la tierra para obtener el agua de una fuente constante de abastecimiento, ya fuera un río o un lago, y era dirigida hacia una afluente principal o acequia primaria que recibía el nombre de acalote ${ }^{8}$; a partir de ésta se ramificaban múltiples acequias secundarias que recibían el nombre de apantles (aunque en la actualidad a cualquier canal prehispánico se le da el nombre genérico de apantle). Estas acequias secundarias eran conducidas a núcleos de sembradíos conectados entre sí por pequeños canales, formando una red de camellones denominados chinampas atlazompa. La excavación debía hacerse con una pendiente, y en caso de que en algunos tramos los desniveles que se encontraban a su paso fueran demasiado pronunciados, se utilizaban troncos ahuecados, llamados canoas, para conectar los tramos interrumpidos. Los anchos de dichas acequias secundarias eran de $50 \mathrm{~cm}$ a $1.50 \mathrm{~m}$, y eran reforzadas con piedras en las partes en que así se requiriera.

\footnotetext{
${ }^{8}$ Acalote: Atl-agua, calli-casa, otli, camino. VALERO DE GARCÍA LASCURÁIN, Ana Rita, La ciudad de México-Tenochtitlán, su primera traza 1524-1534, Editorial Jus, México, 1992 p. 51.
} 

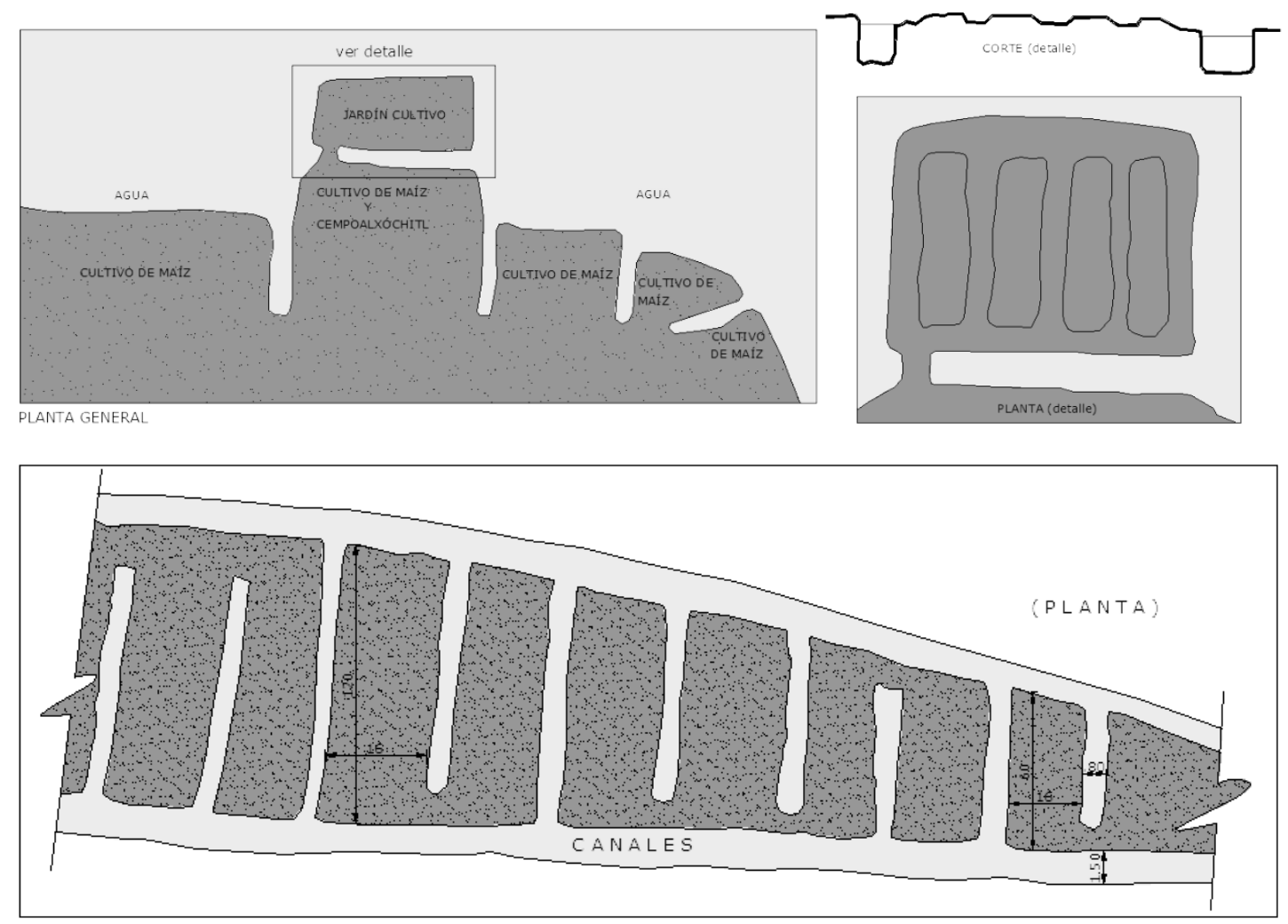

Cultivos de chinampas o camellones atlazompa, tierra adentro y laguna adentro, alimentadas por acequias. Redibujo de imágenes tomadas del libro, Historia de la Agricultura, Época prehispánica siglo XVI, de Rojas Rabiela, Teresa, Sanders, William, Tomo II, Instituto Nacional de Antropología e Historia, México, 1989 p. 72, 73 y 105. Redibujo: Alejandro Jiménez Vaca.

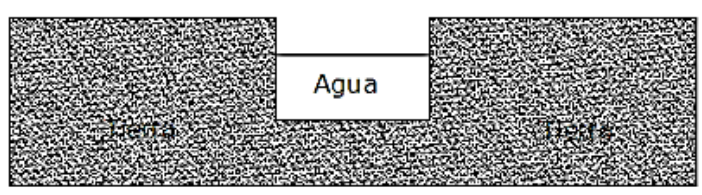

Teopantecuanitlan, Guerrero
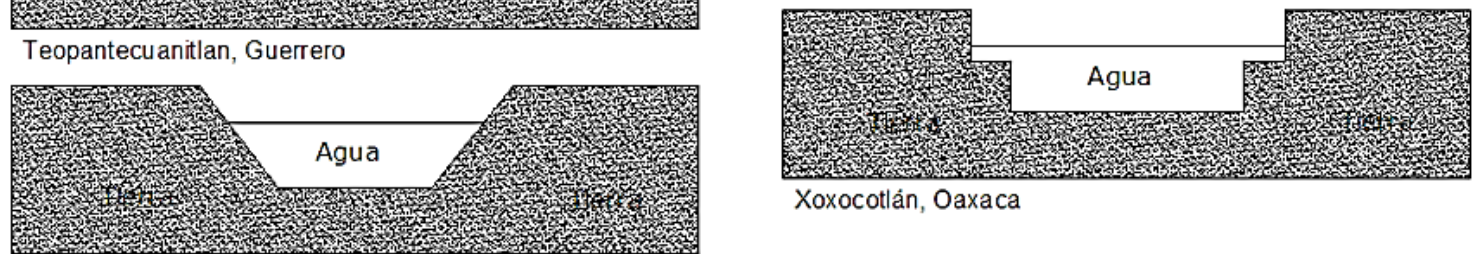

Santa Clara Coatitlán, México
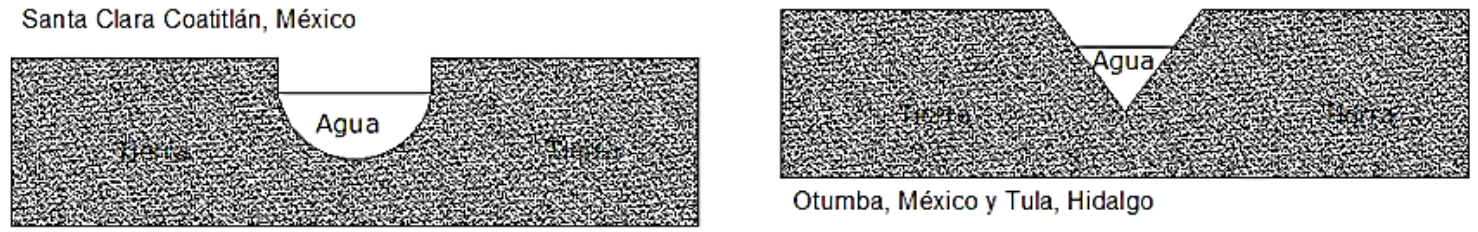

Tlaxcala

Otumba, México y Tula, Hidalgo

Tipologías de acequias prehispánicas. Dibujo de Alejandro Jiménez Vaca, basado en datos de Teresa Rojas Rabiela, Semblanza Histórica del Agua en México, SEMARNAT, CONAGUA, México, 2009, p. 13 
Las formas de los canales desarrollados en Mesoamérica fueron, en orden cronológico, las siguientes: en corte y en forma rectangular (Teopantecuanitlan, Guerrero); en forma trapezoidal (Santa Clara Coatitlán, México); en“U” (Tlaxcala); y en escalonado (Xoxocotlán, Oaxaca). Más tarde apareció la forma de "V" (Otumba, México y Tula, Hidalgo) ${ }^{9}$.

Como se ha señalado anteriormente, las acequias de la Ciudad de México variaban en el método de tierra firme, siguiendo el método de las chinampas laguna adentro; mismo que se utilizó para ganarle terreno al lago, delimitando la zona que se iba a cubrir mediante empalizadas de otates o carrizos clavadas en el fondo del lago, y que se llenaban de piedras y tierra. Este procedimiento era utilizado de forma general para delimitar el área de tierra firme con respecto al lago; en pocos casos se utilizó piedra que en ocasiones iba protegida con un aplanado de cal, como en las calzadas de Iztapalapa y Tacuba ${ }^{10}$, conforme lo mencionado por Hernán Cortés en sus Cartas de Relación, en que las acequias mantenían el aspecto de palizadas, y que contenían la tierra en sus bordes cuando fueron observadas por los conquistadores españoles en los primeros encuentros con los mexicas. Posteriormente, en el período virreinal, fueron sustituidas por muros de piedra que ahora contenían las acequias.

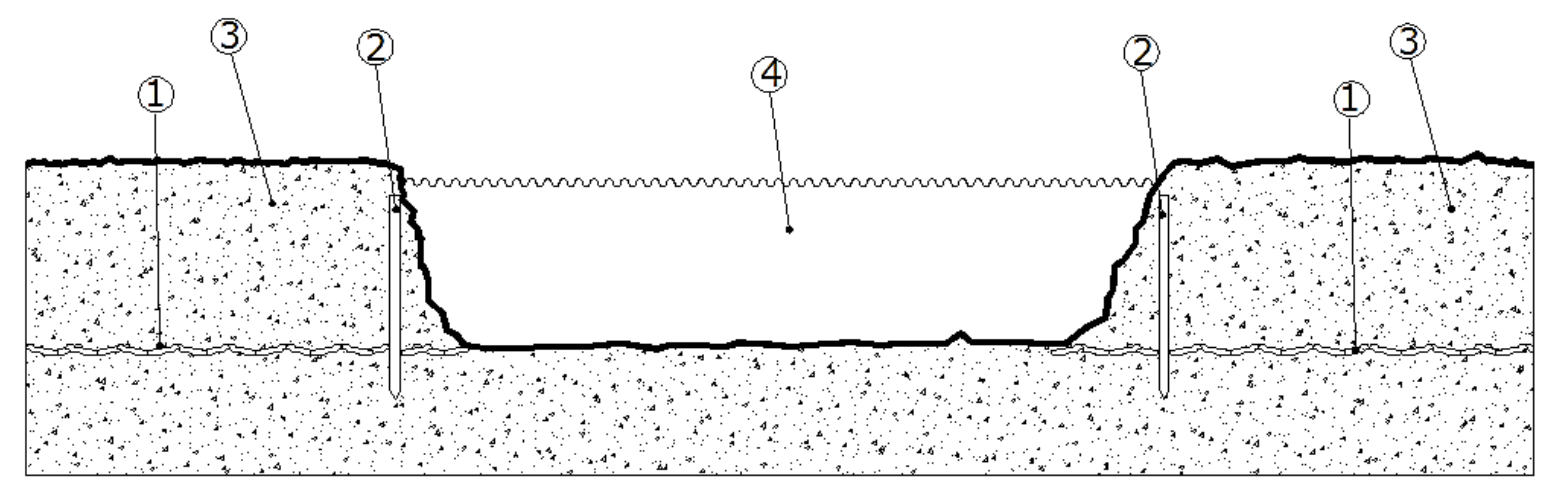

1.- LAJAS DE PIEDRA.

2.- ESTACADO DE MADERA.

3.- TIERRA.

4.- ACEQUIA.

Hipótesis de Acequia prehispánica. Alejandro Jiménez Vaca, 2008.

\footnotetext{
${ }^{9}$ ROJAS RABIELA, Teresa, Semblanza Histórica del Agua en México, SEMARNAT, CONAGUA, México, 2009, p. 13

10 CARBALLAL StAEDTLeR, Margarita y FLORES HERNÁNDEZ, María, Flores, Revista Arqueología Mexicana, "Lagos del Valle de México", Vol. XII, Núm. 68, p, 31 y 32.
} 


\section{B.- Acequias Europeas y Modernas}

Atribuida su autoría a Pedro Juan de Lastanosa"11,"Los Veintiún Libros de los Ingenios y Máquinas de Juanelo Turriano", dan cuenta de la forma de construir las acequias en el siglo XVI, proporcionando las particularidades que debían de tener los canales para irrigación, los cuales eran de forma trapezoidal y medían dieciséis palmos $(3.36 \mathrm{~m})$ en la parte más ancha y doce palmos $(2.52 \mathrm{~m})$ en la parte de menor anchura, siendo ésta el fondo de la acequia y la altura dada en cuatro palmos $(84 \mathrm{~cm})$. Dicho tratado también muestra un croquis de proporciones para acequias mayores siguiendo este patrón.

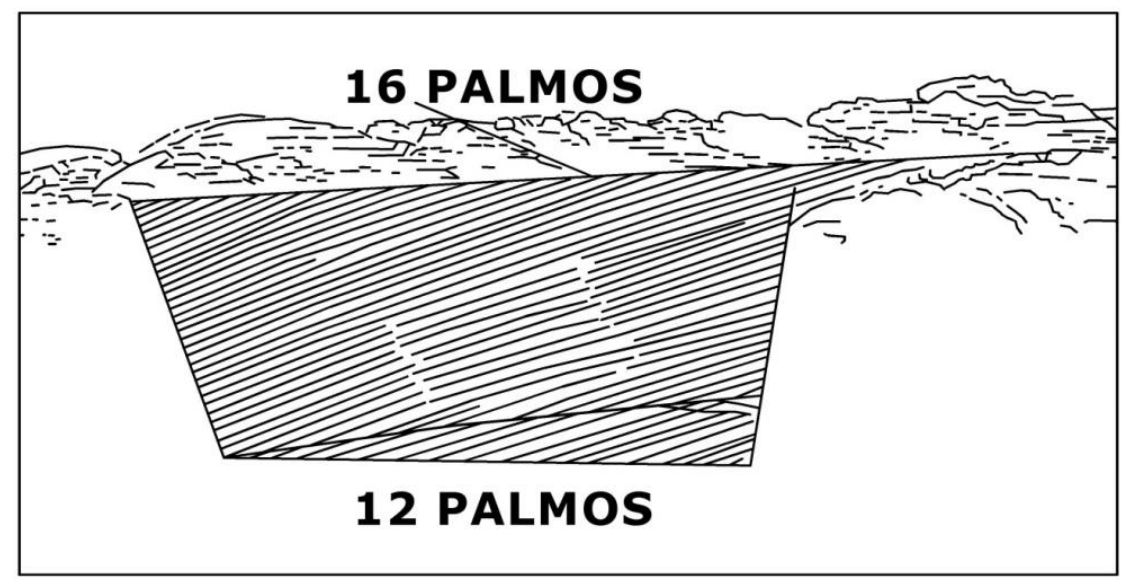

Dibujo de Alejandro Jiménez Vaca, basado en una imagen tomada de Los Veintiún Libros de los Ingenios y Máquinas de Juanelo Turriano, Tomo II, Biblioteca Nacional. Madrid, Ministerio de Cultura, Fundación Juanelo Turriano y Ediciones Doce Calles, España, 1996, p. 107

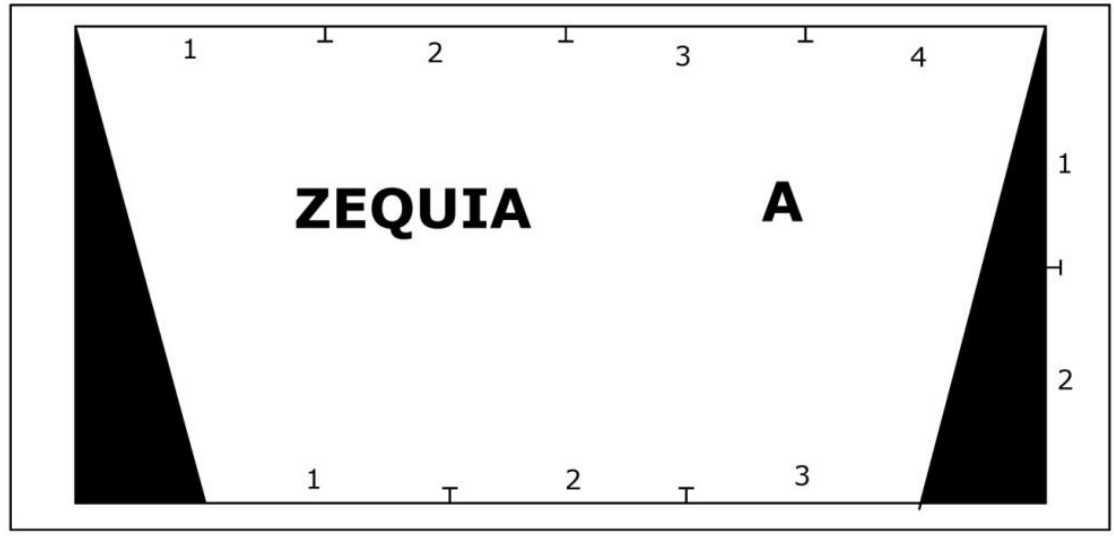

Dibujo de Alejandro Jiménez Vaca, basado en una imagen tomada de Los Veintiún Libros de los Ingenios y Máquinas de Juanelo Turriano, Tomo II, Biblioteca Nacional. Madrid, Ministerio de Cultura, Fundación Juanelo Turriano y Ediciones Doce Calles, España, 1996, p. 113.

${ }_{11}$ PASTRANA SALCEDO, Tarsicio, Agua y Arquitectura, Ingeniería Hidráulica Virreinal, Tesis de Doctorado, Facultad de Arquitectura, UNAM, 2008, p. 59. 
El libro también muestra la manera en que debía asegurarse la boca de la acequia en la unión con la fuente de abastecimiento, en este caso los ríos; además de los distintos usos que se le daba (incluyendo dentro de estos usos aparte de los ya mencionados -como la irrigación y la navegación- los fosos utilizados en la protección de ciudades y las trincheras utilizadas en batallas. Además, dicho tomo hace la comparativa de las acequias con respecto a los ríos, siendo las acequias ríos calmados, pero que igualmente deben contemplarse las reparaciones que deban sufrir de forma similar a los ríos.

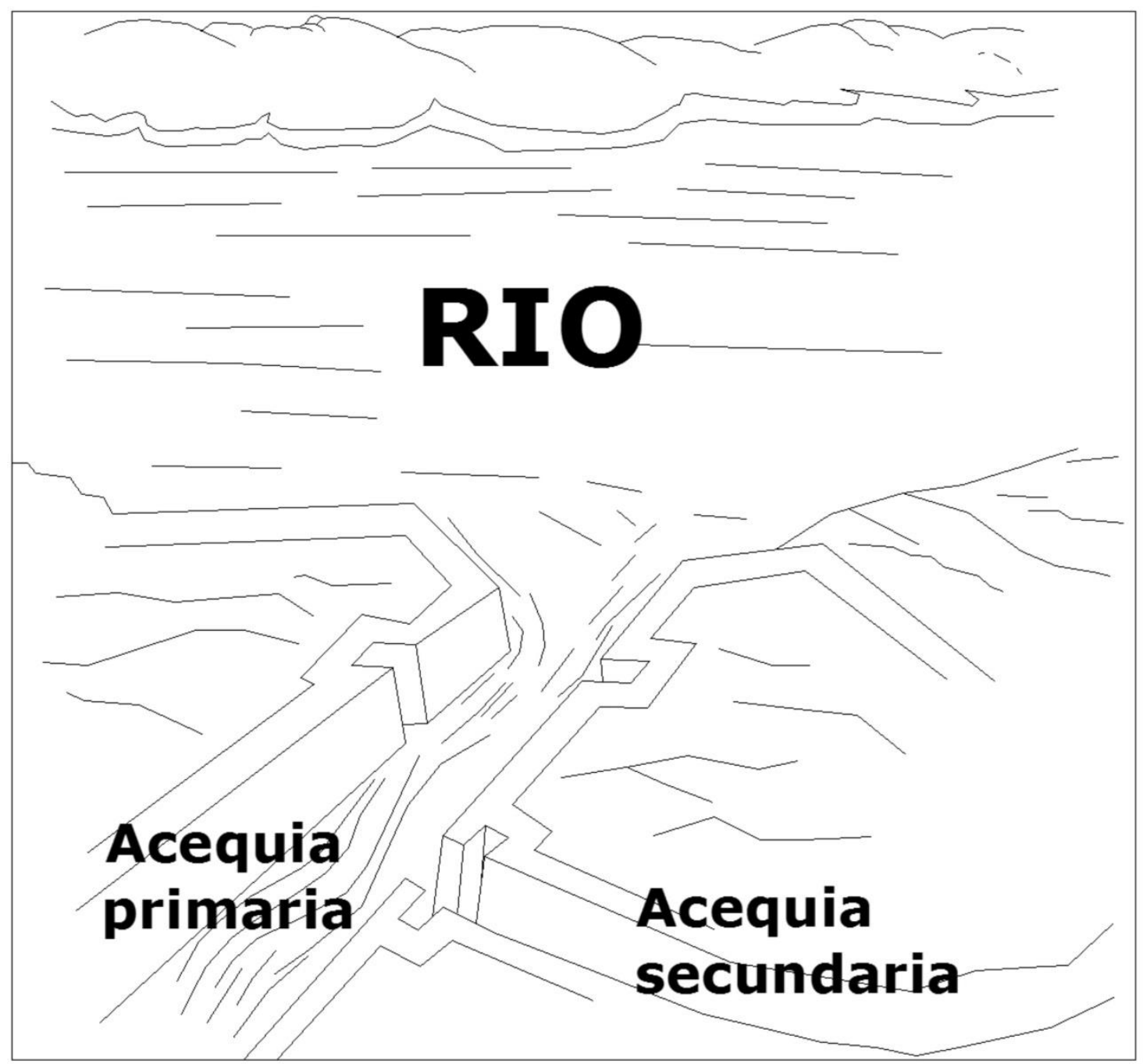

Dibujo de Alejandro Jiménez Vaca, basado en una imagen tomada de Los Veintiún Libros de los Ingenios y Máquinas de Juanelo Turriano, Tomo II, Biblioteca Nacional. Madrid, Ministerio de Cultura, Fundación Juanelo Turriano y Ediciones Doce Calles, España, 1996, p. 108. 
Aparte de lo mencionado con antelación, se relatan las distintas formas de repartir el agua de una afluente principal, por ejemplo, un río, de manera que la captación de cada acequia sea similar en cantidad a las demás.

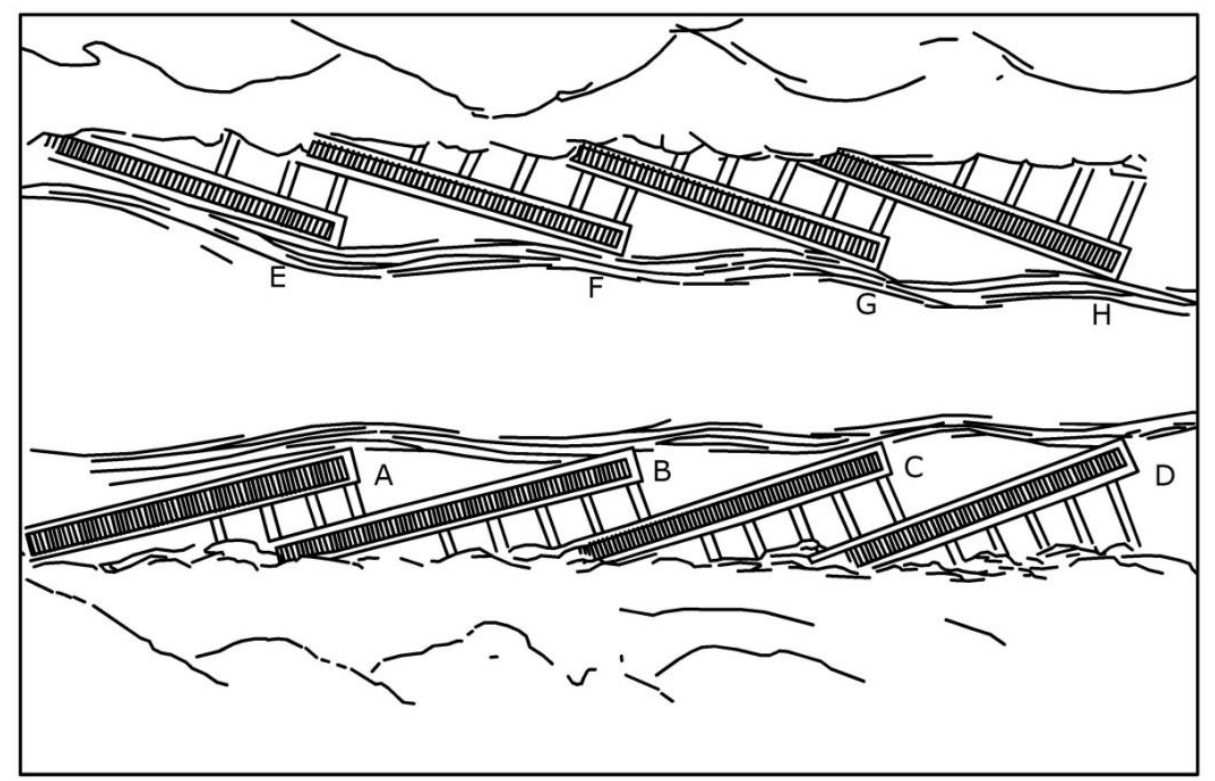

Redibujo de Alejandro Jiménez Vaca, basado en una imagen tomada de Los Veintiún Libros de los Ingenios y Máquinas de Juanelo Turriano, Tomo II, Biblioteca Nacional. Madrid, Ministerio de Cultura, Fundación Juanelo Turriano y Ediciones Doce Calles, España, 1996, p. 114.
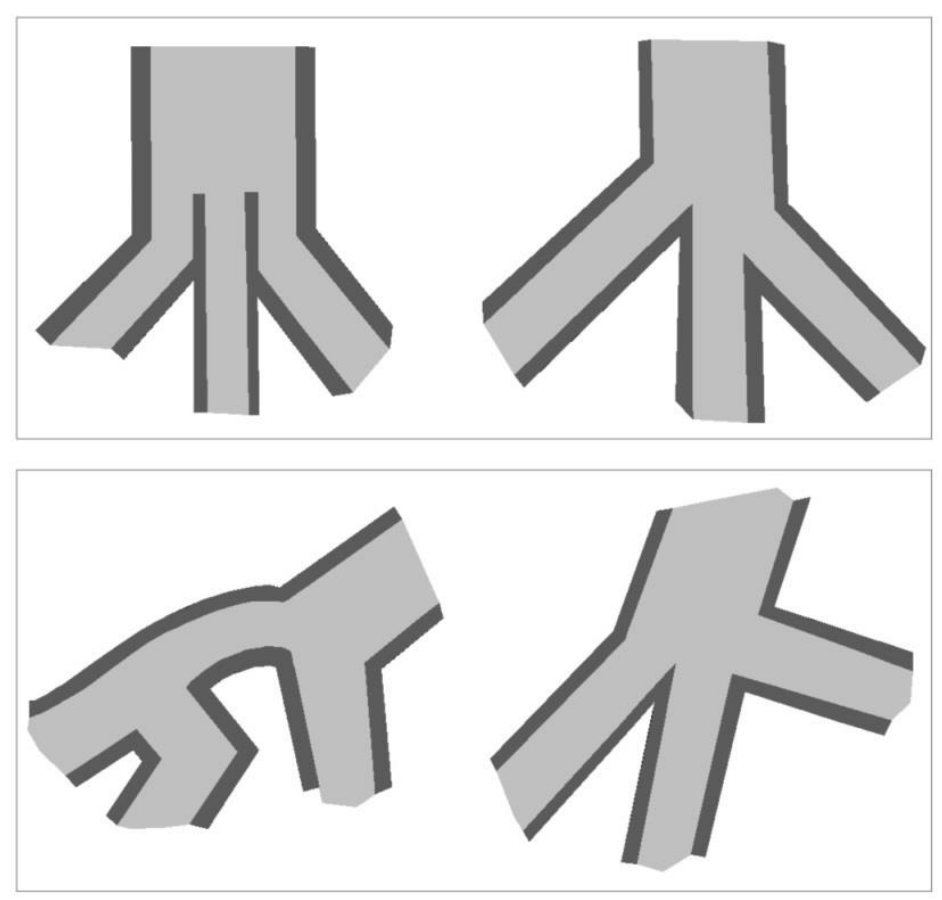

Redibujo de Alejandro Jiménez Vaca, basado en una imagen tomada de, Los Veintiún Libros de los Ingenios y Máquinas de Juanelo Turriano, Tomo II, Biblioteca Nacional. Madrid, Ministerio de Cultura, Fundación Juanelo Turriano y Ediciones Doce Calles, España, 1996, p. 470. 
Por medio de breves citas, en varios libros que tratan en sus capítulos sobre la arquitectura hidráulica puede inferirse que el método de construcción de las acequias europeas en el período novohispano no varía mucho en cuanto a los métodos que se siguen actualmente para su construcción. Bien lo describe José Antonio Alzate, al hacer una fuerte crítica al proyecto de la Zanja Cuadrada de Ignacio de Castera, en donde hace ver la pendiente necesaria para la circulación de las aguas, además de las distintas presiones necesarias para arrastrar diferentes materiales en una acequia, elementos que son considerados en la actualidad para su construcción, además de los que componen el sistema de acequias, como los puentes y los sifones, los cuales pueden utilizarse separadamente o como un solo elemento (puente-sifón). El sifón tiene una doble utilidad al servir como desfogue de la presión de la acequia, a la vez que puede utilizarse como medio de abastecimiento o distribución para cultivos. La diferencia de las antiguas acequias con las modernas es que algunas se revisten de concreto en lugar de ir directamente sobre la tierra excavada, además de existir una variedad de compuertas en el mercado que hace más sencilla su construcción.

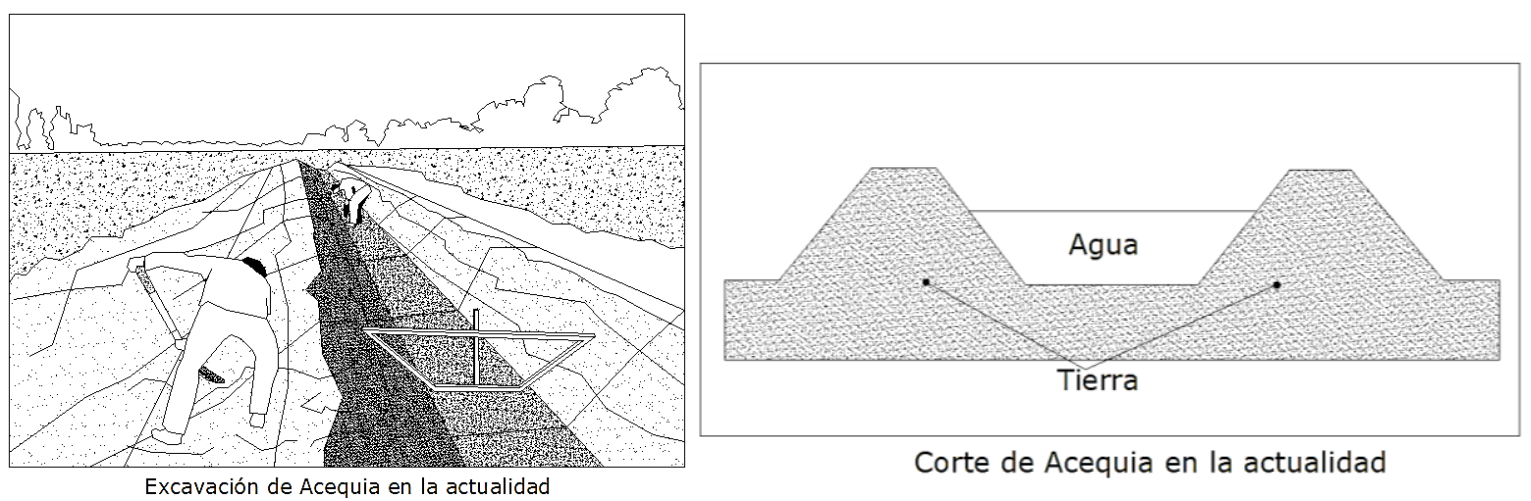

Construcción de acequia, con una plantilla trapezoidal hecha con tablas de madera; y Corte de una acequia contemporánea. Dibujos de Alejandro Jiménez Vaca, basados en imágenes del manual Acequias de Riego, de la revista Hojas Divulgadoras, de F. Domínguez García Tejero, Madrid, España, Agosto,1950. 


\section{C.- Alimentación de las Acequias en la Ciudad de México}

El abastecimiento de agua de las acequias se da de diversas formas, ya sea por medio de aguas superficiales como ríos, lagos, presas y albercas, o subterráneas, como pozos y manantiales; en el caso de la ciudad de México, las alimentaciones de las acequias se realizaban por medio de los ríos que se encontraban en la parte norponiente de la cuenca, ubicados en la Sierra de las Cruces y en la Sierra de Guadalupe. Dichos ríos eran el Tlalnepantla, el San Mateo, de los Remedios, Azcapotzalco, los Morales, Tecamachalco, Cuajimalpa, Tacubaya, La Piedad, Mixcoac y Coyoacán. Dado que en los lagos centrales y del norte de la cuenca el punto más bajo era el lago de Texcoco, se producían corrientes que dirigían el agua hacia allí. En lo que respecta a los lagos Xochimico-Chalco en el sur, éstos se encontraban en un punto más alto respecto al lago de Texcoco, sin embargo, por estar dividido por diques naturales y artificiales en la zona de Coyocán a Iztapalapa y Culhuacán, el paso de las corrientes se restringía sólo a los canales de navegación que conectaban estas zonas -región que hasta el siglo XIX fue revalorada para desaguar el lago de México-Texcoco, a la par que se seguía con el proyecto de la zona norte de la cuenca-.

Es así, que las corrientes que seguían las acequias en la ciudad seguían el trayecto de las corrientes del lago, es decir del norponiente al surponiente, y de poniente a oriente; $y$ en lo que respecta a la acequia de Mexicaltzingo (que conectaba la ciudad con la zona sur de la cuenca), ésta seguía la corriente hacía el sur y posteriormente ya en los lagos de Xochimilco-Chalco, hacia el oriente. Sin embargo, por la dirección de los vientos que en la mañana eran del norponiente al surponiente, y en la tarde cambiaban de oriente a poniente, se provocaba un efecto que hacía que las corrientes se invirtieran levemente (aunque eran las corrientes dominantes las que se han señalado inicialmente). 


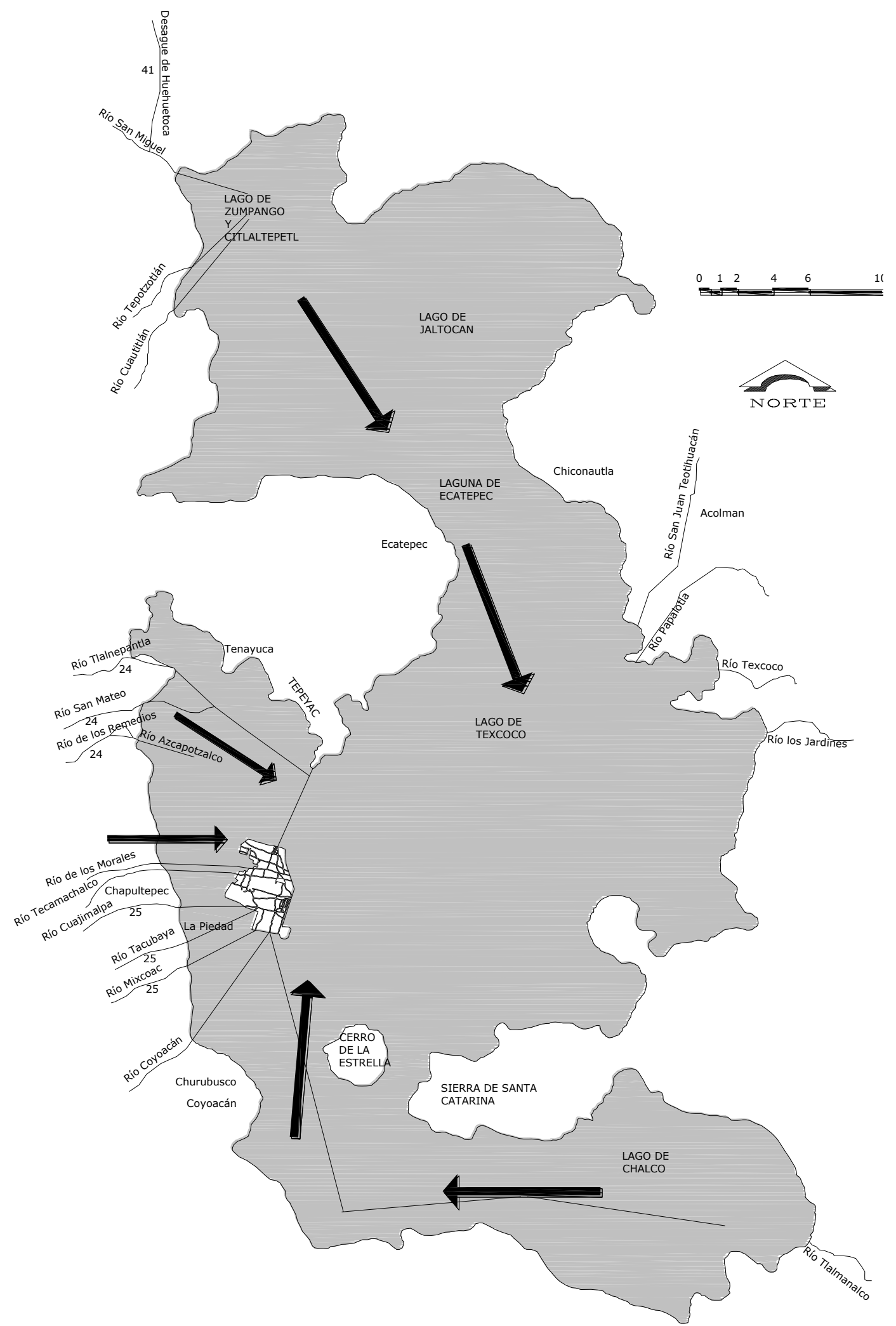

Alimentación de las acequias y dirección de las corrientes en el sistema de lagos de la Cuenca de México. Plano de Alejandro Jiménez Vaca, basado en el publicado por Ángel Palerm, en el libro Obras hidráulicas prehispánicas en el sistema lacustre del Valle de México, SEP, INAH, México 1973, p. 233. 


\section{3.- Las acequias como condicionantes en la conformación de la traza urbana de la Ciudad de México}

\section{A.- Las Calles}

El sistema hidráulico de la cuenca de México se había ganado el respeto en la población de la Ciudad de México ante las continuas inundaciones que la afectaban, y que databan desde el México Prehispánico (pasando por la catastrófica inundación de 1629), lo que provocó que las poblaciones asentadas en la época virreinal se sometieran a las corrientes naturales que tenía la cuenca, sin olvidar que desde finales del siglo XVI ya habían comenzado los trabajos para construir el desagüe de los lagos, y minimizar con esto los efectos que provocaba el vivir en una zona eminentemente lacustre; este sometimiento hizo que las acequias continuaran en la mayoría de los casos con su trayecto original, y en algunas ocasiones se prolongará la longitud de ellas, haciendo que el trazo de las calles se viera supeditado a las limitantes marcadas por dichos elementos. Si bien no hay documentación que pueda dar testimonio de su precedente, hasta muy avanzado el siglo XIX había disposiciones en las que la lotificación de solares no impedía que los inmuebles pudieran estar sobre las acequias siempre y cuando no se interrumpiera el flujo de las mismas, así como su limpieza y su buen estado. Aunque se trataba de que calles y acequias coincidieran con el trazo de las manzanas, había casos en que sus trayectorias formaban manzanas con formas irregulares. El trazado de las calles que existía desde tiempos de Alonso García Bravo, primer Gran Alarife de la ciudad, y al cual se debe su primera planeación, no era tan perfecto en su rectitud como comúnmente se cree, hecho que se puede apreciar en calles como República de Perú y Apartado (las cuales siguen el trayecto de la acequia conocida como de Santo Domingo); otro caso es la calle de Roldán, que correspondía al trazo de la acequia de Mexicaltzingo o de la Viga; prolongación de ésta era la Acequia Real, que corría por Corregidora y Dieciséis de Septiembre, dando vuelta por Gante hacia Venustiano Carranza, siguiendo su camino hasta el Antiguo Barrio de San Juan. 


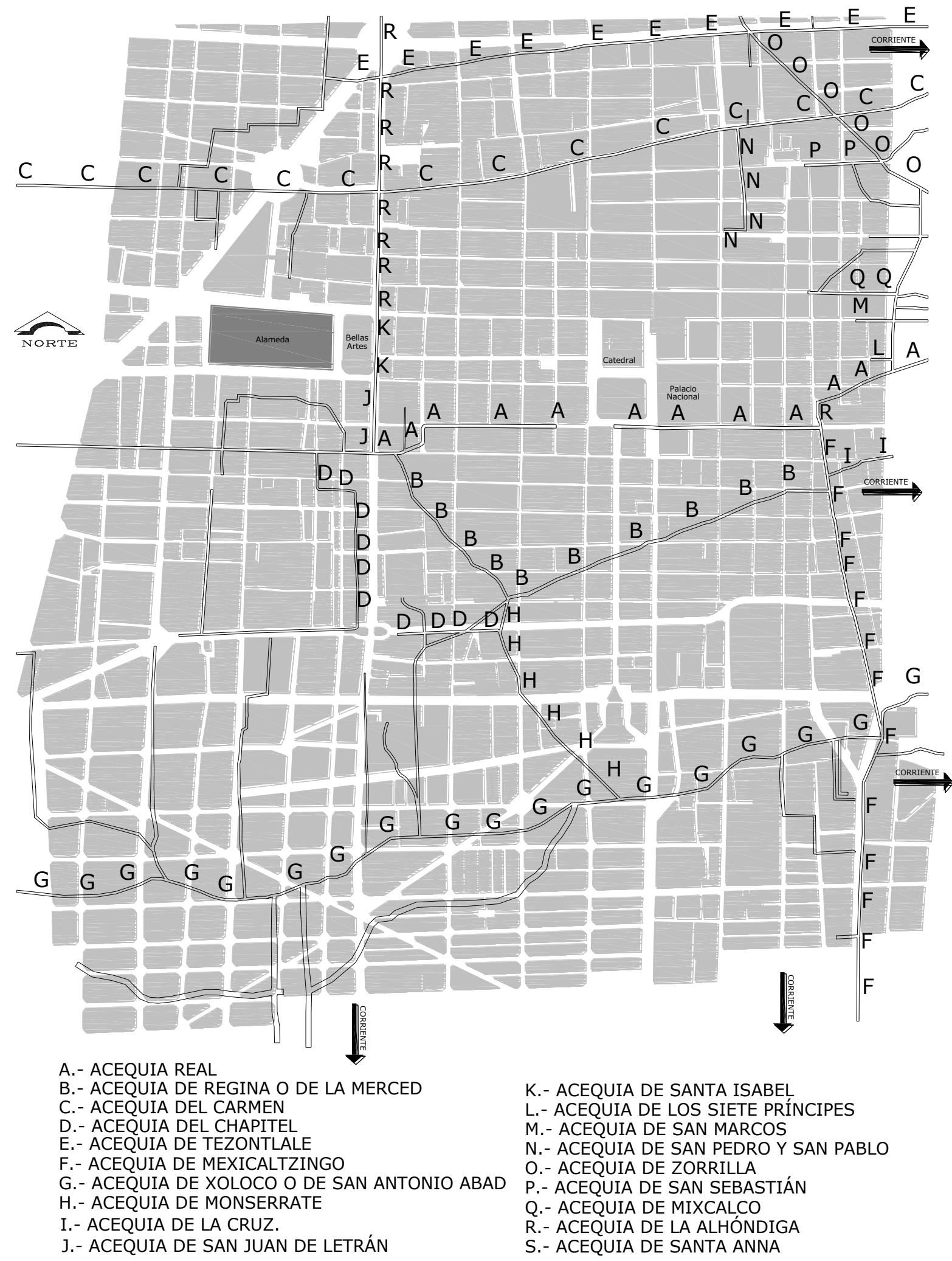

Plano actual de la Ciudad del Centro Histórico de la Ciudad de México, con el trazo de las acequias sobrepuestas. AJV, 2008. 


\section{B.- Las Plazas}

Así como las acequias repercutieron en la traza de las calles de la ciudad, también tuvieron influencia en la creación de espacios públicos como plazas, parques y atrios. Ejemplos como este se pueden observar en la Acequia de la Merced, la cual deja en su trayecto dos plazas en los Conventos de Regina Coelli y de la Merced, además del Parque del Conde en las cercanías del Hospital de Jesús, y de la pequeña plaza en el Barrio de la Merced en la capilla del señor de la Humildad (en la actual calle de Manzanares). Entre otras plazas que se formaron de forma similar se pueden contar las siguientes: la plaza del Colegio de las Vizcaínas, en la cual también existía un puente, y la pequeña plaza frente a la Casa del Diezmo. En cuanto a los atrios, varios se formaron por el trayecto de una acequia o por el cruce de dos de éstas (tal es el caso del atrio del Convento del Carmen, Santa Isabel y San Lázaro).

\section{B.- Los Paseos}

Una de las actividades para el esparcimiento y la convivencia entre los pobladores de la ciudad de México fue el pasear, actividad que se realizaba en espacios públicos como plazas, calles, y la propia Alameda central. Sin embargo, había caminos de tierra y agua que se incorporaron a esta actividad, como fueron los casos del Paseo de Revillagigedo o de la Viga, y el Paseo Nuevo o de Bucareli, además de algunas calzadas en las que se ve la incorporación de canales o acequias a ambos lados de todo el trayecto, como ocurre con la calzada de la Piedad, la calzada de Guadalupe, la calzada de Vallejo y el Paseo de Azanza. En

lo que respecta a los paseos más conocidos, y comenzando por la Alameda, se pueden observar acequias en los lados norte y oriente en la Perspectiva de Juan Gómez de Trasmonte de la Ciudad de México de 1628, las cuales debieron servir para el riego de sus jardines, además de abastecimiento para el Huerto del Convento de San Diego. El Paseo más famoso relatado por los cronistas fue el de la Viga, el cual contaba con un camino de tierra, y corría paralelo al canal. Dicho paseo, además de servir como vía de comunicación acuática hacia el sur de la cuenca de México, también fue utilizado como zona de esparcimiento; en él se 
paseaba en canoas y trajineras, además de existir múltiples entretenimientos de música y danza en los embarcaderos de los pueblos de Iztacalco y Santa Anita, diversiones que incluían alimentos que se podían comprar para degustar en las trajineras, embarcaderos y portales de pequeños negocios que daban hacia el canal de la Viga; mientras que en la calzada que corría paralela se podía ver a numerosas personas paseando a pie, a caballo y en variados carruajes, dependiendo el nivel socioeconómico de los propietarios. ${ }^{12}$

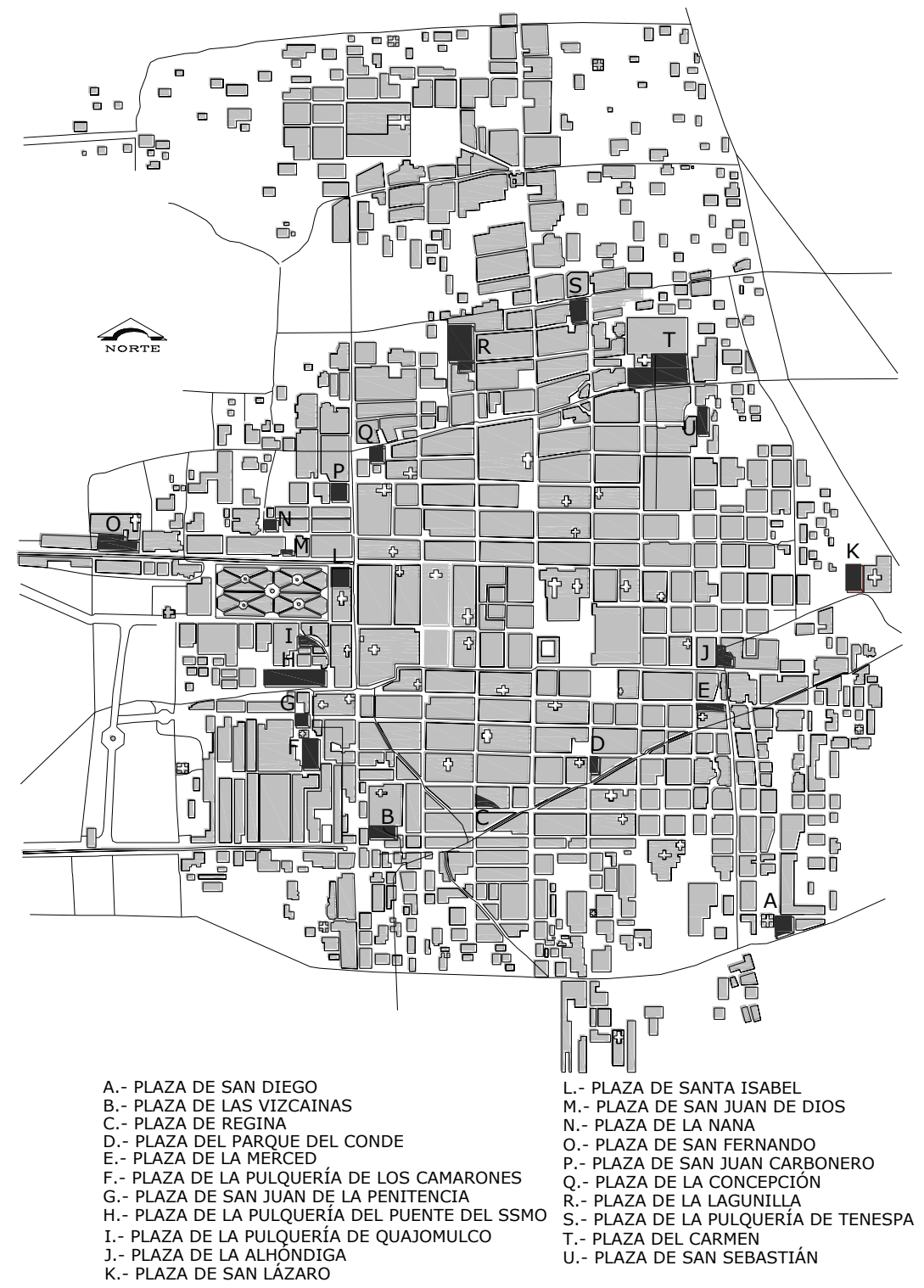

Ubicación de plazas en el plano de Manuel de Villavicencio, de 1782, AJV, 2008.

\footnotetext{
12 NOVO, Salvador, Los paseos de México, Fondo de Cultura Económica, México, 1974, p. 31-33 ERSKINE INGLIS, Frances La vida en México durante una residencia de dos años en ese país, Editorial Noriega, Madrid, España, 2009, p. 85-90
} 


\section{4.- Las Acequias en el siglo XVIII}

Se puede hacer un seguimiento del trayecto del agua, su cierre y su ampliación a partir del plano de Upsala, en el cual se pueden observar varias acequias y pequeñas lagunas que en planos posteriores desaparecen, siendo probable que algunas hayan sido cegadas o se hayan cubierto bajo bóvedas; tal es el caso de las ubicadas en la Alameda, que debieron seguir existiendo para su irrigación, o las ubicadas en la calzada de la Piedad (que no vuelven a aparecer en documentos posteriores al plano de Upsala). En el caso de la acequia de la calzada de Tacuba descrita por Cervantes de Salazar ${ }^{13}$, que irrigaba en todo su trayecto huertas dispuestas a ambos lados, desaparece en algunos planos sin saberse el motivo, ya sea que fuese cegada o dirigida mediante caños cubiertos, rescatándose parcialmente a finales del siglo XVIII y en el siglo XIX, donde por medio de litografías se da cuenta de su existencia.

Las acequias sufren durante el siglo XVIII una transformación en su trazo, sobre todo las que se encontraban en la periferia, notándose en el plano de Pedro de Arrieta y los maestros de la Arquitectura de 1737, que éstas se dirigían hacía lagunas que rodeaban la ciudad. En planos posteriores, como el de Manuel de Villavicencio de 1782, y el de Diego García Conde de 1793, se nota la construcción de nuevas acequias y el desvío de las existentes para formar un polígono de forma irregular que rodea la ciudad, además de la desaparición de las que existían dentro. La hipótesis del trazo de las acequias que se presenta en esta investigación corresponde a la etapa antes del cierre del polígono, complementándose la información entre todos los planos descritos anteriormente, pues en algunos planos la información es parcial al pasar algunos canales por debajo de inmuebles que no permiten apreciarlos de forma completa.

13 CERVANTES DE SALAZAR, Francisco, México en 1554, UNAM, México, 2007, p 82, 83. 

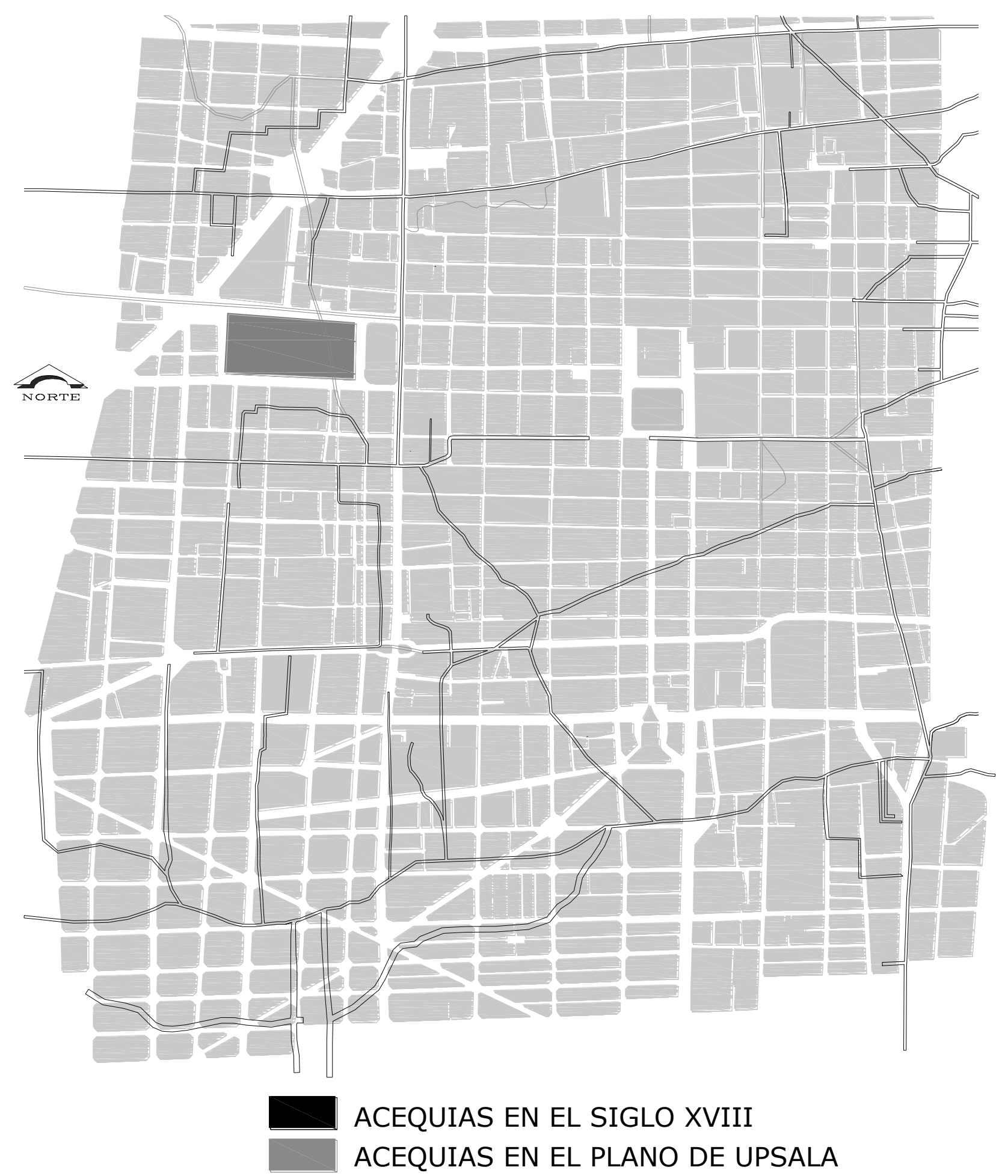

Acequias en el siglo XVIII, con la ubicación de las acequias desaparecidas que se presentan en el plano de Upsala. Dibujo de AJV 2008. 


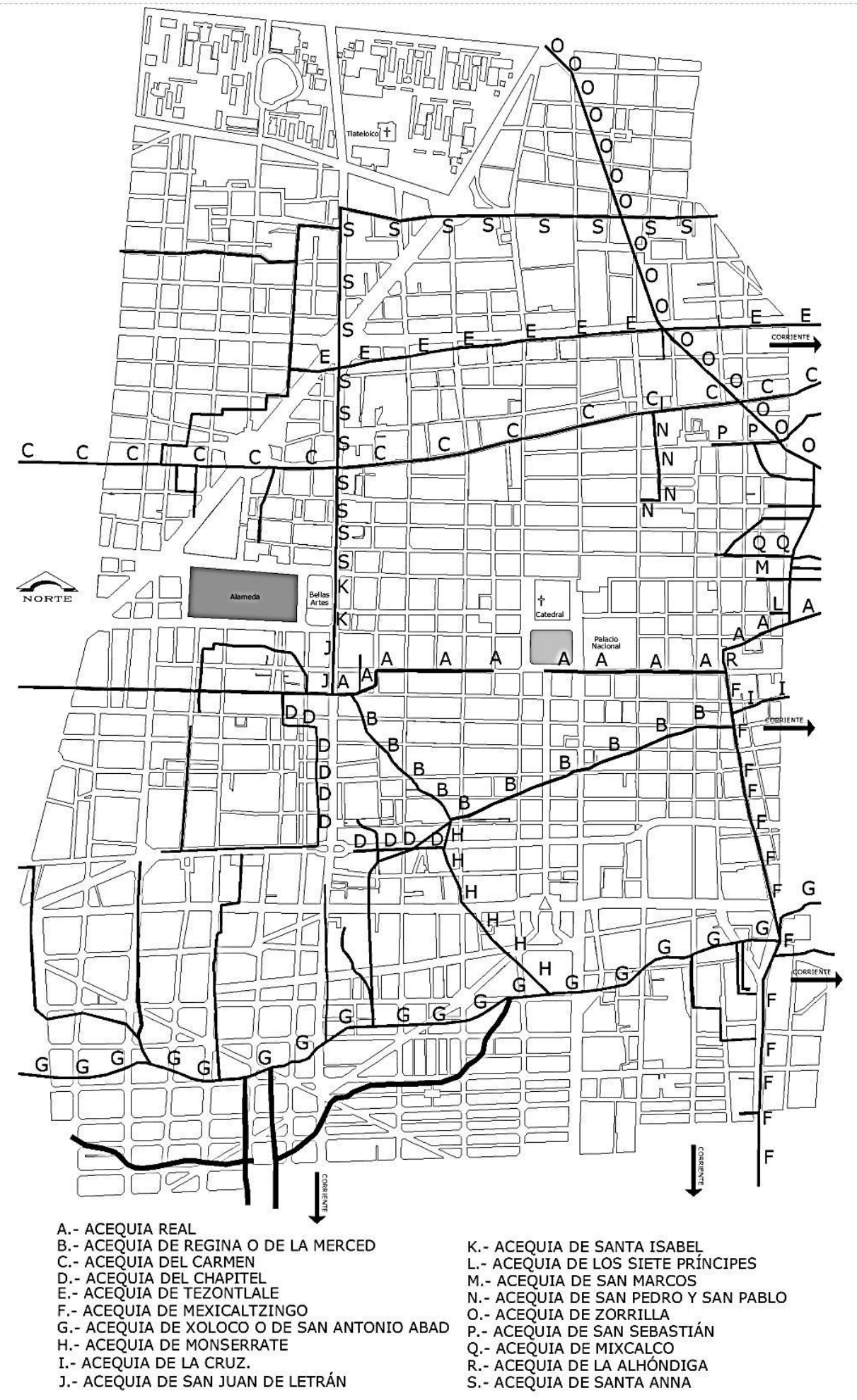

Plano de localización de las acequias en un plano actual de la ciudad de México. Plano realizado por Alejandro Jiménez Vaca, año 2012. 


\section{Las acequias de la Ciudad de México se dividían en Principales y} Secundarias; las principales según varios estudios y cronistas eran siete, y cruzaban la ciudad tanto de Poniente a Oriente como de Norte a Sur. A continuación, se menciona cuáles eran, y la fecha en que fueron cegadas ${ }^{14}$.

\begin{tabular}{|c|c|c|c|}
\hline Acequia & $\begin{array}{l}\text { Año en que fue } \\
\text { cegada parcialmente }\end{array}$ & $\begin{array}{l}\text { Tramo que fue } \\
\text { cegada }\end{array}$ & $\begin{array}{l}\text { Año en que fue } \\
\text { cegada totalmente }\end{array}$ \\
\hline 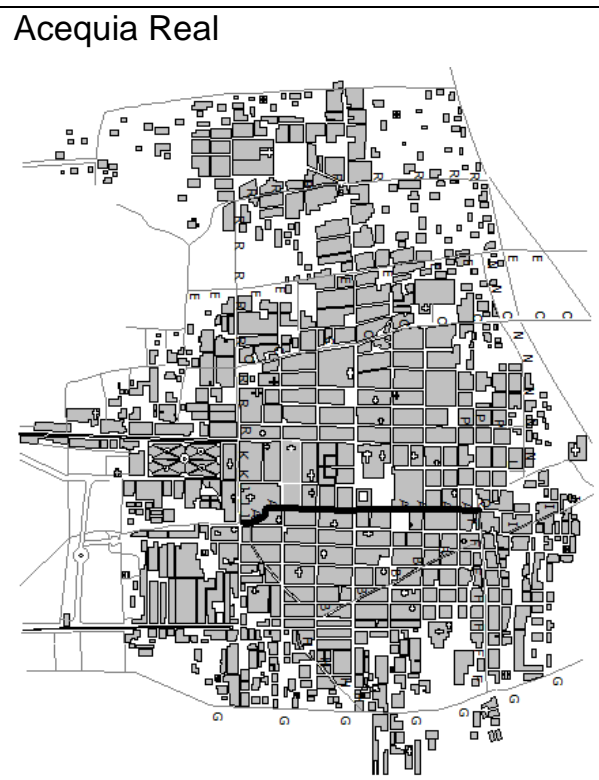 & $\begin{array}{l}\text { 1788, en } \text { el } \\
\text { virreinato de don } \\
\text { Manuel Flores }\end{array}$ & $\begin{array}{l}\text { Tramo entre el } \\
\text { Puente del Hospital } \\
\text { Real, pasando por } \\
\text { Zuleta a espalda del } \\
\text { convento de San } \\
\text { Francisco, y callejón } \\
\text { de Dolores hasta el } \\
\text { Coliseo. }\end{array}$ & \\
\hline
\end{tabular}

${ }^{14}$ HERNÁNDEZ PONS, Elsa Cristina, La Acequia Real: Historia de un Canal de Navegación, Tesis de Doctorado en Estudios Mesoamericanos, Facultad de Filosofía y Letras, UNAM, 2002. CUEVAS AGUIRRE Y ESPINOSA, Francisco de, Extracto de las diligencias y reconocimiento de los Ríos, Lagunas y desagües de la capital de México y su valle: de los caminos para su comunicación y su comercio, México SEFI, 1979. 


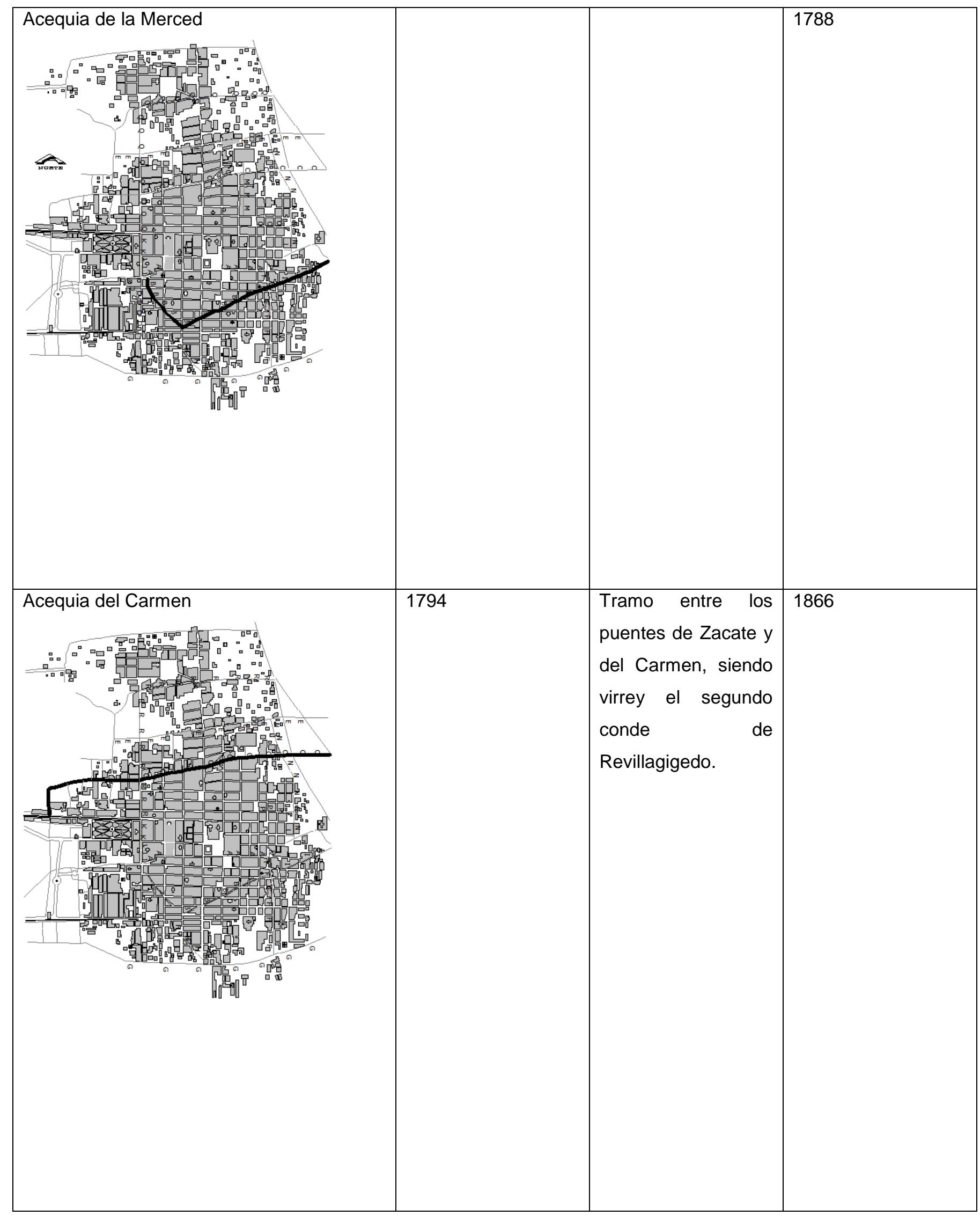




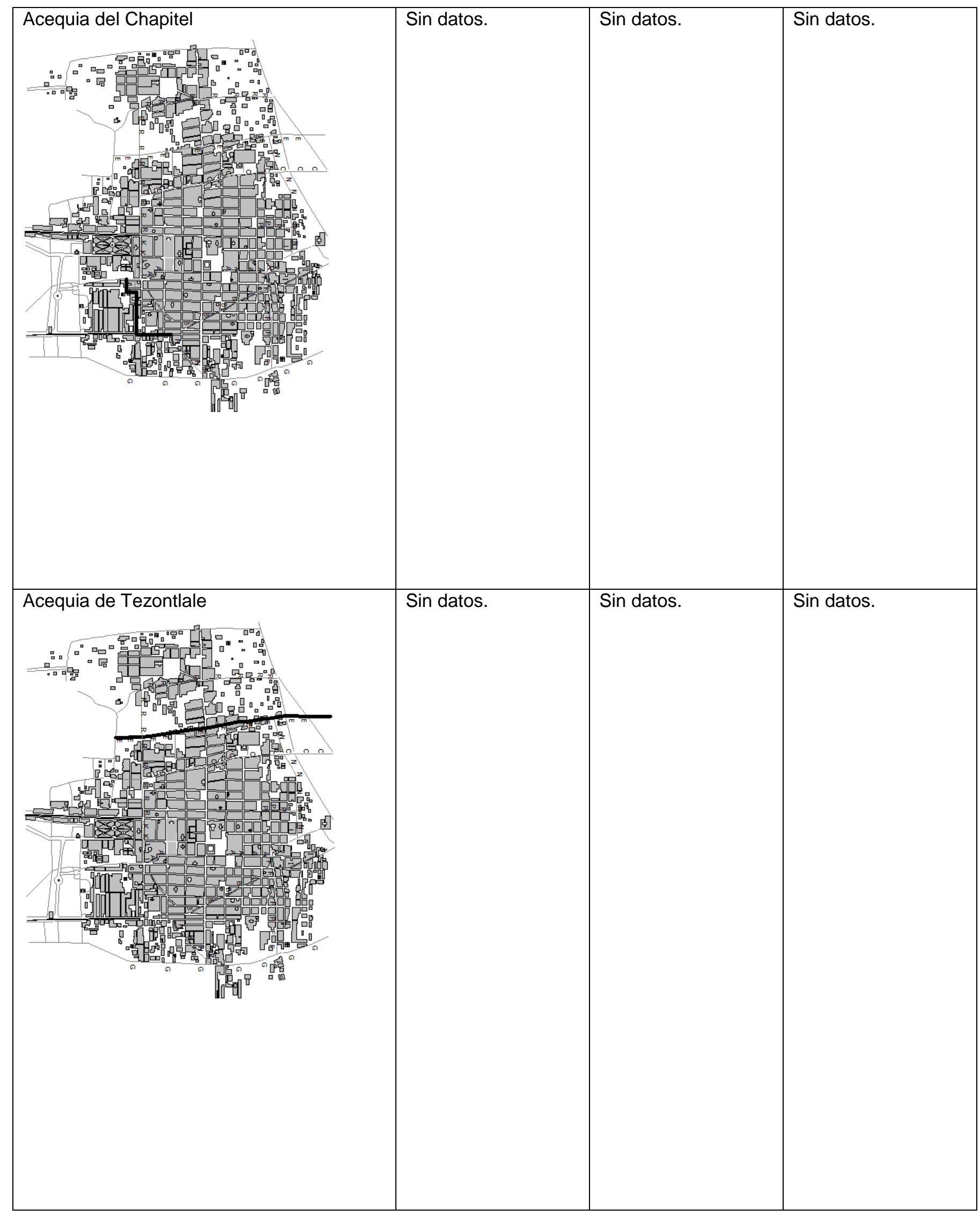




\begin{tabular}{|c|c|c|c|}
\hline 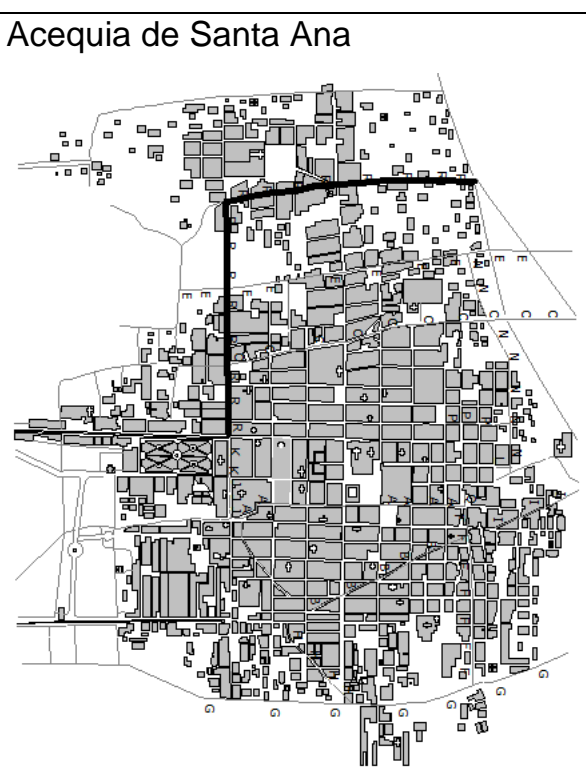 & 1792 y 1793 & $\begin{array}{l}\text { Tramo de sur a } \\
\text { norte. Se derribaron } \\
\text { los puentes entre } \\
\text { ellos, así como el de } \\
\text { la Mariscala, vecino } \\
\text { a la caja de agua del } \\
\text { acueducto de San } \\
\text { Cosme, situado } \\
\text { frente a la calle de } \\
\text { San Andrés. }\end{array}$ & $\begin{array}{l}\text { 1862, tramo de } \\
\text { Oeste a Este }\end{array}$ \\
\hline 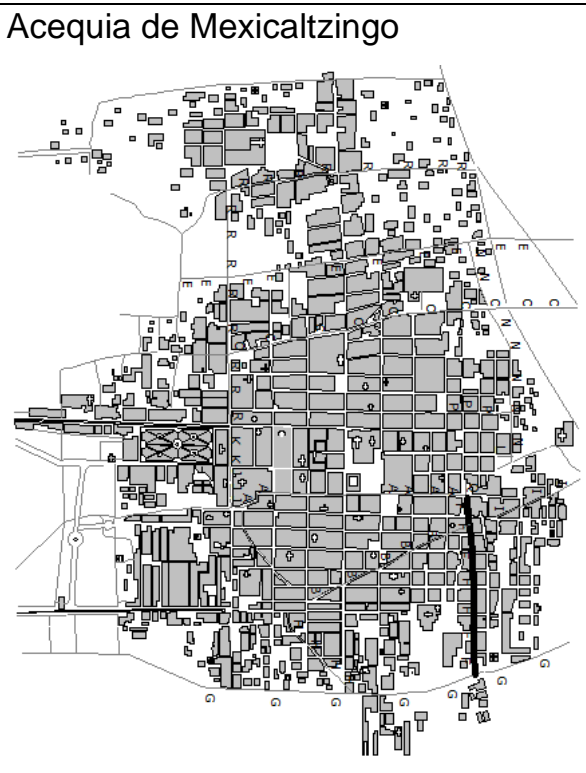 & & & $\begin{array}{l}\text { 1902, desde la } \\
\text { segunda calle del } \\
\text { embarcadero hasta } \\
\text { la Escobillería. Los } \\
\text { tres ramales que } \\
\text { corrían hacia el } \\
\text { Este, } \\
\text { introduciéndose por } \\
\text { los tulares y tierras } \\
\text { de Pacheco, hoy } \\
\text { segunda de } \\
\text { Ampudia. }\end{array}$ \\
\hline
\end{tabular}




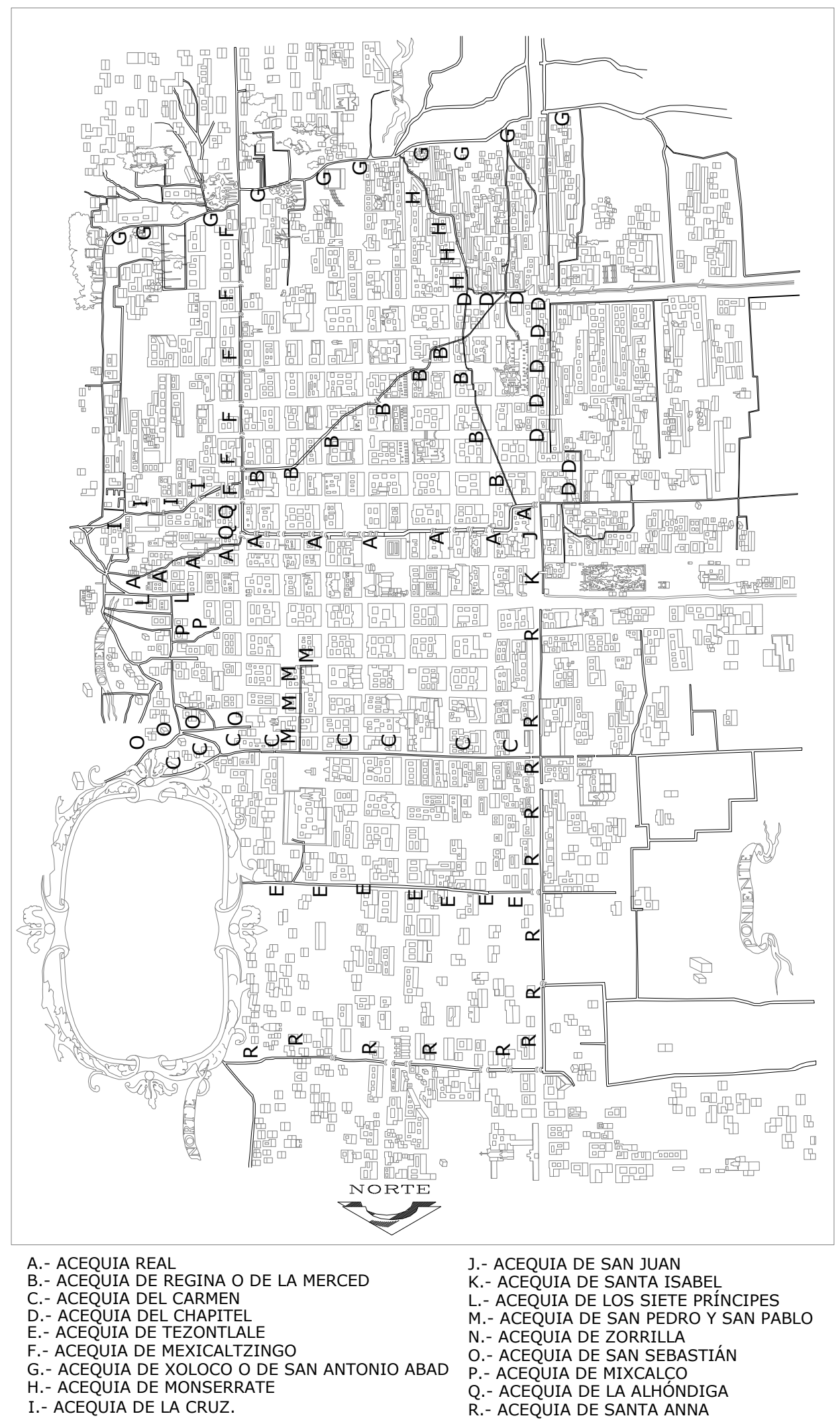

Plano de Pedro de Arrieta y los Maestros de la Arquitectura de 1737. Redibujo de Alejandro Jiménez Vaca, 2008. 


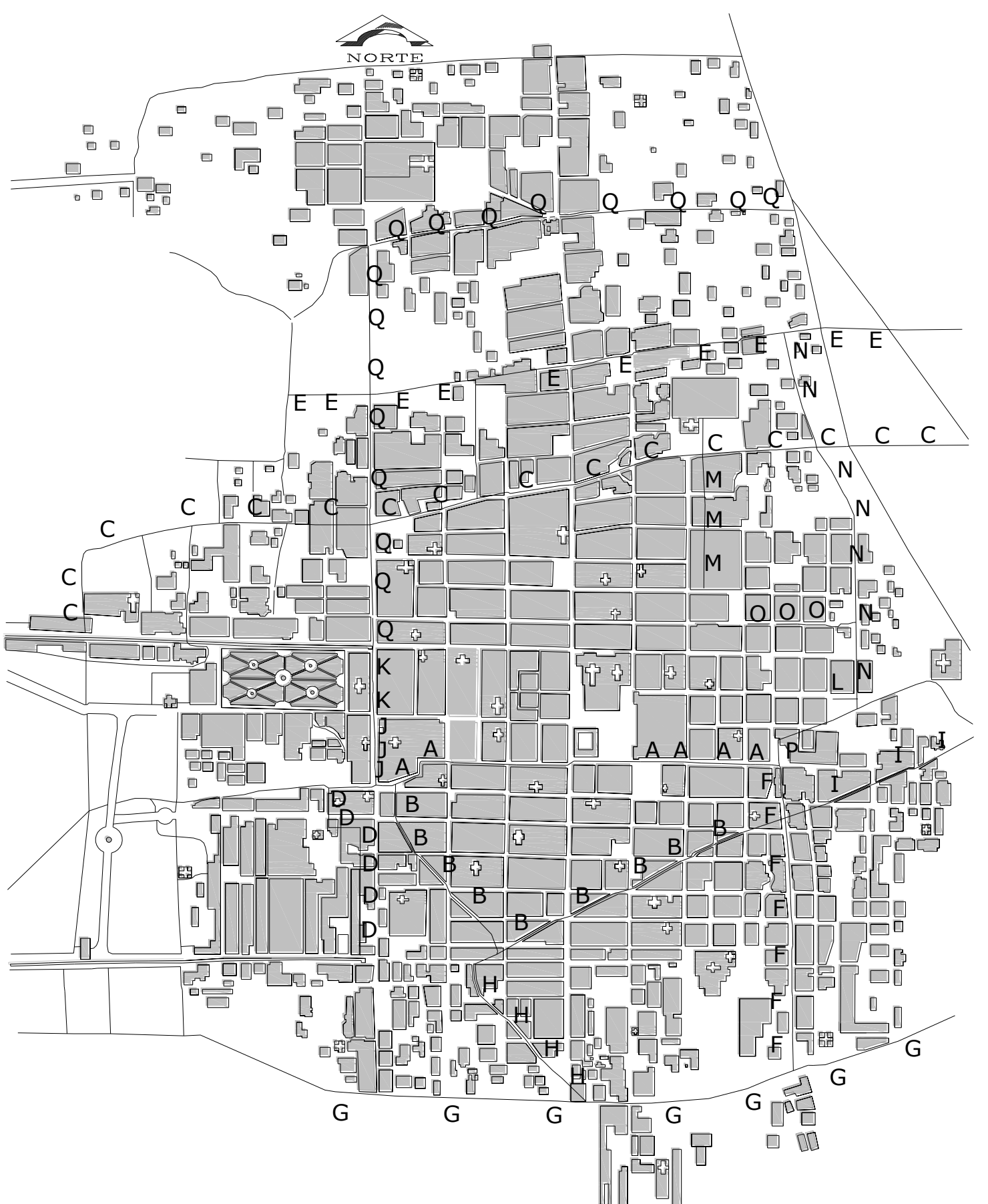

A.- ACEQUIA REAL

B.- ACEQUIA DE REGINA O DE LA MERCED

C.- ACEQUIA DEL CARMEN

D.- ACEQUIA DEL CHAPITEL

E.- ACEQUIA DE TEZONTLALE

F.- ACEQUIA DE MEXICALTZINGO

G.- ACEQUIA DE XOLOCO O DE SAN ANTONIO ABAD

H.- ACEQUIA DE MONSERRATE

I.- ACEQUIA DE LA CRUZ.
J.- ACEQUIA DE SAN JUAN

K.- ACEQUIA DE SANTA ISABEL

L. - ACEQUIA DE LOS SIETE PRÍNCIPES

M.- ACEQUIA DE SAN PEDRO Y SAN PABLO

N.- ACEQUIA DE ZORRILLA

O.- ACEQUIA DE MIXCALCO

P.- ACEQUIA DE LA ALHÓNDIGA

Q.- ACEQUIA DE SANTA ANNA

Plano de Manuel Villavicencio de 1782, siendo el virrey don Martín de Mayorga. Redibujo de Alejandro Jiménez Vaca, 2008. 


\section{5.- Las acequias como infraestructura urbana}

Una de las principales características por las que fueron conocidas y admiradas las acequias fue su utilización como vía de comunicación acuática, provocando en los cronistas una visión romántica en la forma de apreciar la ciudad. Las crónicas alentaban la imaginación de los que no conseguían visitar la urbe, llegando a ser conocida la Ciudad de México con el célebre nombre de "la Venecia de América"15. Con esta idea surgieron las representaciones de las acequias mexicanas en estampas europeas con un aspecto de canales venecianos. Si bien había diferencias con respecto a la distante ciudad portuaria, como la de estar en un lago y no cerca del mar, también se presentaban coincidencias que hacían que la comparación no fuera tan errada, como la de contar con un embarcadero comercial en el que la actividad era intensa, puentes de los que se cuidaba el aspecto estético y la navegación por sus aguas.

Excepcional testimonio ha quedado de ello a través de las excavaciones que se hicieron a principios de la década de los años ochenta del siglo pasado en la Acequia Real, dando cuenta de los métodos constructivos y su conformación ${ }^{16}$. En base a la aportación de estos datos se puede llegar a una aproximación de su disposición y medidas, siendo el ancho total de la acequia de 7 a 8 metros; su contención estaba hecha de muros o pretiles de 30 hasta 120 centímetros, y de diversos materiales como recinto o ladrillo, con una profundidad de 1.60 hasta 2.50 metros. Se accedía a ella a través de vanos abiertos en los pretiles, y se bajaba por medio de escaleras a pequeños desembarcaderos (Ver figura 1).

Un ejemplo claro de esta acción es la litografía del siglo XIX de la calle de Roldán y su desembarcadero, obra de Casimiro Castro, donde se puede observar que la navegación se hacía en medio de la acequia, mientras en las orillas se ejecutaba el desembarque de mercancías hacia la calle. Asimismo, se puede ver el sistema constructivo de los puentes: en primer plano el puente de la Merced hecho de vigas con pretiles de piedra y barandal de madera, al fondo el puente de

\footnotetext{
${ }^{15}$ VETANCOURT, Agustín de; San Vicente, Juan Manuel de; Viera, Juan de; La Ciudad de México en el Siglo XVIII (1690-1780) Tres Crónicas, Dirección General de Publicaciones, CONACULTA, México, 1990.

${ }^{16}$ HERNÁNDEZ PONS, Elsa Cristina, La Acequia Real: Historia de un Canal de Navegación, Tesis de Doctorado en Estudios Mesoamericanos, Facultad de Filosofía y Letras, UNAM, 2002.
} 
la Leña, hecho de bóveda de cañón corrido con pretiles de piedra y rampas de acceso desde la calle. Es posible observar, en adición, el pretil discontinuo de la acequia, que permitía el desembarque en distintos puntos de la calle.

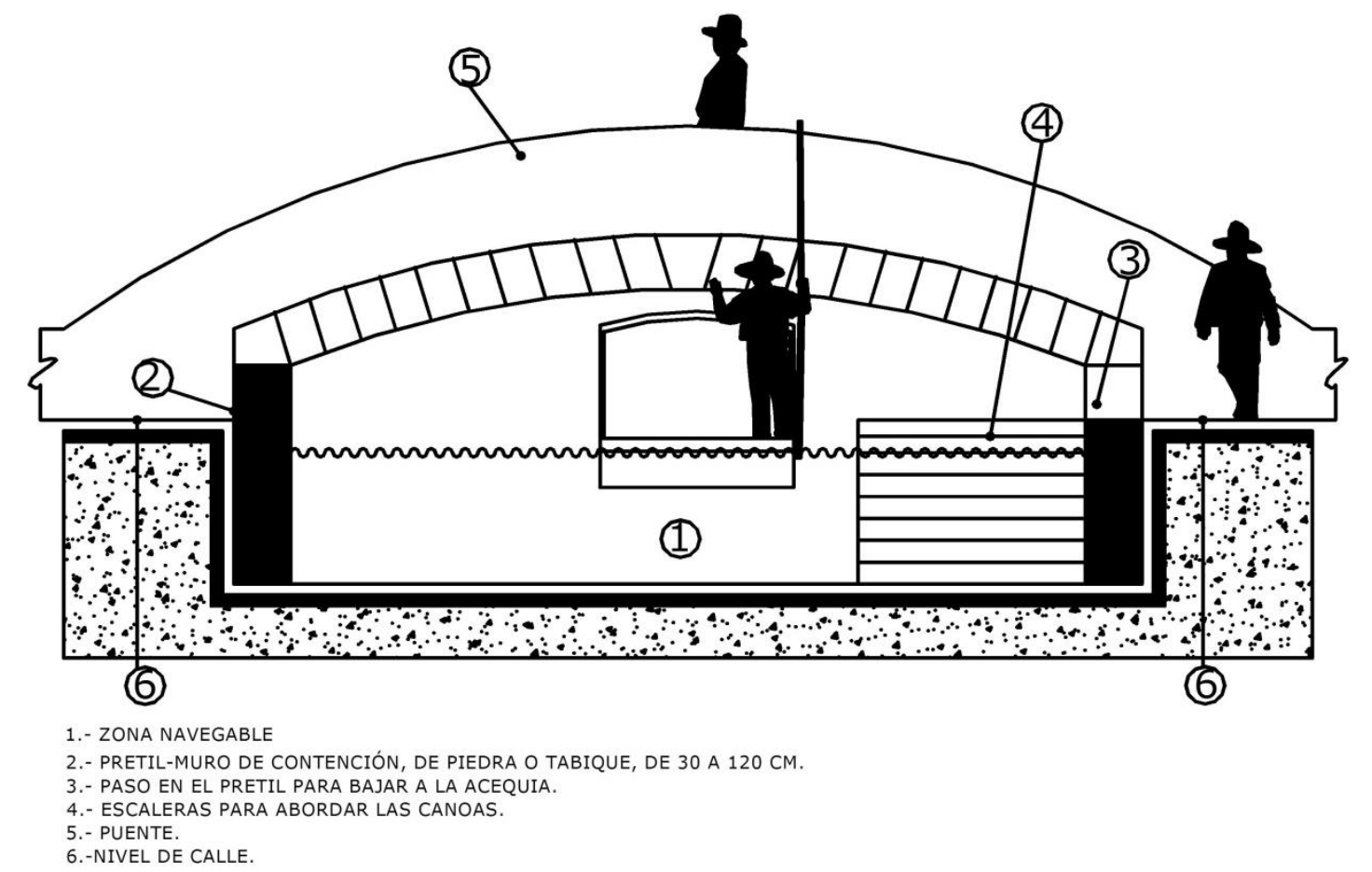

Figura 1, Croquis hipotético de las acequias, basado en datos de la tesis de Elsa Cristina Hernández Pons, La Acequia Real: Historia de un Canal de Navegación, Tesis de Doctorado en Estudios Mesoamericanos, Facultad de Filosofía y Letras, UNAM, 2002, p. 78. Dibujo: Alejandro Jiménez Vaca.

\section{6.- Infraestructura complementaria de las acequias}

\section{A.- Puentes}

Un elemento urbano ligado a las acequias eran los puentes. Como es bien sabido, éstos llegaron a adoptar la nomenclatura que se daba a las calles, estribando su origen en diversas circunstancias, ya sea en la actividad u oficio que se desempeñara en la zona, o en un suceso histórico. La nomenclatura se debía también a un edificio o templo destacado, o a que viviera un personaje ilustre en alguna calle de la ciudad.

Los antiguos puentes mexicas, hechos de varias vigas de madera perfectamente labradas y colocadas una junto de otra como lo describe Hernán Cortés, podían quitarse, dejando una barrera de agua que hacía imposible el 
pasar de un lado al otro. Dichos puentes fueron suplantados por otros, colocados de forma permanente para el paso de vehículos y personas.

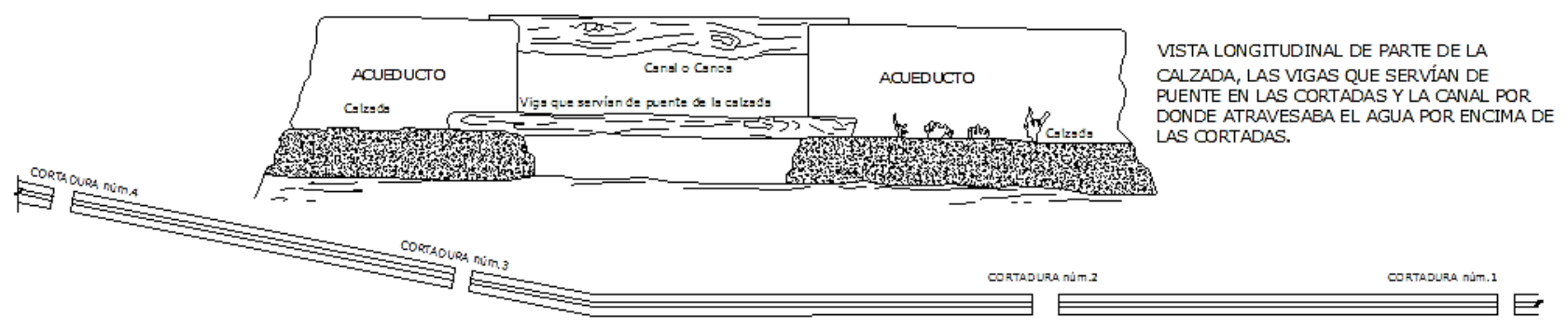

LAS QUATRO CORTADAS DE LA CALZDATLACOPAN QUE ESTABAN ABIERTAS DURANTE LA RETIRADA DE LOS ESPAÑOLES, LANOGHE TRISTE , 30 DE JUNIO DE 1520. LAS OTRAS CUATRO CORTADAS, QUE QUEDABAN DENTRO DE LA CIUDAD, LAS CONSERVABAN TAPADAS LOS ESPAÑOLES ESA NOOHE.

Acueducto y puente prehispánico en la calzada de Tlacopan. Imagen tomada del libro Origen, vida y muerte del acueducto de Santa Fé, de Raquel Pineda Mendoza, Instituto de Investigaciones Estéticas, UNAM, México, 2000, p. 28. Redibujo:

Alejandro Jiménez Vaca.

Básicamente, se pueden clasificar los puentes según sus métodos constructivos en dos tipos:

A.- Los de Vigas: El sistema constructivo se componía de forma muy similar a la bóveda franciscana; constaba de viguería, tablazón, terrado y empedrado, y a los lados podía tener pretiles de piedra o un barandal de madera (ver figura 2).

B.- Los de Bóveda: El sistema constructivo se componía de una pequeña bóveda de cañón corrido de dos o tres metros de ancho, y aproximadamente 5, 6 o más metros de longitud de un arco rebajado de cinco o más puntos. Encima de tal bóveda se colocaba un terrado y sobre éste el empedrado; a los lados se colocaban pretiles de piedra (ver figura 3).

El acceso a los puentes desde las calles se hacía por medio de rampas que conectaban estos dos elementos.

Puentes de mayores dimensiones con estos sistemas constructivos se encontraban en las inmediaciones de la ciudad, siendo de trascendencia los ubicados en las garitas de la Viga y San Lázaro, además del puente ubicado en el pueblo de Iztacalco, el cual fue representado por Casimiro Castro en la litografía llamada El Pueblo de Iztacalco, donde se ve pasar el pequeño vapor que viajaba de Chalco a la Ciudad de México, remolcando una pequeña embarcación de carga. (ver figura 4). 

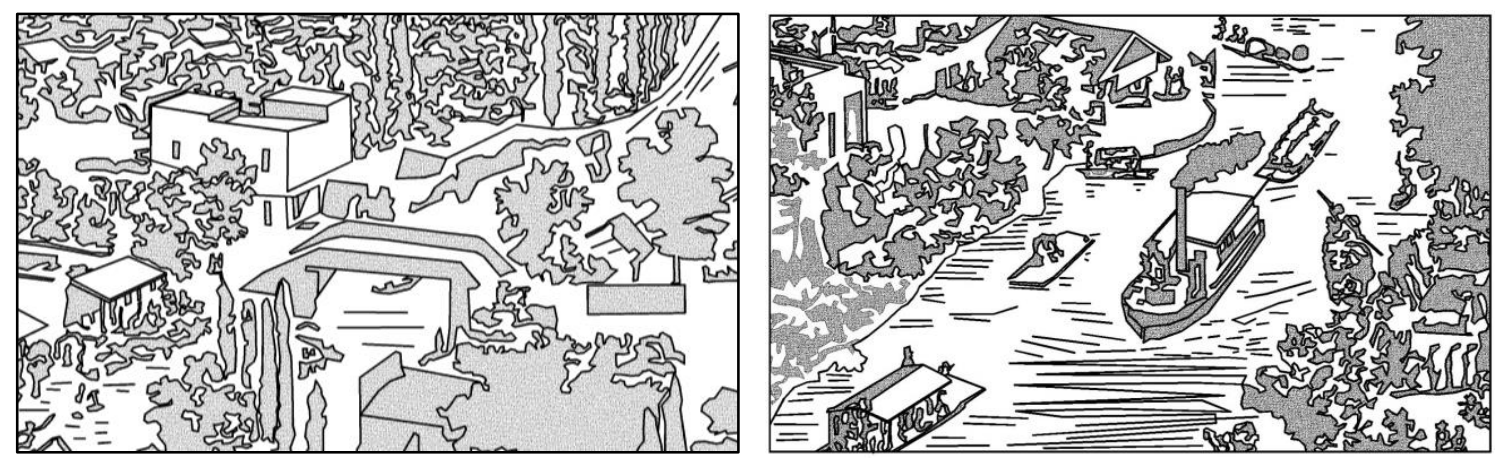

Figura 4. En estos dibujos se puede percibir el paso de un buque de vapor, después de pasar por el puente del pueblo de Iztacalco, perteneciente a una de las diversas rutas de vapores que existieron durante el siglo XIX y principios del siglo XX para la comunicación de la ciudad de México con el poblado de Chalco. Dibujo de Alejandro Jiménez Vaca, 2020, basado en un fragmento de la Litografía de Casimiro Castro del puente del pueblo de Iztacalco, Revista Arqueología Mexicana,

Editorial Raíces S.A. de C.V., México, No.68, p. 84.

Existían puentes provisionales -si es que se les puede llamar así-, conformados por dos o tres vigas colocadas sobre piedras, los cuales eran colocados de forma clandestina por los propietarios de casas y comercios, ya que el tener un puente era una gran ventaja en cualquiera de los dos casos, porque facilitaba el paso de las personas sin que tuvieran que trasladarse hacia el puente que se localizaba en algún lugar de la calle; además, en el caso de los comercios aseguraba el tránsito constante de personas, y por ende acarreaba mayores ventas; lo que se puede constatar en diversos documentos del Archivo Histórico del Distrito Federal, en los que se nota la preocupación que causaba la inseguridad de estos puentes, tanto de los peatones como de las embarcaciones que circulaban debajo de ellos, asimismo había una inquietud por el aspecto estético de tales elementos arquitectónicos, por lo que se ordenó en varias ocasiones su retiro o sustitución por otros de mejor aspecto, ya sea de vigas o de bóveda. 


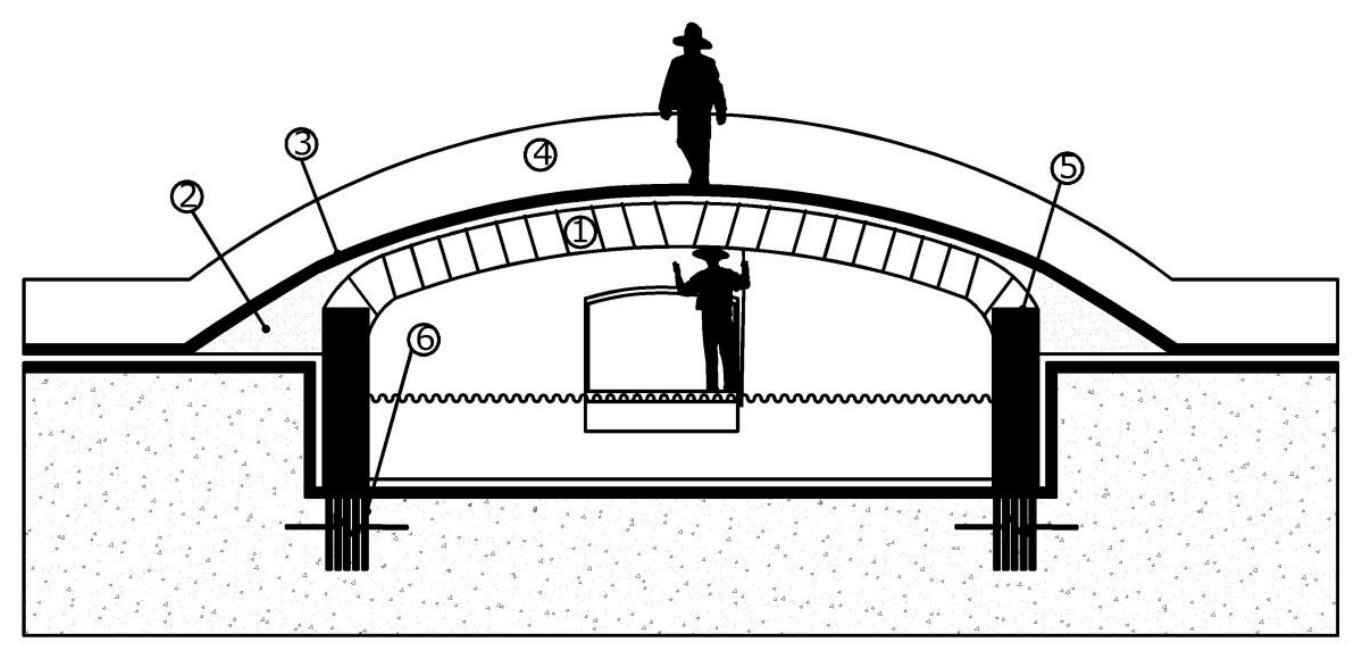

1.- BÓVEDA DE PIEDRA.

2.- TERRADO.

3.- EMPEDRADO.

4.- PRETIL DE PIEDRA DEL PUENTE.

5.- PRETIL-MURO DE CONTENCIÓN DE LA ACEQUIA.

6.- CIMENTACIÓN A BASE DE ESTACADO DE MADERA.

Figura 2. Croquis hipotético de un puente de bóveda, basado en datos de la tesis de Elsa Cristina Hernández Pons, La Acequia Real: Historia de un Canal de Navegación, Tesis de Doctorado en Estudios Mesoamericanos, Facultad de Filosofía y Letras, UNAM, 2002, p.79, 80. Dibujo: Alejandro Jiménez Vaca.

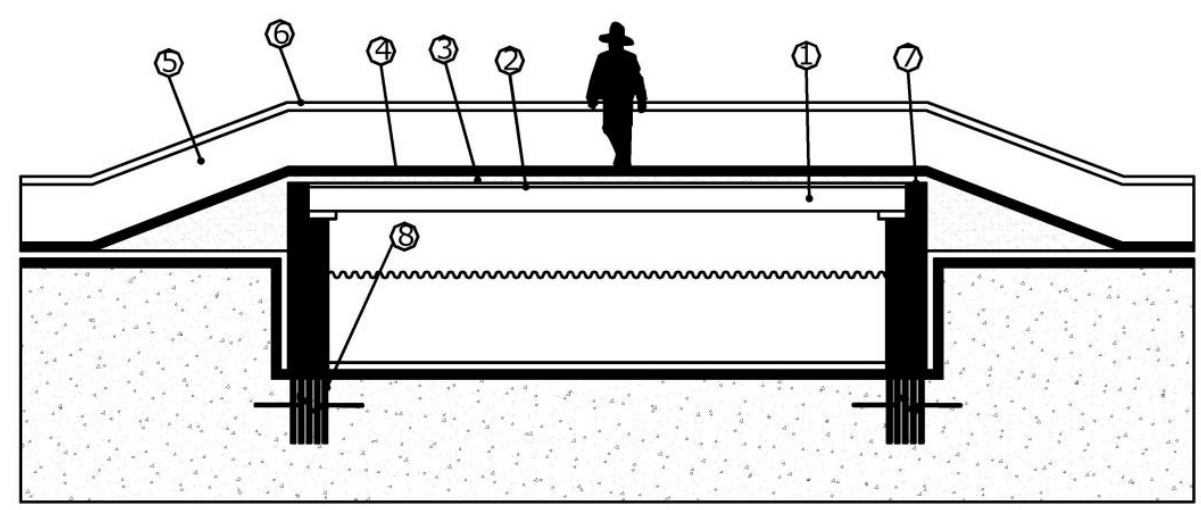

1.- VIGAS DE MADERA.

2.- TABLAZÓN.

3.- TERRADO.

5.- PRETIL DE PIEDRA DEL PUENTE.

6.- BARANDAL DE MADERA.

7.- PRETIL-MURO DE CONTENCIÓN DE LA ACEQUIA.

8.- CIMENTACIÓN A BASE DE ESTACADO DE MADERA.

Figura 3. Croquis hipotético de un puente de vigas. basado en datos de la tesis de Elsa Cristina Hernández Pons, La Acequia Real: Historia de un Canal de Navegación, Tesis de Doctorado en Estudios Mesoamericanos, Facultad de Filosofía y Letras, UNAM, 2002, p. 79, 80 y 88. Dibujo: Alejandro Jiménez Vaca.

\section{B.- Compuertas}

Las compuertas eran elementos importantes para evitar las inundaciones e ir mediando los niveles de agua en el lago de Texcoco y las acequias en la ciudad. Se encontraban en el albarradón de Ahuízotl o de San Lázaro, y permanecieron 
en uso hasta el final del período virreinal. En el plano de Johannes Vingboons ${ }^{17}$, se logra ver las ocho compuertas que existieron, y que aparecen parcialmente en otros planos y representaciones perspectivas de la ciudad: durante la mañana se abrían las compuertas para desfogar las acequias, y después de permanecer cierto período de tiempo abiertas, se cerraban en las tardes por el cambio de nivel del agua en los lagos, a causa de los vientos que soplaban de oriente a poniente, elevando el nivel del lago de Texcoco ${ }^{18}$ del lado poniente. Se evitaba con esto que se inundara la ciudad ${ }^{19}$ (Ver figura 5).

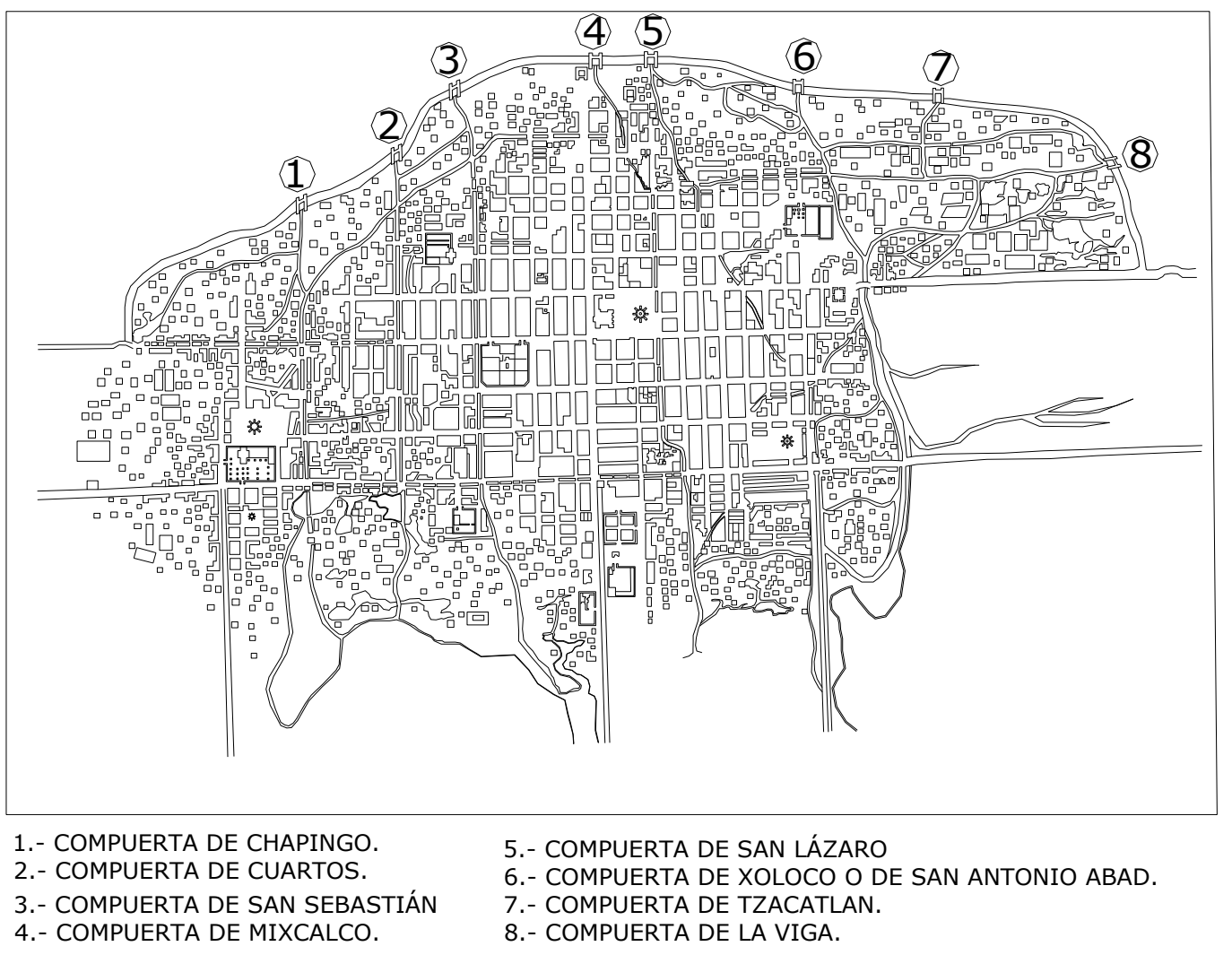

Figura 5. Localización de las Compuertas en el Plano de Johannes Vingboons, de 1665, basado en la perspectiva de Juan Gómez de Trasmonte de 1628.

\footnotetext{
${ }^{17}$ Plano de Johannes Vingboons, de 1665, basado en la perspectiva de Juan Gómez de Trasmonte de 1628.

${ }^{18}$ Estos vientos históricamente han provocado distintos problemas en la ciudad, en el período virreinal llevaban las sales del lago hacia los acueductos, lo que provocaba enfermedades gastrointestinales. En el período del porfirismo y posteriormente en el período revolucionario, el lago de Texcoco desecado arrastraba polvo y salitre, evento que producía erupciones en la piel, irritación en la garganta y enfermedades gastrointestinales.

${ }_{19}$ GARCíA SALGADO, Tomás, Conferencias del bicentenario de la fundación de la Escuela de Pintura, Escultura y Arquitectura, UNAM, México, 1984.p.150
} 
Debido a la disminución en el nivel de agua de los lagos, provocada por el proceso de desecamiento al que éstos estaban sujetos, se hizo necesario el rescate de los viejos sistemas prehispánicos para el control de las aguas mediante la implementación de albarradones, presas y compuertas que facilitaran la contención de agua en los lagos y que hicieran posible la irrigación en haciendas, parcelas, huertos y sembradíos, así como la navegación dentro de la ciudad y hacia las poblaciones vecinas, Además, mediante las compuertas se controlaba el flujo de las aguas de todo el sistema de lagos en el que estaba imbuida la Ciudad de México, abriendo las compuertas ubicadas en los albarradones existentes entre los lagos de Xaltocan y Zumpango, para desfogar las aguas del lago de México y Texcoco en el mes de diciembre, para volver a cerrarlas en los meses de junio y julio, y de esta manera volver a acumular agua en la temporada de lluvias ${ }^{20}$.

Las compuertas de las acequias secundarias o menores podían ser de tajadera o de tornillo, operadas manualmente por una sola persona; sin embargo, de las acequias principales que daban a las grandes compuertas ubicadas en el albarradón de Ahuizotl o de San Lázaro no es posible determinar mucho con precisión. Teresa Rojas Rabiela proporciona algunos datos de cómo eran esas grandes compuertas, mencionándolas como "de madera con puerta y llaves, y que se usaban vigas para su operación", asimismo señala que "en el siglo XVIII se operaban con cadenas de hierro". Dados los datos obtenidos de planos catastrales actuales, y de datos de archivos históricos en que se puede advertir que los anchos de las acequias oscilaban desde las 13 varas (10.85 mts) a las 10 varas (8.35 mts), se percibe que tales compuertas eran de grandes dimensiones, y debieron haber sido operadas por varias personas a la vez. Un atisbo del aspecto de cómo pudieron haber sido lo proporciona la perspectiva de Juan Gómez de Trasmonte de 1628, en la que se observan las amplias dimensiones de las acequias, y los grandes muros que albergaban a las compuertas.

Condición requerida para el buen funcionamiento de una acequia es la inclusión de sifones, aunque no hay datos que puedan dar testimonio de su

\footnotetext{
${ }^{20}$ CUEVAS AGUIRRE Y ESPINOSA, Francisco de, Extracto de las diligencias y reconocimiento de los Ríos, Lagunas y desagües de la capital de México y su valle: de los caminos para su comunicación y su comercio, México SEFI, 1979.
} 
existencia. No obstante la gran cantidad de parcelas y sembradíos en los poblados periféricos de la ciudad, es muy probable que se hayan utilizado en sustitución de acequias pequeñas para el abasto de agua en los huertos. Ejemplo de esto lo da el pasaje de Francisco Cervantes de Salazar a través de los protagonistas de su crónica México en 1554, donde pasan Zamora, Alfaro y Zuazo, en los alrededores de la Ciudad de México. En dicho texto se describe a las huertas que se encontraban al lado de la calzada de Tacuba, y que eran alimentadas por caños sacados directamente del acueducto que pasaba por esta calle ${ }^{21}$.

Descuidado era el trato que se le daba a las acequias que continuamente estaban sucias; ello dio pie a que se promulgaran leyes que prohibieran su contaminación, costumbre que desde tiempos prehispánicos no se pudo erradicar, hasta el momento en que las acequias fueron cegadas. Queda testimonio de este hecho en las excavaciones arqueológicas de numerosos pedazos de cerámica de barro de procedencia prehispánica, así como en una gran cantidad de objetos de la época virreinal ${ }^{22}$, desde mayólicas y porcelanas hasta lebrillos, bacinicas, escupideras y botellas de vidrio. También se cuenta que, en 1791, mientras se planeaba la sustitución de la acequia de Santa Isabel por una atarjea, se decidió cegarla por los malos olores a causa del estancamiento de las aguas, aparte de la gran cantidad de inmundicias que se arrojaban ahí y porque "la gentualla de la baja plebe" "descargaban el vientre" en este sitio ${ }^{23}$. También era común el que la gente diera de beber a sus animales agua de las acequias o arrojar animales muertos en ellas, surgiendo penalidades por estas acciones con multas impuestas hacia quien hiciere esta acción, o de no saberse quién era el causante se le adjudicaba al vecino más cercano ${ }^{24}$.

\footnotetext{
${ }^{21}$ CERVANTES DE SALAZAR, Francisco, México en 1554, UNAM, México, 2007, p. 82 y 83.

${ }^{22}$ HERNÁNDEZ PONS, Elsa Cristina, La Acequia Real: Historia de un Canal de Navegación, Tesis de Doctorado en Estudios Mesoamericanos, Facultad de Filosofía y Letras, UNAM, 2002.

${ }^{23}$ HERNÁNDEZ FRANYUTI, Regina, Ignacio de Castera, Arquitecto y urbanista de la Ciudad de México, 1777-1811, Instituto Mora, México, 1997, p 58.

24 BARRIO LORENZOT, Juan Francisco del, El trabajo en México durante la época colonial: ordenanzas de gremios de la Nueva España; compendio de los tres tomos de la compilación nueva de ordenanzas de la muy noble, insigne y muy leal e imperial ciudad de México, Sría. De Gobernación, México 1920.
} 


\section{7.- Las acequias en la producción}

Otra de las características de las acequias fue la de convertirse en elementos distribuidores de agua para la manutención de distintos rubros de producción, tanto en la repartición para las zonas agrícolas localizadas en las zonas periféricas de la ciudad, como en las zonas dentro de la misma en que distintos oficios necesitaban la utilización de agua para poder desempeñar su actividad. En lo que se refiere a la conformación de las huertas de los alrededores, en los pequeños canales se observaban sus contornos delimitados por ahuejotes, ${ }^{25}$ silueta inconfundible que aún se puede observar en las zonas sobrevivientes de chinampas en el sur de la ciudad. A este respecto quedan como testimonio disposiciones legales muy tardías del siglo XIX, en donde se tenía como obligación plantar árboles en las riberas de las acequias para asegurar de esta manera que se conservaran en buen estado y no perdieran su forma, pues no hay que olvidar que las acequias no son formaciones naturales, sino que son creadas por el hombre, y que como cualquier otra obra de esta naturaleza, si no reciben el mantenimiento adecuado pueden llegar a deteriorarse, 0 en el caso de las acequias, azolvarse, y en situaciones extremas llegar al cegamiento. Dentro de la ciudad los conventos contaban con pequeñas acequias dirigidas hacia las huertas; muy conocida es la de San Francisco, cuyas huellas quedan visibles actualmente en la traza urbana de la ciudad, además de los Conventos del Carmen y de Santo Domingo. En el Plano de 1737 de Pedro de Arrieta y los Maestros de la Arquitectura, pueden observarse alimentaciones de agua por medio de pequeñas acequias.

Oficios que necesitaban el agua eran ubicados en zonas donde les fuera fácil obtenerla; así, los curtidores se ubicaron en el sur-oriente de la ciudad, en la calle y puente que llevaba el nombre de su oficio y que corresponde en la actualidad a la calle de Misioneros (continuación de la calle de Regina). Existía allí alguna puerta falsa con una escalerilla de piedra para bajar a la acequia (que era exclusiva de los trabajadores). Por medio de ordenanzas se tenía prohibido arrojar

\footnotetext{
25 Árbol que crece en las riberas de los canales. Plano de los Maestros de Arquitectura de 1737, Pedro de Arrieta y otros.
} 
a los canales los desperdicios producto de su labor. Esto se hacía con frecuencia, contribuyendo a que los canales se azolvaran, además de producir fetidez en el aire. Los Tintoreros también la ocupaban para enjuagar las telas, pero en el caso de las sedas se les tenía prohibido usar la existente en las acequias, ya que ésta era turbia y grasosa, teniendo que lavarlas en agua limpia y clara, ya que si lo hacían en "agua de los canales" cambiaba con el tiempo el color y se pudría la prenda, cosa que pasaba, pues existía la ordenanza previendo esta acción que se sancionaba con una multa. Los tundidores que cortaban la tela para igualarla, debían colgar sus telas dando hacia las acequias para evitar molestias en los transeúntes que pasaban por las calles si éstas llegaban a volar.

\section{8.- Las acequias en la vida diaria y su influencia en la arquitectura}

Las acequias hicieron que en algunas ocasiones la arquitectura se supeditara a su forma, y en otras se hiciera caso omiso y se construyera sobre ellas, tomando en cuenta el libre flujo de las aguas que debía ocurrir debajo del inmueble. En determinados casos la acequia quedaba en las colindancias de los inmuebles, haciendo que los propietarios se vieran obligados a construir un puente para comunicarse directamente con la calle, o construir un pequeño embarcadero con escalera hacia la acequia. Testimonio de esto es la fotografía de la acequia de Roldán que nos presenta Guillermo Tovar de Teresa ${ }^{26}$ en su libro sobre el patrimonio perdido de la Ciudad.

${ }^{26}$ TOVAR DE TERESA, Guillermo, La Ciudad de los Palacios; Crónica de un Patrimonio Perdido, Edit. Vuelta, México, 1992. p 145. 


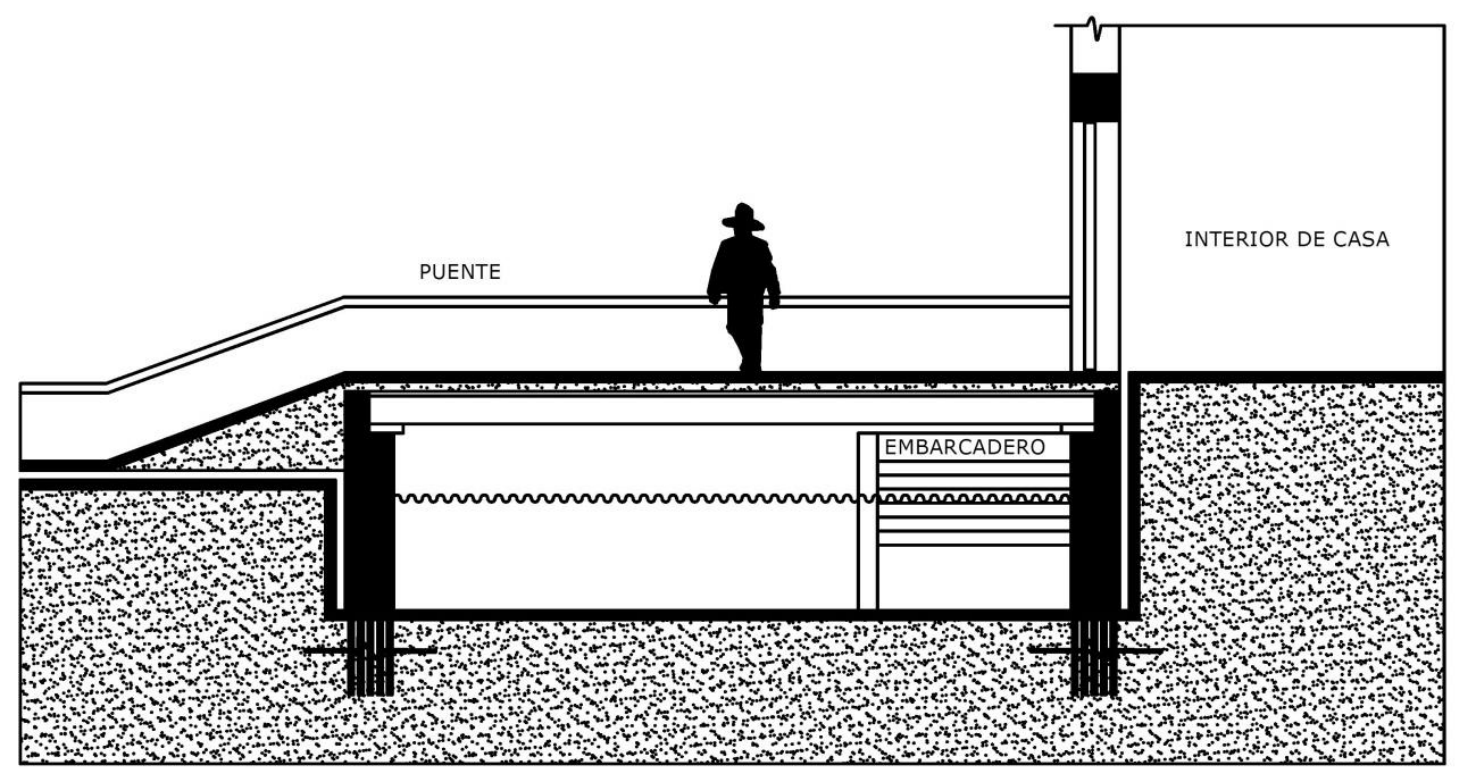

Esquema de casa con puente y con embarcadero, basado en una fotografía de la calle de Roldán de mediados del siglo XIX, tomada del Libro La Ciudad de los Palacios: Crónica de un Patrimonio Perdido, de Guillermo Tovar de Teresa, p 145.

Así, las edificaciones contaban con una puerta falsa, es decir una puerta trasera que daba hacia las acequias, siendo el acceso principal al inmueble la puerta que daba hacia las calles de tierra. Esta no era una regla general, pero se cumplía en la mayoría de los edificios que se encontraban cerca de un canal. La función de tales puertas era la de servir de acceso de servicio o de abastecimiento a los inmuebles. Muy conocida era la Puerta Falsa del Convento de la Merced, calle que conservó este nombre por varios siglos y que corresponde en la actualidad a la calle de República de Uruguay.

La necesidad de evacuar las aguas provenientes de las lluvias para evitar inundaciones hizo que las calles tuvieran pendientes que iban dirigidas hacia las acequias. En el caso de los edificios que se encontraban en las proximidades, se nota una pendiente hacia las acequias, a la vez que se pueden observar gárgolas que dan hacia ellas. Ejemplos de esto se pueden observar en múltiples edificios, como los ubicados en la Calle de Roldán, en Dieciséis de Septiembre, Corregidora y Apartado. Sin embargo, en los inmuebles que daban hacia las acequias que se encontraban entre los inmuebles no puede percibirse esta invariante, tal es el caso de la Acequia de la Merced. A través de algunos datos se puede verificar que tal invariante se aplicaba a los inmuebles de igual forma, como ocurrió en las casas 
ubicadas en el Callejón de Lecheras ${ }^{27}$. También se puede observar en el interior de la casa de Mesones 91-93, donde aún se localiza una gárgola que daba hacia la Acequia de la Merced. Había gárgolas que no estaban dirigidas hacia las acequias, siendo la dirección de éstas los patios interiores de las construcciones, aguas que es probable hayan sido utilizadas para acumular agua y para usarse en las distintas tareas domésticas de los mismos edificios.

\section{9.- Mantenimiento de las acequias}

Para el buen funcionamiento de una acequia, es indispensable que ésta se halle bajo constante mantenimiento, debido a que se trata de una construcción, y como cualquier obra realizada por el hombre, que tiene un uso continuo, debe cuidarse; de lo contrario puede sufrir deterioros o en casos extremos azolvamiento, y cegarse. Tal mantenimiento debía hacerse por lo menos una vez al año, limpiándose los azolves que pudieran existir en todo su trayecto. No obstante, por lo extenso de las acequias que existían en la Cuenca de México era imposible que se realizara de esta manera, quedando registros de la Ciudad de México como el único poblado que realizó trabajos de manera adecuada. Por desgracia, éstos no se hicieron con la constancia requerida; tal limpieza se efectuó sólo en tres ocasiones, conforme a los datos que se da en el reconocimiento y limpia de las acequias en el año de 1748: dos correspondientes al siglo XVII y una en el siglo $\mathrm{XVIII}$, quedando registros de algunos otros reconocimientos de las acequias de la urbe, y en algunas ocasiones de los respectivos presupuestos para la limpieza de las mismas, sin que llegaran a efectuarse por lo excesivo de los costos.

El mantenimiento más constante que se realizó en las acequias fue de tipo correctivo, es decir, se limpiaban sólo las zonas que iban presentando problemas, ya sea por azolves que se acumulaban y que provocaban inundaciones parciales de ciertos poblados, o porque dificultaban la navegación a través de sus aguas ocasionadas por la excesiva acumulación de basura o arena, además las

\footnotetext{
${ }^{27}$ HERNÁNDEZ PONS, Elsa Cristina, La Acequia Real: Historia de un Canal de Navegación, Tesis de Doctorado en Estudios Mesoamericanos, Facultad de Filosofía y Letras, UNAM, 2002.
} 
acequias sufrían reparaciones mayores, las cuales consistían en la re-excavación de secciones que se habían cegado por azolves, así como en la delimitación o reconstrucción de las orillas o ribas de las acequias. También se realizaba la reconstrucción de diques en los lugares donde los hubiera, así como el sembrado de árboles en las orillas y la reparación de pretiles ${ }^{28}$. Estos últimos trabajos era común que se realizaran en la Ciudad de México.

A través de continuos reconocimientos en la Ciudad de México para la reparación y limpieza de las acequias, quedó asentada su distancia y trayectoria, así como el registro de la ampliación de su longitud en el período virreinal. Uno de estos registros corresponde al año de 1637, y lo refiere Luis González Obregón, ${ }^{29}$ constatándose el crecimiento de las acequias en diferentes etapas, observándose en ello una continuidad de tales elementos urbanos de comunicación, formando parte integral del funcionamiento de la ciudad.

\begin{tabular}{|l|l|}
\hline Acequia & Longitud \\
\hline Acequia Real & 3,000 varas \\
\hline Acequia de la Merced & 2,139 varas \\
\hline Acequia del Carmen & 1,095 varas \\
\hline Acequia del Chapitel & 2,046 varas \\
\hline Acequia de Tezontlale & 1,646 varas \\
\hline Acequia Santa Ana & 3,840 varas \\
\hline Acequia de Mexicaltzingo & 2,850 varas \\
\hline
\end{tabular}

Longitud de las acequias de la Ciudad de México en el año de $1637 .^{30}$

Uno de los reconocimientos de las acequias de la Ciudad de México se da el 1 de abril de $1700^{31}$, en el que por medio de los Capitulares Don Miguel de Cuevas de Dávalos y Don Pedro Ximenez de los Cobos, acompañados de varios peritos Maestros del Arte de la Arquitectura, entre los que figuraba Pedro de

\footnotetext{
${ }^{28}$ Existen datos en el que los Arquitectos Mayores de la ciudad de México se encargaban de la reparación de las acequias, siendo tarea común de su quehacer, en este caso se cita como ejemplo el expediente en el que Francisco Antonio Guerrero y Torres se encarga de la reparación de pretiles de la Acequia Real, del tramo que iba del Puente de la Leña hasta el Hospital Real. AGN, Obras Públicas, Año 1787, Vol. 27, exp. 5.

${ }^{29}$ GONZÁLEZ OBREGÓN, Luis, Las Calles de México, Editorial Porrúa, México, 2009, p. 149.

${ }^{30}$ Ibídem.

${ }^{31}$ Documento del Archivo General de Indias, una copia de este documento me lo proporcionó el Dr. José Manuel Mijares y Mijares y fue parte de su archivo personal.
} 
Arrieta, se realizó un reconocimiento respecto al estado que guardaban en esa época las calzadas, acequias y acueductos, para efectuar posteriormente las reparaciones necesarias. En el caso de las acequias se señalan las trayectorias de las mismas, realizándose una tasación del costo de la limpieza de cada una de ellas, dando un total de cuarenta y tres mil cincuenta pesos tan sólo en lo que se refiere a la limpieza, y por lo que respecta al costo total de las obras referidas en este reconocimiento, que contemplaba la reparación de calzadas y acueductos, éste ascendía a la cantidad de ciento cinco mil trescientos cincuenta pesos; además, se contemplaba un presupuesto para un mantenimiento anual, el cual ascendía a la cantidad de dieciocho mil pesos, donde los Maestros Mayores de Arquitectura hacen ver el deterioro y acumulación de basura y fango ocurrido en las acequias, lo que provocaba que el agua de las calles cercanas no fuera dirigida hacia aquéllas, sino al contrario, el agua de éstas salía e inundaba las calles vecinas, siendo necesario en algunas ocasiones realizar una re-excavación, como ocurrió en el caso de la acequia del Chapitel, donde algunas secciones se encontraban totalmente cegadas por la cantidad de azolves acumulados, ocasionando una serie de inconvenientes por las inundaciones que acontecían en las cercanías de estos tramos. Por ello era necesario, además de la situación referida con anterioridad, realizar de forma general una limpieza que hiciera bajar de una a dos varas el nivel del fondo de las acequias, y de este modo garantizar el flujo de las aguas para evitar que se quedaran estancadas. De tal manera, se hacía ver que si no se efectuaba esta limpieza, varias calles de la ciudad podrían verse inundadas, introduciéndose el agua en los templos y casas vecinas. La importancia de este documento radica en un punto que no contemplan otros, que es el considerar en el presupuesto una partida adicional dedicada al mantenimiento anual de las obras, hecho que es de destacar, pues el mantenimiento es necesario para el correcto funcionamiento de los edificios y para evitar su deterioro. Ante tales argumentos, estos trabajos no se llegaron a realizar en décadas, siendo hasta mediados del siglo XVIII que se efectuó un nuevo reconocimiento, y se realizaron los trabajos de limpieza que las acequias necesitaban urgentemente. 


\begin{tabular}{|l|l|l|l|}
\hline Acequia & Longitud & Ancho & Presupuesto limpieza \\
\hline Acequia Real & 4,067 varas & 8 varas & 13,000 pesos \\
\hline Acequia de la Merced & 2,832 varas & 6 varas & 8,000 pesos \\
\hline Acequia del Chapitel & 3,721 varas & 7 varas & 8,550 pesos \\
\hline Acequia del Carmen & 5,696 varas & De 6 a 7 varas & 4,600 pesos \\
\hline Acequia de Tezontlale & 3,835 varas & De 7 a 8 varas & 5,100 pesos \\
\hline Acequia Santa Ana & 3,800 varas & sin datos & 2,200 pesos \\
\hline $\begin{array}{l}\text { Acequia s/n al oriente, de Santa Cruz hasta } \\
\text { la Acequia del Carmen. }\end{array}$ & 1,009 varas & 6 varas & 1,600 pesos \\
\hline
\end{tabular}

Longitud de las acequias de la Ciudad de México en el año de $1700 .{ }^{32}$

En el año de 1748 se realiza lo que sería la tercera limpieza que se hizo de las principales acequias en la Ciudad de México en todo su trayecto, quedando testimonio de este hecho en un documento denominado "Extracto de los autos de diligencias y reconocimientos de los ríos, lagunas, vertientes y desagües..." del Lic. Joseph Francisco de Cuevas Aguirre y Espinoza ${ }^{33}$, siendo en el decreto, con fecha de 31 de enero de 1748, donde se relatan los reconocimientos de las acequias de la Ciudad de México que se realizaron en ese año. Sumando la longitud de todas ellas, se obtenía un total de veintidós mil trescientas sesenta y tres varas. De esta forma se aprovecharon ciertos datos para hacer una comparativa con otros reconocimientos realizados en el siglo XVII, en donde se hace hincapié en la extensión de las acequias, en las cuales a pesar de ser las mismas y tener casi el mismo trayecto, la longitud aumentó considerablemente, teniendo en sus inicios una longitud en la totalidad de todas las acequias de dieciséis mil seiscientas dieciséis varas ${ }^{34}$, es decir cinco mil setecientas cuarenta y siete varas menos que la longitud total de las acequias existentes en el año de 1748. También se hace referencia a dos limpiezas que se hicieron en el siglo XVII,

\footnotetext{
${ }^{32}$ Ibídem.

33 CUEVAS AGUIRRE Y ESPINOSA, Joseph Francisco de, Extracto de las diligencias y reconocimiento de los Ríos, Lagunas y desagües de la capital de México y su valle: de los caminos para su comunicación y su comercio, México SEFI, 1979.p. 36-41.

${ }_{34}$ Joseph Francisco de Cuevas no define la fecha de este dato, solo menciona como referencia “... del impresso del Desague...”, Ibídem, p. 36. tal pareciera que es el mismo documento al que se refiere González Obregón y el cual es atribuido a Cepeda y Carrillo en el año de 1637. GONZÁLEZ Obregón, Luis, Op. Cit. p. 149.
} 
una de 1635, en la que el costo ascendió a treinta y cuatro mil pesos, y otra en el año de 1675, sin que ninguna de éstas se hubiera realizado con la misma calidad y empeño que la realizada en 1748, según el dicho del licenciado Cuevas Aguirre y Espinosa, sin que llegaran a los doce mil pesos los costos de los trabajos de limpieza en este año. El licenciado Cuevas Aguirre y Espinosa, sin embargo, no cuenta otras reparaciones que se hicieron, como la construcción de cuatro puentes de bóveda con un costo de menos de cinco mil cuatrocientos pesos, y otros trabajos realizados por Don Joseph de Movellán, que sumaban una cantidad poco mayor de siete mil quinientos pesos ${ }^{35}$. Aun sumando todas estas cantidades, pareciera que se confirma la afirmación que hace Cuevas Aguirre y Espinosa al decir que los costos de tales trabajos son menores a los realizados anteriormente. Otro de los aspectos importantes de este documento es el de señalar los excesos de azolves que se acumularon en las acequias, cegando parcialmente algunas secciones, tales sucesos acontecieron principalmente en la acequia de la Merced, que en su trayecto iba adoptando diferentes curvaturas y se desplazaba debajo de algunas edificaciones, lo que facilitaba el azolve y cegamiento de estos segmentos, y por lo tanto dificultaba su limpieza; el otro caso era el de la acequia de Santa Anna, en el que existían varios tramos que estaban cegados, por lo que fueron re-excavados para que se permitiera el flujo de las aguas. Es probable que sucediera tal situación a causa de las normas establecidas en las ordenanzas novohispanas, en que se contemplaba la obligación de los propietarios de las casas que estuvieran en colindancia con una acequia, a mantenerla limpia de azolves en el tramo que estuviera frente a su propiedad, por lo que esta norma no podía tener cumplimiento en estas zonas, ya que al no existir casas en algunas secciones de esta acequia, quedaban sin el mantenimiento requerido para su correcto funcionamiento, situación que se repetía en las demás acequias existentes en la cuenca de México, de ahí que existieran múltiples zonas donde existían azolves. La forma de solucionar esta situación fue solicitar la mano de obra de los indios a los pueblos cercanos, a los cuales se les asignaba un salario para ejecutar estas obras de limpieza de beneficio común.

${ }^{35}$ Ibídem, p. 41. 


\begin{tabular}{|l|l|}
\hline Acequia & Longitud \\
\hline Acequia Real & 3,398 varas \\
\hline Acequia de Mexicaltzingo & 2,395 varas \\
\hline Acequia de la Merced & 2,005 varas \\
\hline Acequia del Carmen & 3,909 varas \\
\hline Acequia del Chapitel & 3,517 varas \\
\hline Acequia de Tezontlale & 1,907 varas \\
\hline Acequia de Santa Ana & 3,404 varas \\
\hline
\end{tabular}

Longitud de las acequias de la Ciudad de México en el año de 1748.

La mano de obra para la limpieza de las acequias se obtenía principalmente por parte de los indios que residían en los diferentes pueblos que se encontraban en la región, costumbre prehispánica que perduró durante el virreinato, en que eran solicitados para las obras de beneficio común, denominadas "coatequit" "36 y también conocidas también como "tequios", siendo en un inicio los encomenderos del período novohispano quienes proporcionaban la mano de obra hacia el gobierno virreinal, como parte de los tributos que debían aportar a la corona española ${ }^{37}$. Durante esta etapa los indios no recibían remuneración alguna por la labor que realizaban, sin embargo, por el reconocimiento de sus derechos por parte de la corona española en el año de 1549, se hizo obligatorio dar un salario a aquellos que ejecutaban estos trabajos. Al principio de la implementación de tales disposiciones éstas no se llegaron a respetar, por lo que los indios siguieron sin recibir retribución alguna. Debieron pasar varios años para que estas normas realmente se cumplimentaran: al debilitarse las encomiendas, los corregimientos fueron los encargados de la administración pública de las regiones que se encontraban en la cuenca, así como de la recaudación de impuestos, convocando a laborar en obras públicas mediante los denominados "llamamientos" ${ }^{38}$, rotándose los períodos de trabajo en que debían laborar en las obras públicas mediante los denominados "repartimientos", surgiendo la figura administrativa de

\footnotetext{
${ }^{36}$ GIBSON, Charles, Los aztecas bajo el dominio español, Editorial Siglo XXI, México, 2007, p. 227.

${ }^{37}$ Ibídem, p. 226.

${ }^{38}$ Ibídem, p. 227.
} 
"repartidor", el cual se encargaba de asignar mediante determinados períodos de tiempo tareas específicas por parte de la mano de obra disponible, que en su mayoría era por parte de los indios de los poblados ${ }^{39}$, pero que también podía incluir a los reos de las cárceles, obligándolos a trabajar en estas labores como parte de su condena.

Cuando llegaba a haber problemas de azolves en alguna acequia, el ayuntamiento mandaba pedir mano de obra indígena a los pueblos circundantes, para que realizaran estos trabajos de beneficio común, debiendo proporcionar un salario diario por tal actividad a los pueblos a los que se les solicitaba esta mano de obra. La razón de que se eligiera la mano de obra indígena sobre cualquier otra, era por la creencia de que estas eran las personas más aptas para la actividad, entre las que se sumaban otras tareas, como la de encargarse de la navegación de las pequeñas embarcaciones que surcaban por las aguas de las acequias y lagos de la cuenca, auxiliándose de pértigas que se apoyaban en el fondo de los canales, para lo cual se necesitaba cierta fuerza y destreza que ninguna de las castas existentes en la Nueva España tenían, siendo de esta manera que la sociedad virreinal relegaba a los indios a ejercer las tareas más duras, en base a supuestas características físicas que permitía que tuvieran habilidades únicas respecto a otras castas. En los últimos años de la existencia de la Nueva España, a causa de los precarios recursos que existían en las arcas virreinales, y como una medida para aminorar los recursos destinados a las obras públicas, se hacía uso de la mano de obra que proporcionaban los reos de las cárceles, obligándolos a efectuar obras de beneficio público como parte de su condena. En el caso de las acequias, se les asignaron diversas tareas como la limpieza, la excavación de nuevas zanjas y el cegamiento de las que se encontraban en el interior de la ciudad de México, las cuales por cuestiones de sanidad tuvieron que ser intervenidas. Dado lo especial de estas obras, era necesario que sólo una parte de los trabajos la realizaran los reos, destinando las demás tareas a obreros especializados, como por ejemplo los empedradores, que deberían ser hábiles en su trabajo, y los acarreadores de tierra, que en su mayoría

\footnotetext{
${ }^{39}$ Ibídem, p. 229.
} 
eran jóvenes, y eran denominados en obra como "cabritos". La decisión de que ciertas actividades las efectuaran tales trabajadores respondía a una necesidad de seguridad, ya que su labor requería de movilidad en amplias áreas, actividades que no podían destinárseles a los reos, ya que si se les asignaban estas tareas podría ocurrir el hecho de que pudiesen huir ${ }^{40}$.

La preocupación por el buen estado de las acequias por medio de un constante mantenimiento planteó la necesidad de realizar la limpieza por medios mecánicos, pretendiendo dejar atrás los tediosos y lentos trabajos que tradicionalmente se hacían de forma manual por parte de los indios de los poblados cercanos. Entre estas consideraciones de incorporar maquinaria para la limpieza de las acequias, existe en el Archivo General de la Nación el registro de los "Pontones", es decir pequeñas embarcaciones con cucharas que servían para excavar y extraer los azolves de las acequias; tal pareciera que la utilización de estas embarcaciones fue una práctica común, ya que existe en documentos de archivos la referencia de un funcionario que sustentaba el título de "sobrestante de los pontones", el cual podía solicitar se abrieran o cerraran las compuertas de las acequias para evacuar los excesos de agua, ${ }^{41}$. Además, se localizó en el archivo Histórico del Distrito Federal un expediente, en el período en que gobernó el virrey Revillagigedo, que habla sobre la construcción de una pequeña flota de pontones y canoas para la limpieza de las acequias, teniendo por lo menos una continuidad de tres años en su utilización, en el que se dedicaba un presupuesto anual al mantenimiento de estas embarcaciones y al sueldo de los operarios ${ }^{42}$; en adición, constan dos registros más de estas máquinas durante el virreinato, una que se construyó en el año de $1795^{43}$, y otra de un proyecto que tal pareciera jamás se llegó a construir; el primero se refiere a un Pontón que limpiaría la acequia que iba de México a Chalco, y el cual fue construido por un carpintero llamado Joseph de

\footnotetext{
${ }^{40}$ AGN. Fondo Indiferente Virreinal, Sección Ríos y Acequias, Exp. 113 C. 6486

${ }^{41}$ AGN, Fondo Indiferente Virreinal, Sección Policía y Empedrados, 1792, Exp. 32, C. 6466.

${ }^{42}$ Archivo Histórico del Distrito Federal, Fondo Ayuntamiento del Gobierno del Distrito Federal, Sección Ríos y Acequias, Vol. 3873, Exp. 171, año 1775. Existe un presupuesto anual del 24 de mayo de 1794 en el que se contempla un presupuesto anual de mil ochocientos noventa y tres pesos para la construcción de esta pequeña flota de cinco pontones y cuatro canoas, además de incluirse dentro del mismo los sueldos de 18 operarios.

${ }^{43}$ AGN. Obras Públicas, Vol. 7, exp. 4.
} 
Lago y sería operado por dos personas; sin embargo, ante el dicho del subdelegado de la provincia de Chalco, quien se encargó de las erogaciones para la limpia de la acequia, tal Pontón tenía muchas imperfecciones que hacían difícil su maniobrabilidad, lo que provocaba que la limpia de la acequia fuera poco eficiente, optándose finalmente por dedicar los trabajos de la limpieza a indios que los realizaron de manera manual y por el desmantelamiento de dicha embarcación; el segundo registro es el que se refiere a un proyecto de la construcción de un Pontón, tal propuesta surgió el 11 de Agosto de 1821 por parte del ingeniero José Bravo ${ }^{44}$, contramaestre de los Buques de la Armada Nacional, en el que se señala mediante un croquis y la descripción del mismo, su propuesta de la construcción de un Pontón, es decir, una embarcación con una cuchara para excavar y que se ocuparía de diversas tareas, entre ellas la construcción de fosos o acequias para la protección de la ciudad, así como para profundizar y ensanchar las existentes. Se planteaba que este mismo aparato sirviera para la limpieza de las acequias y los lagos, minimizando el costo y tiempo de los trabajos; tal máquina sería operada por sólo diez hombres, extrayendo en cada cucharada de cuatro a cinco quintales de fango ${ }^{45}$, con un costo total de mil a mil quinientos pesos, y con opción de construirse en la herrería de la Casa de la Real Moneda, donde podrían reducirse los costos a seiscientos pesos. Tal propuesta fue puesta a consideración del Director Sub-Inspector de Ingenieros, donde por medio de un informe escrito al margen de la misma propuesta de José Bravo, se expone que el autor de esta idea era una persona conocedora de su materia y consideraba que en realidad el proyecto tendría un efecto positivo en los trabajos de limpieza y construcción de acequias, por lo que él consentía en que tal proyecto se llevara a cabo.

Tal propuesta, no obstante, jamás se llegó a realizar, probablemente por el cambio de gobierno que aconteció al mes siguiente de que José Bravo la

\footnotetext{
${ }^{44}$ AGN. Fondo Indiferente Virreinal, Sección Ríos y Acequias, Exp. 28 C. 5794

${ }^{45}$ El quintal se dividía en 4 arrobas de 25 libras cada una, es decir un quintal tenía 100 libras, que es igual a 45.36 kilogramos, por lo que 4 quintales equivalen a 181.44 kilogramos y 5 quintales equivalen a 226.8 kilogramos. ALMONTE, Juan Nepomuceno, Guía de forasteros y repertorio de conocimientos útiles, Facsímil de 1852, Instituto Mora, México, 1997, p. 471.
} 
presentara. La imposibilidad de su ejecución tal vez tuvo su causa en la consumación de la Guerra de Independencia.

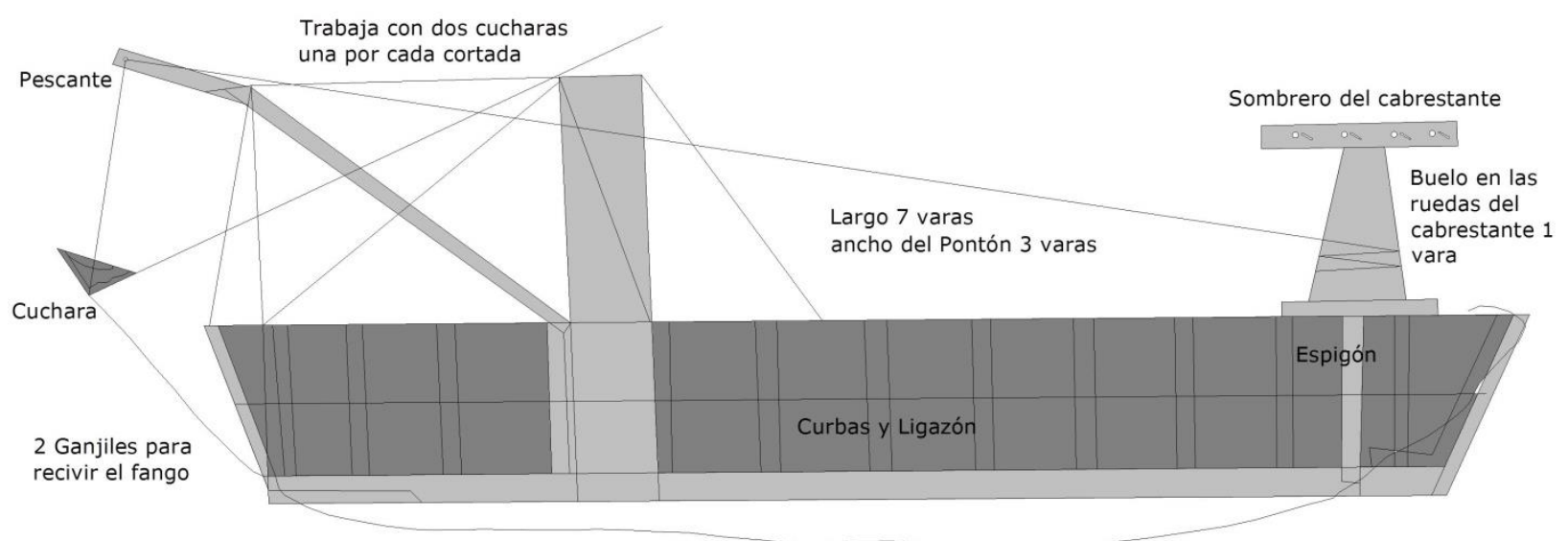

"Pontón" de José Bravo, el cual serviría para la limpieza de las acequias y los lagos. En una de las notas, Bravo hace referencia a 2 "ganjiles" o gánguiles, es decir, dos pequeñas embarcaciones a los lados del pontón, que servirían para recibir el fango. Redibujo de imagen tomada del AGN. Fondo Indiferente Virreinal. Sección Ríos y Acequias, Exp. 28, C.

5794. Redibujo: Alejandro Jiménez Vaca.

\section{0.- Las reformas borbónicas, desuso, cegamiento y construcción de nuevas acequias.}

El proceso de desecamiento de los lagos a través de la construcción del desagüe de la cuenca por medio del túnel de Huehuetoca y el tajo de Nochistongo, ya había comenzado a provocar efectos notorios en la vida de la ciudad; uno de ellos era el bajo nivel de agua a consecuencia de la mengua en el flujo de las corrientes del lago, provocando estancamientos de agua, lodos e inmundicias que se iban acumulando tanto en las acequias donde se dificultaba la navegación de canoas, como en las calles, donde el continuo transitar de carretas causaba que el empedrado de las calles se deteriorara, provocando "baches" donde se acumulaba el agua de las lluvias.

Un proyecto que complementaba el desagüe de la cuenca fue el realizado por el Maestro Mayor de la Ciudad y del Real Desagüe, Ildephonso Iniesta Vejarano, para el aprovechamiento de las aguas del Rio Cuautitlán, región por la 
cual también se desaguaban los lagos, desarrollándose un reglamento y repartimientos mediante acequias con datas de agua hacia los propietarios de los diferentes ranchos, haciendas, quintas y molinos, por donde se desarrollaba el trayecto del río, determinándose las características de las acequias que se nutrían de éste, debiendo ser de mampostería y alimentadas con datas que estaban medidas en dígitos ${ }^{46}$.

Proyectos de desagüe por el alto costo de las obras fueron desechados, desde el propuesto por Don Luis de Fuenmayor (1607), hasta el de Antonio Alzate (1767), los cuales proponían drenar los lagos por el lado sur oriente en el lago de Chalco, traspasando la Sierra Nevada, o bien hacia el nor-oriente de la cuenca hacia la zona de Teotihuacán. Es así que, para desaguar la cuenca, se determinó como opción más viable la ruta hacia el norte, por las grandes ventajas de los desniveles, distancias cortas y el aprovechamiento de ríos existentes, como el río San Miguel o San Gabriel, el río Cuautitlán y el río Tula. Ya en 1774, Joaquín Velázquez de León preveía que el desagüe de Huehuetoca sería insuficiente, y propuso hacer un desagüe por Tequixquiac, idea que se retomaría hasta el siglo XIX en diferentes momentos y que finalmente se concretaría casi a finales del siglo durante el régimen de Porfirio Díaz.

Proyectos que quedaron inconclusos debido a la guerra de independencia y las intervenciones extranjeras que siguieron después fueron promovidos en su inicio por el virrey Iturrigaray y avalados por Alejandro de Humboldt, contemplando el desagüe de los lagos mediante la construcción de canales que servirían para drenar los lagos de Zumpango y San Cristóbal, a la vez que irrigarían grandes zonas de cultivo, haciendo más eficiente el desagüe y aprovechando las aguas que producirían tales obras ${ }^{47}$.

\footnotetext{
46 SANDRE OSORIO, Israel, Boletín del Archivo Histórico del Agua, SEMARNAT, CONAGUA, México, Año 12, No. 35, enero-abril, 2007, p. 46 a 49.

${ }^{47}$ MUSSET, Alain, El Agua en el Valle de México, siglos XVI-XVIII, Pórtico de la Ciudad de México, México, 1992, p 194 a 205.
} 


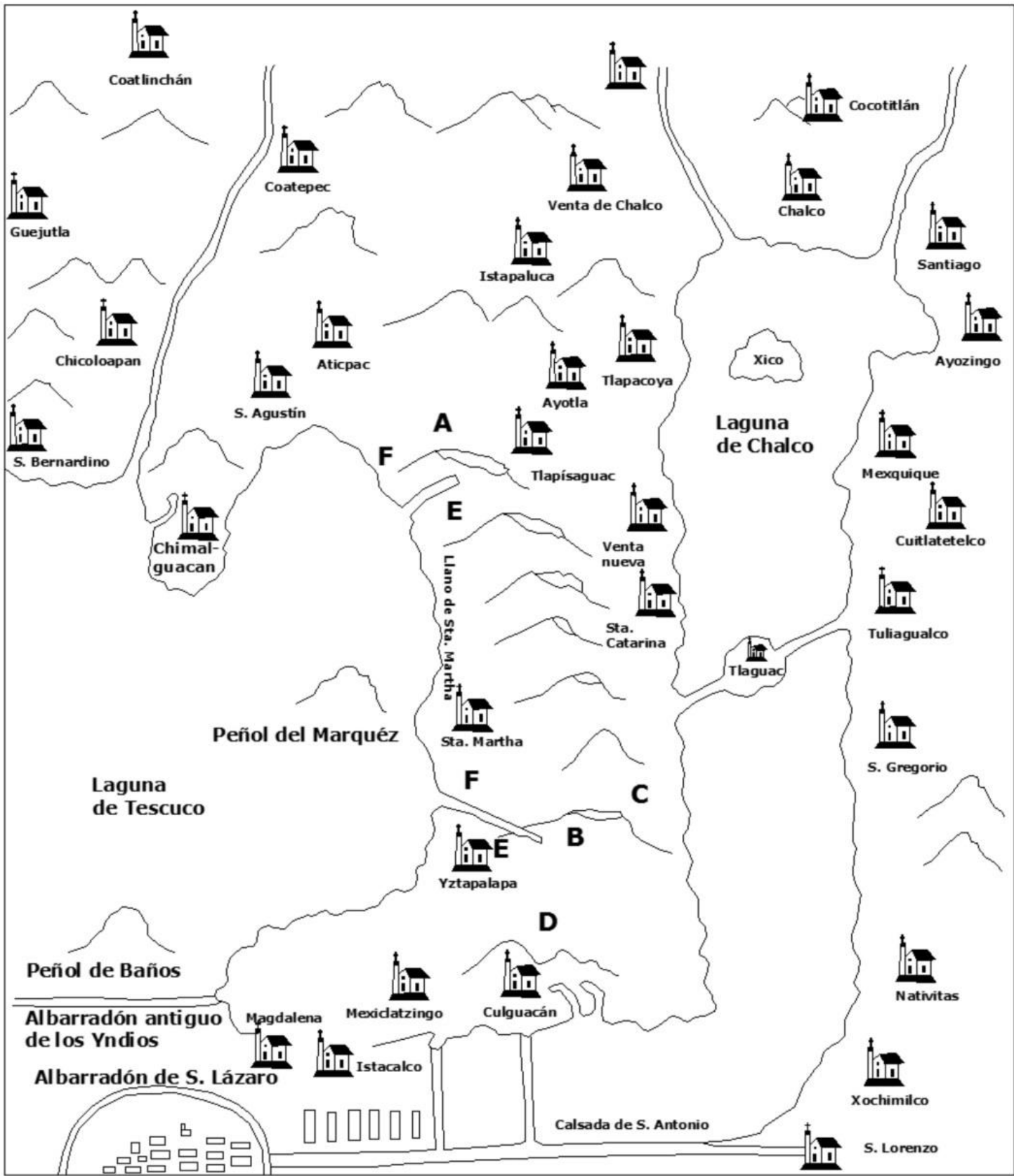

Proyecto de desagüe del Arquitecto jesuita Joseph Antonio Alzate y Ramírez, el cual consideraba la construcción de una acequia en dos probables lugares, uno localizado al sur-oriente del lago de Texcoco hacia el volcán de la Caldera, y el otro probable punto de desagüe se localizaba en el cerro de San Nicolás, ambos con compuertas en la boca de la acequia para controlar el flujo del agua, evacuando sólo los excesos, permitiendo que se continuara con las actividades productivas de los lagos para evitar de esta forma las inundaciones. Redibujo de imagen tomada de www.agn.gob.mx. AGN, Mapa 0021,

1767. Redibujo: Alejandro Jiménez Vaca

Para contrarrestar el efecto causado por el estancamiento de las aguas dentro de la ciudad de México; hecho que provocaba fetidez en el aire, se tomaron varias acciones, como la renivelación de las calles para conducir el agua 
directamente a las acequias limítrofes, y la sustitución de la mayoría de las acequias por atarjeas, las cuales eran drenajes subterráneos que conducían las aguas a las acequias periféricas. La ejecución de tales obras estuvo a cargo del Maestro Mayor de Arquitectura Ignacio de Castera, el cual a través de obras de urbanización mejoró en un alto grado la imagen de la urbe, a pesar de las críticas que tuvo en contra por parte de la población y de colegas arquitectos, ya que había la creencia de que, si se cegaban las acequias, podría haber inundaciones de grandes dimensiones que amenazarían con volver a ver hundida la ciudad bajo las aguas del lago.

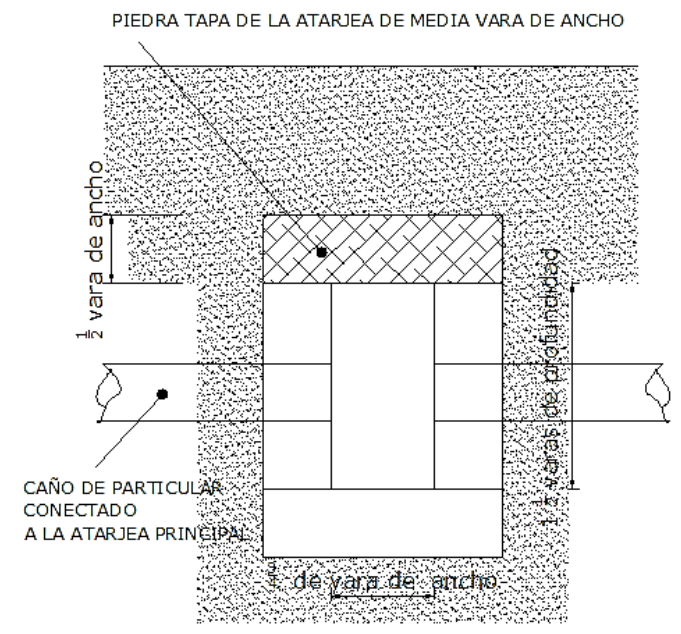

ATARJEA TIPO

\section{1.- La Acequia Maestra}

Como se ha mencionado anteriormente, el descenso en el nivel de los lagos hizo que se replantearan los sistemas de captación y abastecimiento del agua de la cuenca por medio de albarradones, presas y compuertas, que hicieron posible la continuidad del ecosistema que había imperado por siglos en la cuenca, ecosistema que no podía dejarse atrás debido a la dependencia productiva y económica que se había generado tanto en los poblados ribereños como dentro de la propia ciudad (producción que se basaba en la agricultura de las zonas chinamperas, en la caza, pesca y recolección de los lagos, así como en la propia comunicación que existía entre los poblados de la cuenca con la ciudad, por medio 
del transporte acuático en canoas, que habían demostrado ser más eficientes y rápidas que el transporte terrestre).

La comprobada eficiencia que habían tenido las acequias en los rubros descritos anteriormente, además de la protección que proporcionaron en tiempos prehispánicos ${ }^{48}$, hicieron que se considerara su reimplantación o reconstrucción ${ }^{49}$. Ya en planos de mediados de la segunda mitad del siglo XVIII se puede observar el cierre perimetral de la ciudad mediante acequias, constituyendo una sola acequia que la resguardaba y limitaba el acceso de la ciudad por medio de las garitas emplazadas alrededor de la misma, y que servían para el cobro de impuestos.

Ignacio de Castera, con proyectos utópicos como el del Plano Ychnográphico de 1794, que contemplaba la ciudad delimitada por una zanja cuadrada con cuatro plazas en las esquinas, y el proyecto denominado "Alineamiento de calles y circulación de las aguas" de 1793, que estaba inspirado en los ideales de orden y geometría de la Arquitectura de la llustración, planteó la construcción de un gran canal perimetral en forma cuadrada que protegiera a la urbe, además de servir como control de paso mediante 13 garitas colocadas estratégicamente para el cobro de las alcabalas. A este proyecto se sumaron otros para el amurallamiento de la ciudad, sin que prosperaran en su forma.

48 Las acequias en el México prehispánico sirvieron a los mexicas como medio de protección, dado el amplio tamaño del ancho de ellas, haciendo difícil el acceso a la ciudad, razón por la cual Cortés ordena derribar las casas y con los escombros de éstas cegar las acequias, y así de ésta forma poder acceder a la ciudad por tierra firme, sin embargo los mexicas en las noches retiraban los escombros para que las aguas volvieran a circular, encontrándose en este ciclo diario de poner y quitar escombros por parte de ambos enemigos que provocaron que el sitio de MéxicoTenochtitlán se prolongara aún más. Ana Rita Valero de García Lascuráin, La ciudad de MéxicoTenochtitlán su primera traza 1524-1534, Editorial Jus, México, 1992 p. 58.

${ }^{49}$ ROJAS RABIELA, Teresa, SANDERS, William T., Historia de la Agricultura, Época prehispánica siglo XVI, Tomo II, Instituto Nacional de Antropología e Historia, México, 1989. 


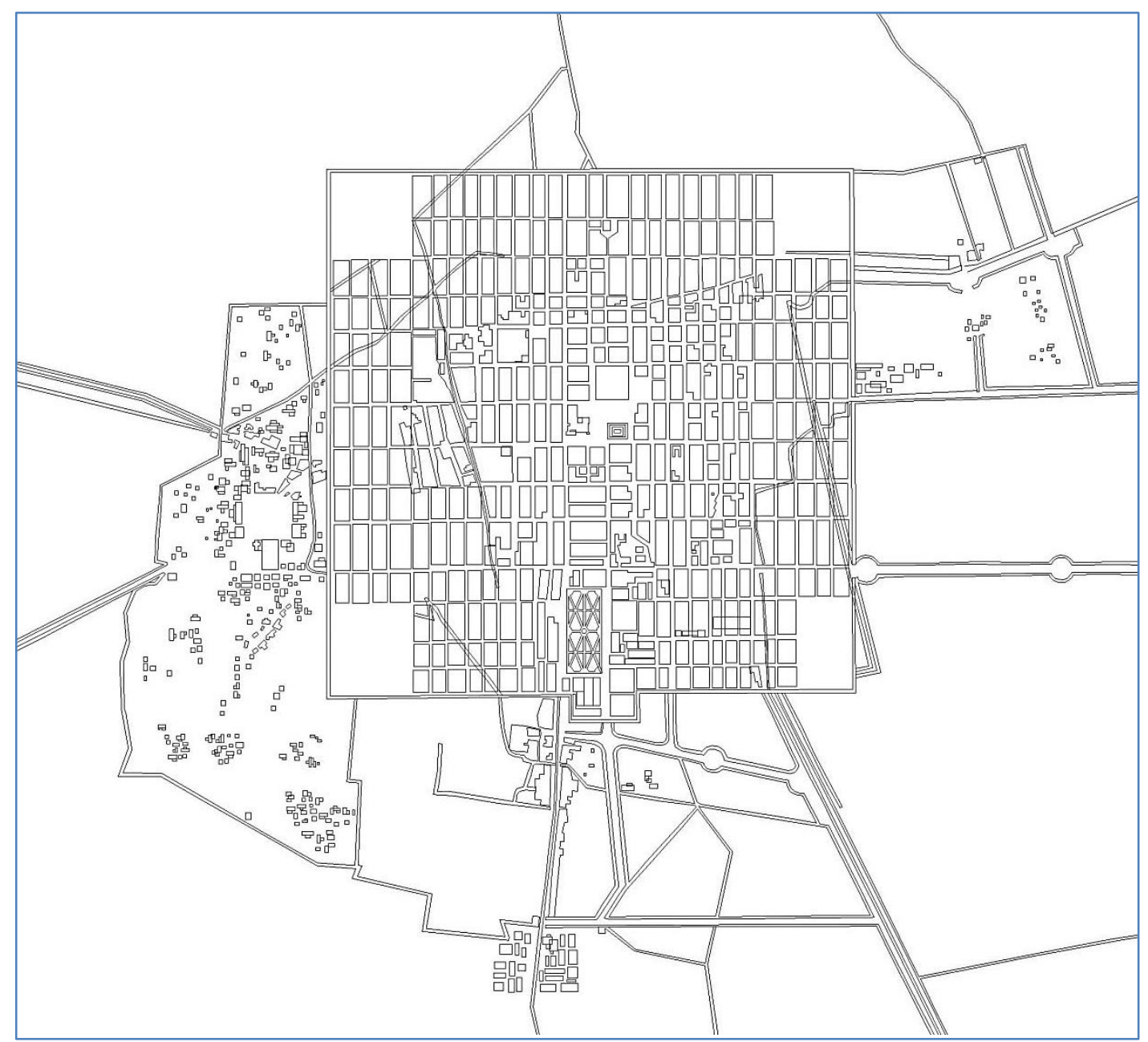

Plano Ychnográphico de Ignacio de Castera, de 1794. Fuente: Biblioteca Digital Mundial: www.wdl.org/es/ ; Dibujo AJV 2020

El concepto de resguardo de la Ciudad de Castera prosperó en sus ideas, pues la construcción de la Acequia Maestra siguió los contornos de los límites que habían demarcado los propios poblados que se asentaban en las orillas de la ciudad, formando un polígono de forma bastante irregular, resguardado por 10 garitas dispuestas en las entradas de los caminos de la ciudad, ya fueran de tierra o de agua, además de otras 8 en las cercanías de la misma ${ }^{50}$. Esta acequia cumplía la función de evacuar las aguas provenientes de las extintas acequias que ahora se conducían por medio de atarjeas hacia las compuertas, y de ahí hacia a

\footnotetext{
${ }^{50}$ DE LA TORRE VILLALPANDO, Guadalupe, Los muros de agua. El resguardo de la Ciudad de México, siglo XVIII, coedición INAH, GDF, México. 1999, p, 44 y45.
} 
la zanja perimetral que desembocaba en los lagos. No obstante, como puede observarse en el plano de 1793 del Teniente Coronel de Dragones Diego García Conde, se aprovechó la zanja para construir varias acequias secundarias que irrigaban diversas zonas de cultivo en los alrededores de la ciudad, además de incluirse dentro de la planeación urbana la conexión de canales de navegación hacia la zona sur y oriente, viéndose aparecer la conjunción de proyectos de circulación y embarcaderos de media luna para canoas, así como zonas arboladas de los Paseos de Azanza y el Paseo de Revillagigedo o de la Viga, además de las avenidas de la Piedad en el sur y de la Villa de Guadalupe en el norte, ambas resguardas por acequias en sus dos lados. En el proyecto de Castera se describe la acequia maestra en figura cuadrada con un perímetro total de 13,200 varas, que captaría el agua de las calles de la ciudad y serviría a la vez para la circulación del agua como abastecimiento y medio de navegación para comestibles y materiales. Dicha acequia se construiría con un muro bien cimentado, formado de tierra apisonada y revestido de adobes, que mediría 2 2/3 varas de alto y 3 1/7 varas en la cresta. A este muro le continuaba una calzada con árboles en sus bordos, formando un camino de ronda o de resguardo que se utilizaría para la vigilancia; a los lados de la calzada dos zanjas, una de doce varas de ancho y otra de ocho, con una profundidad de 3 1/2, desembocando en ella tanto las aguas de servidumbre como las de temporal en un perímetro aproximado de cinco leguas, contando a la vez con compuertas mayores y menores para el control de los niveles del agua ${ }^{51}$.

Es hasta el siglo XIX que se construye el proyecto de la acequia maestra, respetando las indicaciones de Castera, sin concluirse y llegando solamente a edificarse un cincuenta por ciento de lo contemplado, sin conseguir el trazo recto de la zanja cuadrada, pues los antiguos canales se cruzaban, haciendo imposible seguir una geometría perfecta, abandonándose la conclusión del proyecto a

\footnotetext{
51 HERNÁNDEZ FRANYUTI, Regina Ignacio de Castera, Arquitecto y urbanista de la Ciudad de México, 1777-1811, Instituto Mora, México, 1997, p. 59 y 60.
} 
finales del siglo XIX, pues ya era inviable económicamente, y por el crecimiento que la ciudad estaba experimentando ${ }^{52}$.
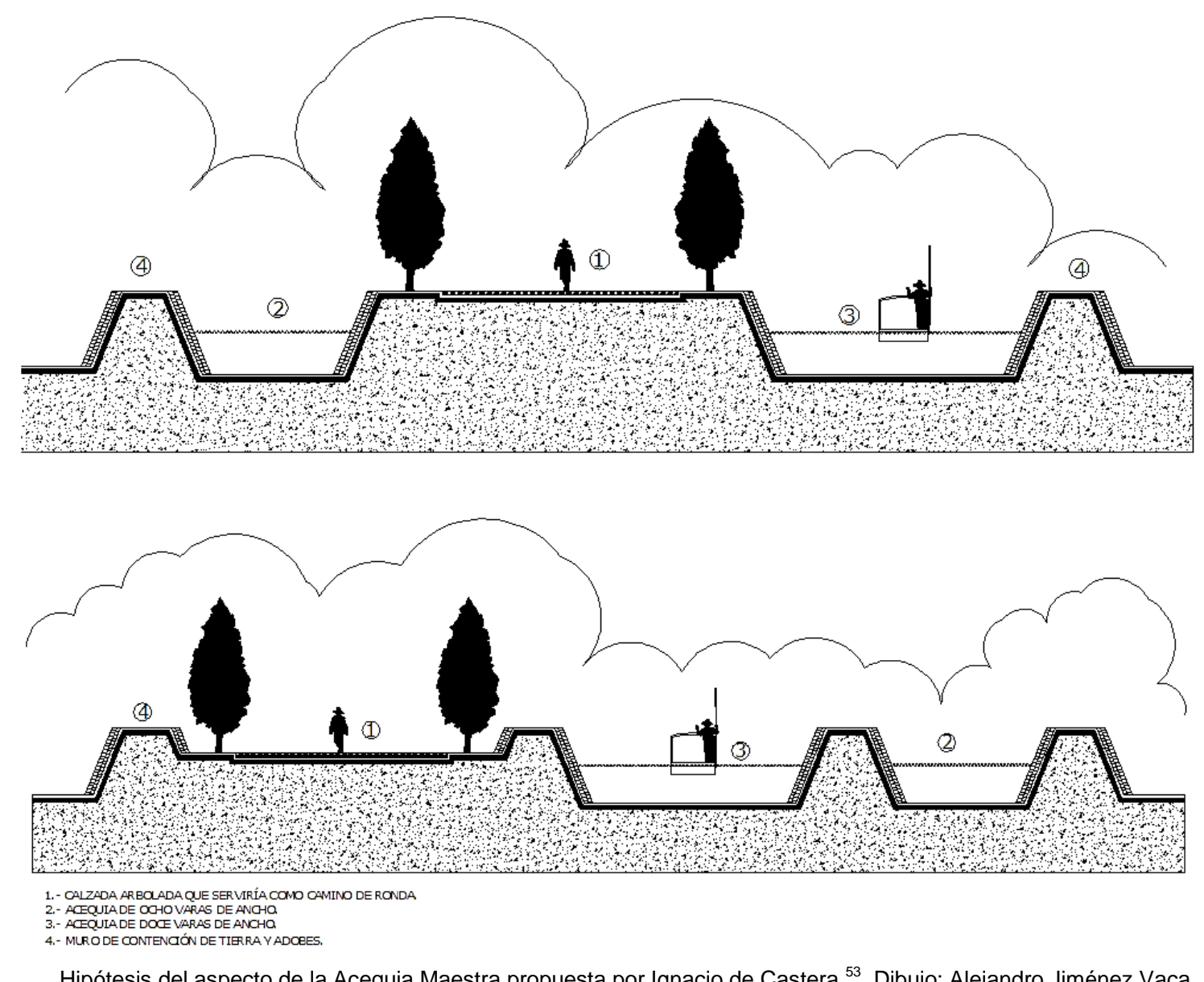

Hipótesis del aspecto de la Acequia Maestra propuesta por Ignacio de Castera. ${ }^{53}$ Dibujo: Alejandro Jiménez Vaca.

52 Datos expuestos por la Dra. Guadalupe de la Torre Villalpando en la Conferencia "Obras para la Defensa de la Ciudad de México durante la independencia", impartida el 17 de Agosto de 2010 en el Auditorio de la Escuela Nacional de Conservación Restauración y Museografía "Manuel del Castillo Negrete".

${ }^{53}$ HERNÁNDEZ FRANYUTI, Regina Ignacio de Castera, Arquitecto y urbanista de la Ciudad de México, 1777-1811, Instituto Mora, México, 1997, p. 59 y 60. 


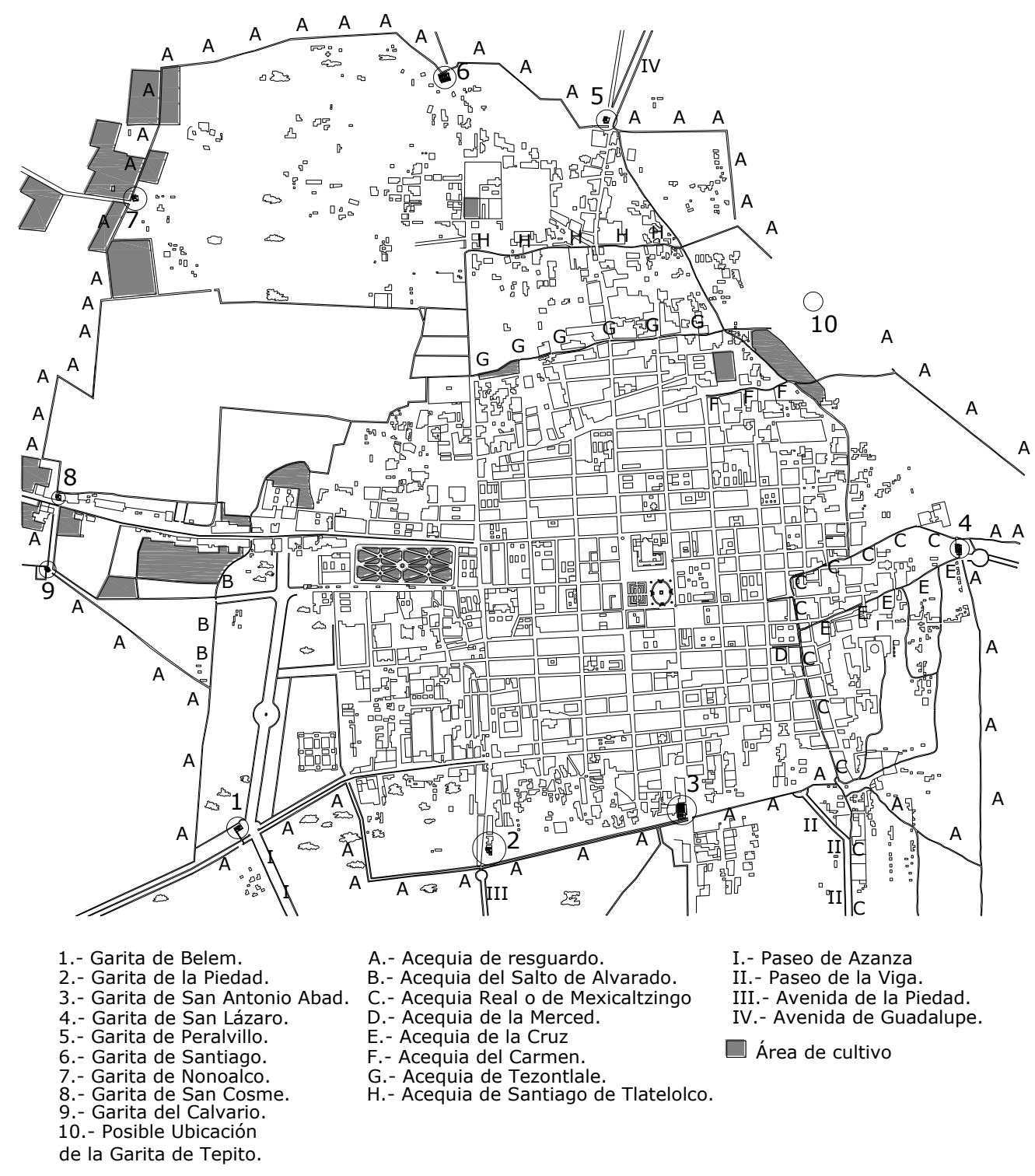




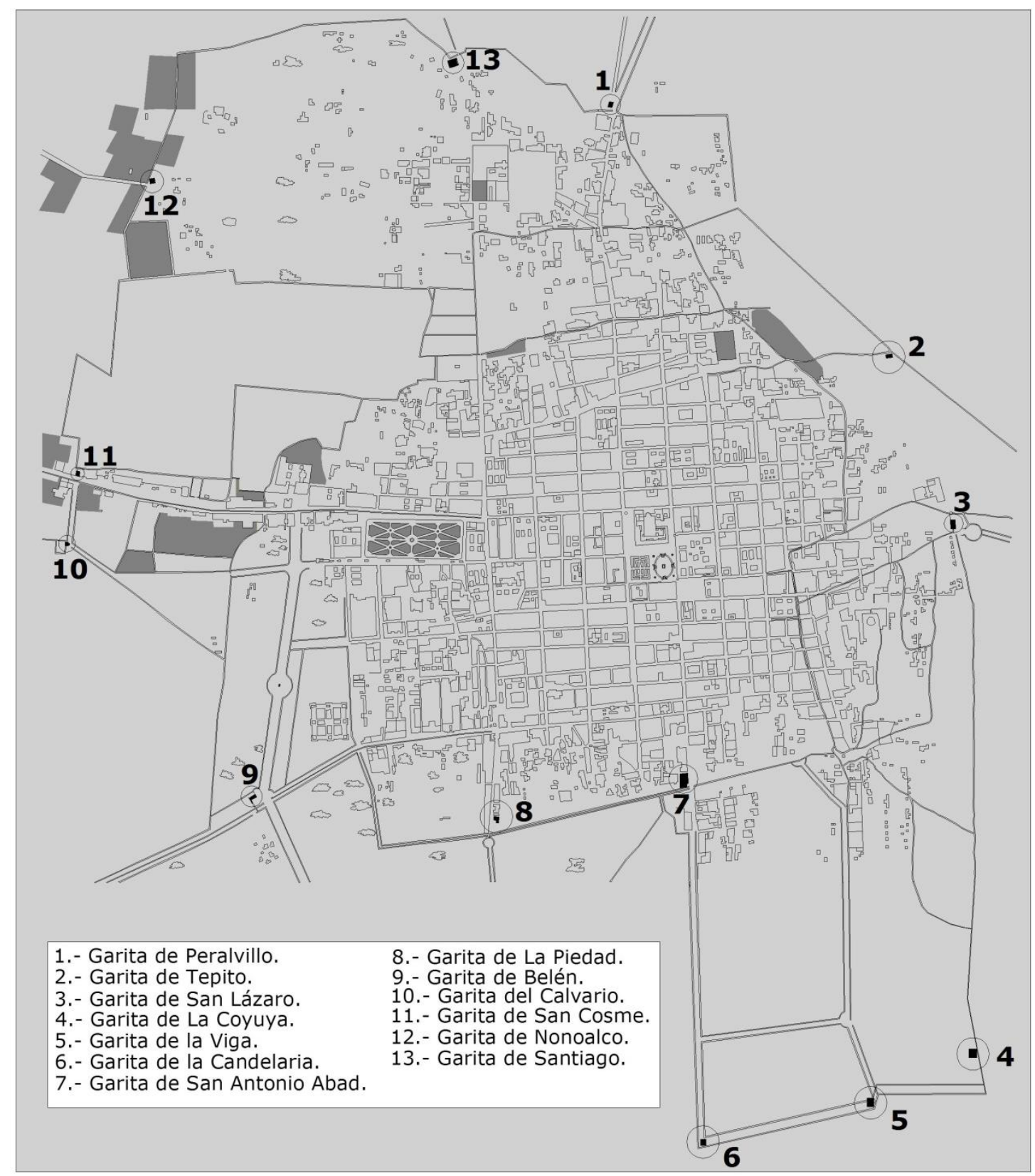

Sobre un impreso de un plano del año de 1791, José del Mazo y Avilés ubica las trece garitas existentes en el año de 1816, las cuales se encontraban en el trayecto de la acequia de resguardo que rodeaba la Ciudad de México, siendo evidente en este plano la utilidad de las acequias como medio de control y protección, contemplándose en el diseño de las garitas la integración con las vialidades terrestres y acuáticas. Ubicación de las garitas sobre el plano de Diego García Conde, de 1793, datos de la ubicación de las garitas en base del plano de José del Mazo y Avilés de 1791 de www.agn.gob.mx. AGN, Mapa 0021, 1791, copia 23 de Marzo de 1816. Dibujo de Alejandro Jiménez Vaca, 2012. 


\section{SEGUNDA PARTE \\ Las Casas Con Acequia}




\section{SEGUNDA PARTE. Las Casas con Acequia}

Como ya se mencionó con anterioridad, las acequias impactaron de diversas maneras en el trazo de la ciudad y en diferentes elementos que componen a la misma, además de esto, repercutieron en la adaptación de diferentes edificios, sobre todo en los de uso habitacional, género que fue el dominante en la mayoría de las edificaciones de la Ciudad de México. A continuación, se expondrán las adaptaciones y/o modificaciones que sufrieron las casas que se encontraban en el trayecto de las acequias, así como los usos que adoptaron los espacios en los que existieron tales elementos.

\section{1.- Definición de Arquitectura Habitacional y tipologías en el siglo XVIII}

Definición de Arquitectura Habitacional: Se conoce como Arquitectura Habitacional a las edificaciones que están dedicadas para que el hombre viva y coexista con su familia nuclear, extensa y/o censal ${ }^{54}$, incluyendo dentro de este término todos los tipos de vivienda, tanto los bienes inmuebles que son propiedad de una persona o familia, como los dedicados a la renta, así como los pertenecientes a todos los diferentes niveles socioeconómicos.

\section{Tipologías de Arquitectura Habitacional en el siglo XVIII}

Existen diferentes clasificaciones de Arquitectura Habitacional en el siglo XVIII; entre los estudios más completos se puede citar el elaborado por Elena Horz Balbás ${ }^{55}$, en el que se enlistan varias tipologías mencionadas por distintos autores, además de realizar una clasificación propia, en la que se contemplan varios tipos y subtipos dependiendo el aspecto funcional y el uso destinado.

\footnotetext{
${ }^{54}$ Familia nuclear: familia consanguínea con una misma vivienda y entrada común; familia extensa: Un solar con entradas separadas para cada familia; familia censal: personas unidas o no por vínculos de parentesco en una vivienda, más sirvientes, empleados y huéspedes. Diccionario de Arquitectura y Urbanismo, CAMACHO CARDONA, Mario, Editorial Trillas, México, 1998. p 339, 340 y383.

${ }^{55}$ HORZ BALBÁS, Elena, La vivienda media de la Ciudad de México, época colonial, Tesis Maestría, Historia del Arte 1980, UNAM, ps. 238, 239.
} 


\section{Clasificaciones de varios autores mencionados por Elena Horz Balbás:}

\section{En el Libro "La Patria y la Arquitectura Nacional" de Federico Mariscal:}

-Casa de Vecindad.

-Viviendas: Taza y plato.

-Casas de un piso.

-Casa de dos pisos o Casa sola.

-Casa Señorial o Palacio.

En el libro "Historia del arte en México" de José Juan Tablada:

-Casona Señorial o Casa Señorial.

-Casa sola.

-Casa de un piso.

-Casas de vecindad y viviendas.

\section{En el libro "Arte Colonial en México".}

-Residencia señorial.

-Casa sola.

-Casa de vecindad.

\section{Clasificación de Elena Horz Balbás:}

Tipo I. Casa Principal.

Tipoll: Casa intermedia.

Subtipo A

Subtipo B

Tipo III: Casa de Servicios compartidos.

Subtipo A: Viviendas dispuestas a lo largo de un patio rectangular.

Subtipo B: Viviendas distribuidas alrededor de varios patios rectangulares.

Tipo IV: Conjunto de accesorias habitacionales.

Tipo V: Casa Pedestre. 
Otra de las clasificaciones más completas es la referida en el "Manual Técnico de Procedimientos para la Rehabilitación de Monumentos Históricos en el Distrito Federal" del INAH ${ }^{56}$, en el cual se mencionan cinco tipologías de Arquitectura Habitacional, las cuales se describen a continuación:

\section{2.- Definición de Casa con Acequia y tipologías}

Casa con Acequia: Es aquella edificación de la Arquitectura Habitacional que tiene relación directa con una acequia, siendo afectada en su partido arquitectónico dependiendo el nivel de relación o comunicación que se encuentre entre ambos elementos.

\section{Tipologías de Casa con Acequia}

La variedad de tipologías de casas con acequia varía dependiendo de la localización del canal respecto al inmueble, encontrándose, independientemente de las diferentes tipologías de la clasificación de Arquitectura Habitacional, una clasificación tipológica respecto a la afectación del inmueble con la cercanía o interacción de la acequia con la edificación. Dentro de ella, aparecen distintos tipos, que a continuación se enumeran:

\section{a.- Casa con acequia exenta}

Este tipo de casas son afectadas en el funcionamiento de la casa solamente cuando existe un puente en la cercanía; está regida la circulación del edificio por un eje que tiene relación directa con el puente que se encuentra enfrente, siendo más evidente en la Casa de los Mascarones que en las casas de Manzanares 26 y las casas de la Alhóndiga 7 y 9 , donde la lejanía del puente ${ }^{57}$

56 GONZÁLEZ AVELLANEDA, Albert, et. al., Manual Técnico de Procedimientos para la Rehabilitación de Monumentos Históricos en el Distrito Federal, INAH, México, p 18, 19, 21, 22, 23, 24, 26, 27, 29, 32.

${ }^{57}$ Puente reconstruido de manera errada durante los primeros años de la década de los ochenta del siglo XX. Este puente se puede observar en las fotos de mediados del siglo XIX, publicadas en el libro de Guillermo Tovar de Teresa, acerca del Patrimonio perdido de la Ciudad de México, en donde se puede observar que este puente es de vigas y no de bóveda como existe actualmente. TOVAR DE TERESA, Guillermo, La Ciudad de los Palacios; Crónica de un Patrimonio Perdido, Edit. Vuelta, México, 1992. 
hace que la circulación se vea menos afectada que en el primer caso. En cuanto al aspecto legal, los propietarios adquirían la obligación de limpiar la acequia y de reparar el puente que estuviera frente a su inmueble, asumiendo los costos que surgieran por esta acción.

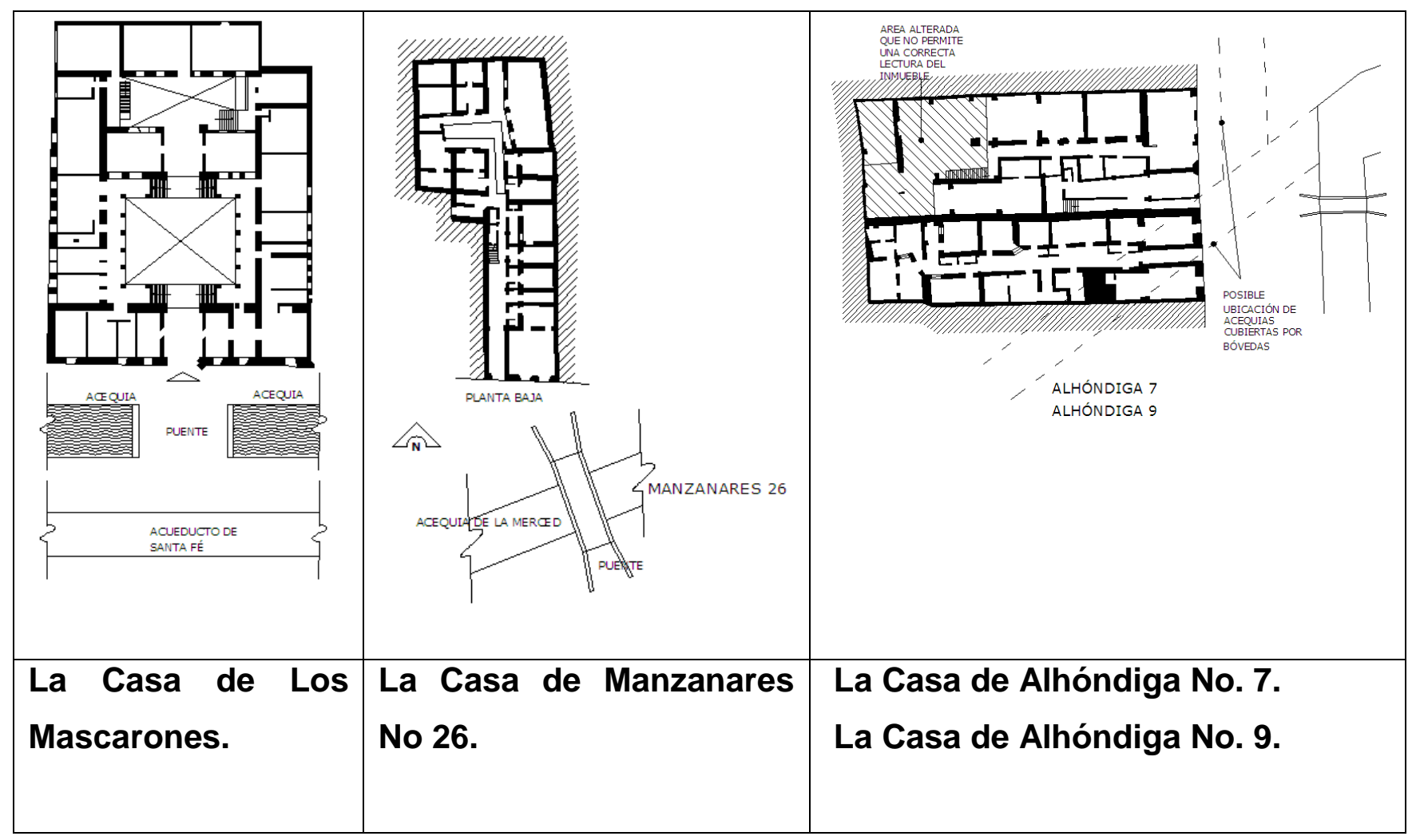

\section{b.- Casa con acequia que cruza el frente del inmueble.}

Este tipo de casa se ve afectada en la fachada del inmueble, teniendo que adoptar la solución de remetimientos o ancones, que dejaban que la acequia circulara sin obstrucciones; a la vez era necesario construir un puente enfrente para poder cruzar; también es probable que hubiera patios que mantuvieran una relación directa con la acequia, y que funcionaran como embarcaderos. En el caso de la casa de Mesones 119, la acequia fue cubierta posteriormente por una bóveda que dejaba que pasara el agua por debajo del inmueble ${ }^{58}$, posible solución que fue adoptada por la casa de Manzanares 25.

${ }^{58}$ Exp. 36 Fecha 1773 Vol. 3716, Aytto. De la Cd. De Mex. Puentes.

Autos de prova del dulcísimo nombre de Jhs. De religiosos del señor San Agustín sobre la liberación que pretende de fabricar el puente que llaman de san Dimas. 


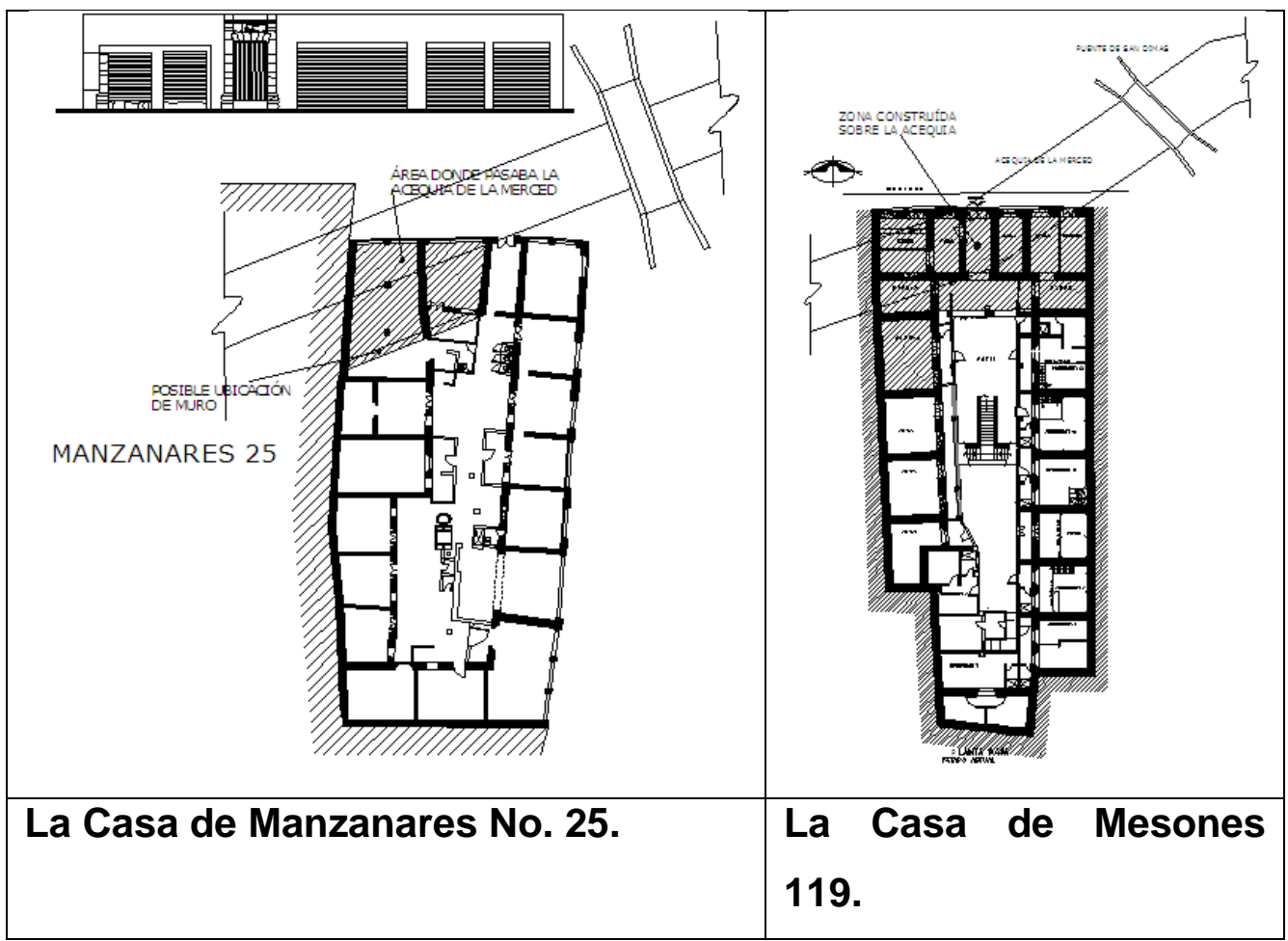

\section{c.- Casa con acequia que cruza la parte posterior del inmueble}

Este tipo de casa era afectada mínimamente en el funcionamiento de la misma, teniendo en la parte posterior una comunicación con la acequia mediante una puerta falsa o puerta posterior y/o de servicio, que servía como embarcadero; a la vez, este tipo de casas adoptaba el ángulo del trazo del canal que pasaba en sus cercanías, afectando el trazo de los muros de las habitaciones contiguas.

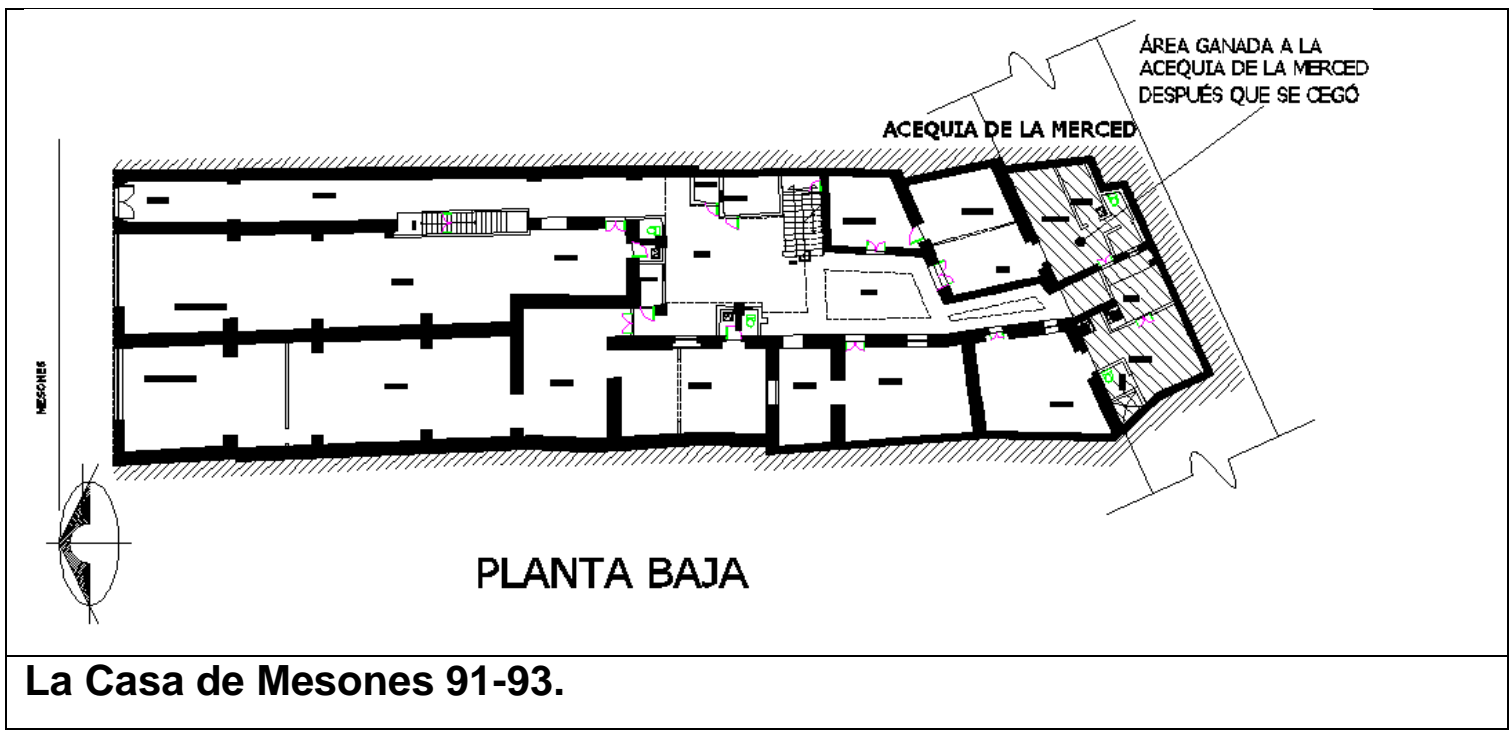




\section{d.- Casa con acequia en la parte interior del inmueble}

Este tipo de edificación se veía fragmentado tanto en sus elementos arquitectónicos como en su funcionamiento, siendo muy probable que hayan existido puentes interiores para comunicar las distintas áreas. Contaba con todos los elementos que se requerían, como zaguán, cochera, accesorias, habitaciones, etc., pero que se veían fragmentados en su circulación por el cruce de alguna acequia. Cuando las acequias se cegaban eran ocupadas por habitaciones.

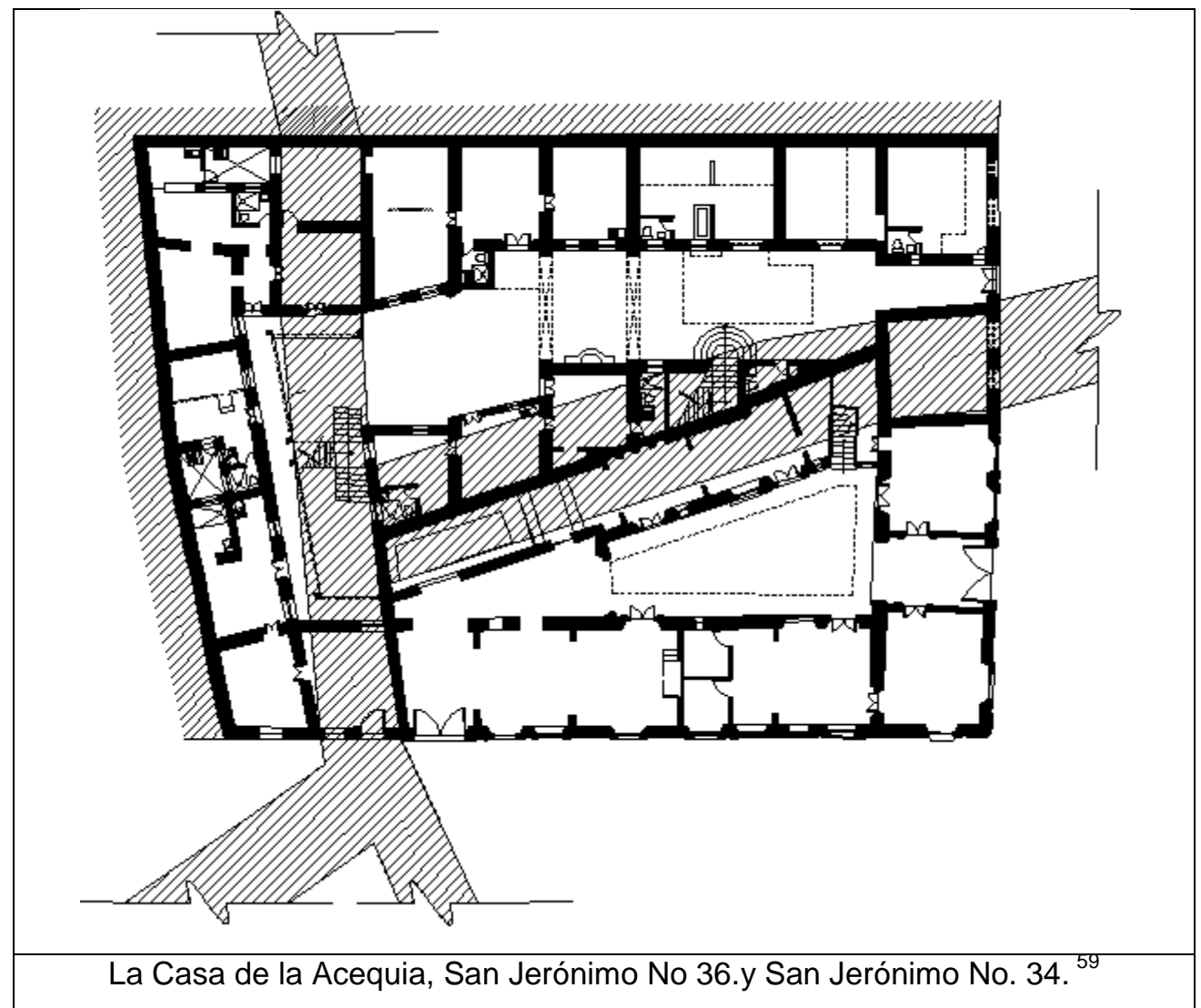

\section{3.- Núcleos de Casas con Acequia}

Para el análisis de las casas que pasan por la acequia, se seleccionaron núcleos de casas del siglo XVIII que estuvieran dentro de una misma manzana o en la manzana contigua. Para tener una lectura general de las casas y las

\footnotetext{
${ }^{59}$ Redibujo del Plano de la Casa de San Jerónimo No. 36, de los archivos personales del Doctor Luis Ortiz Macedo.
} 
modificaciones que tuvieron que adoptar para adaptarse a las acequias, se añadieron casas del siglo XVII y XIX; posteriormente se realizó una hipótesis del estado de los núcleos de vivienda con respecto al aspecto de la planta arquitectónica y sus usos en el siglo XVIII, determinando los elementos característicos de este tipo de inmuebles. De forma posterior, se efectuó la hipótesis de las casas en el siglo XIX, para visualizar los añadidos en las áreas dejadas por las acequias y por los ancones formados por las mismas.

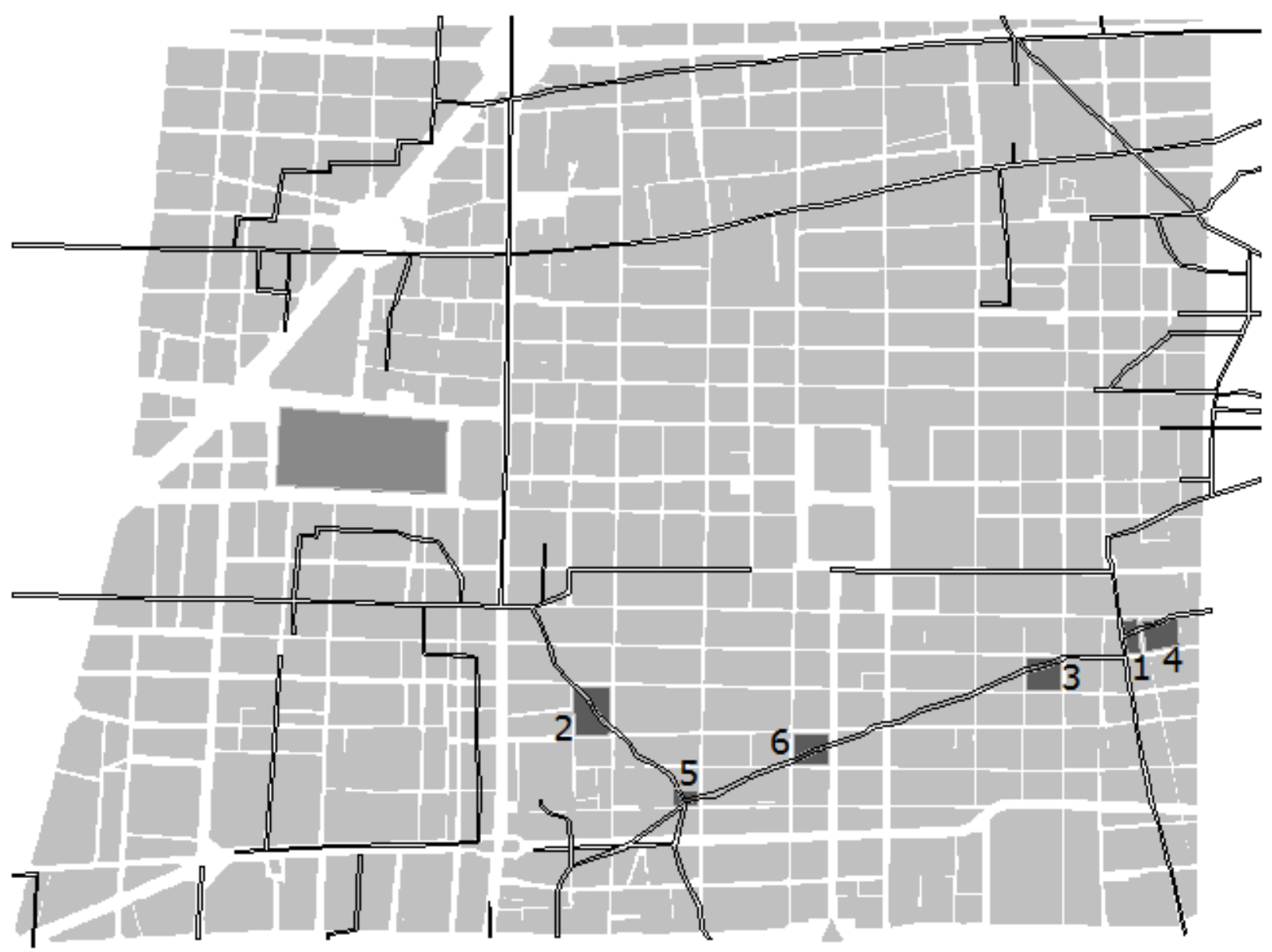
1. - NÚGEO 1.
2. - NUCEO 2.
3.- NÚGEO 3.
4.- NUCEO 4.
5.- NÚGEO 5.
6.- NuQLeO 6. 


\section{1.- Núcleo 1}

Conformado por las casas ubicadas en:

1.- Manzanares 1.

2.- Manzanares 3.

3.- Manzanares 5.

4.- Manzanares 7.

5.- Roldán 22-24.

6.- República de Uruguay 182.

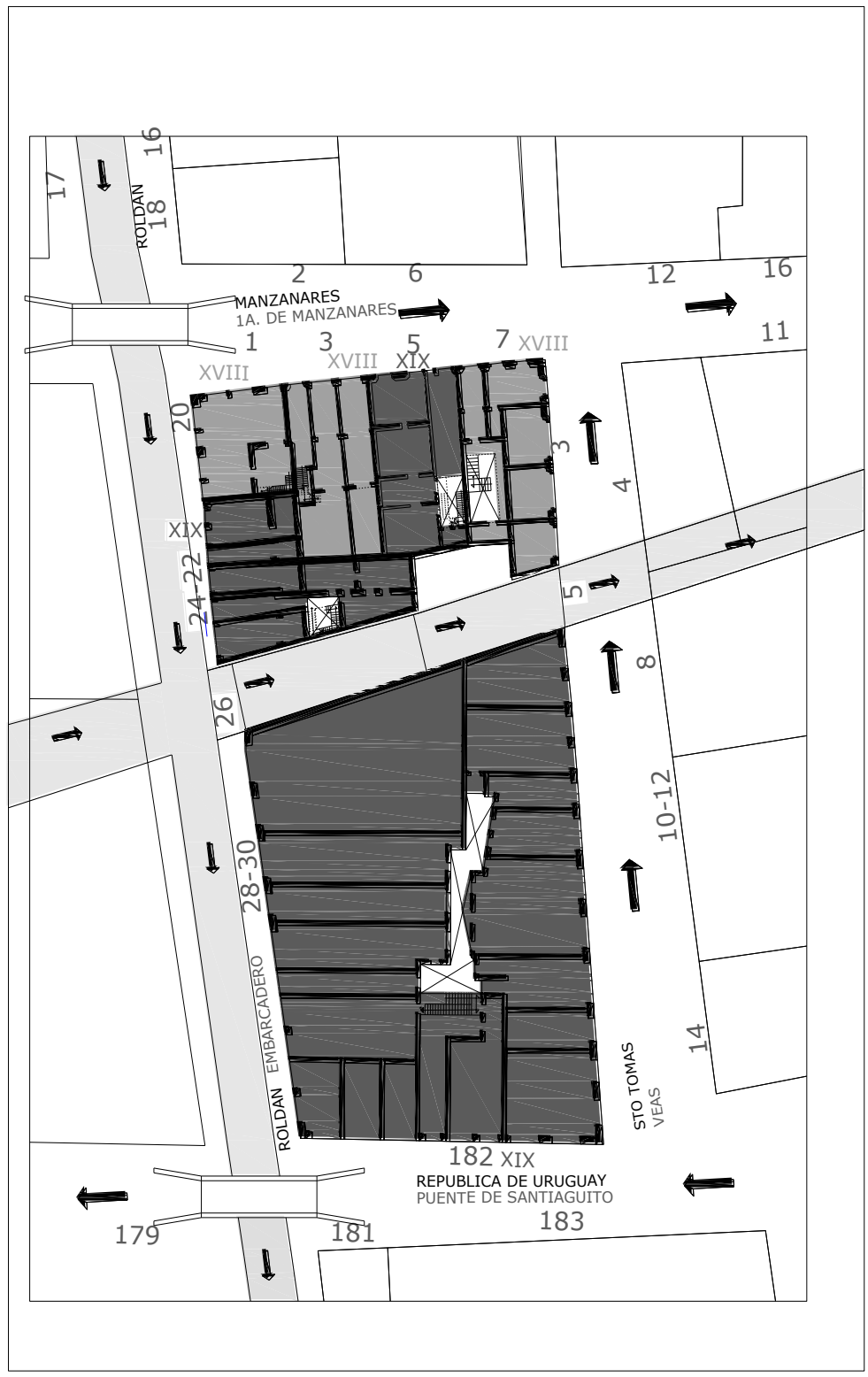

XVIII

XIX 


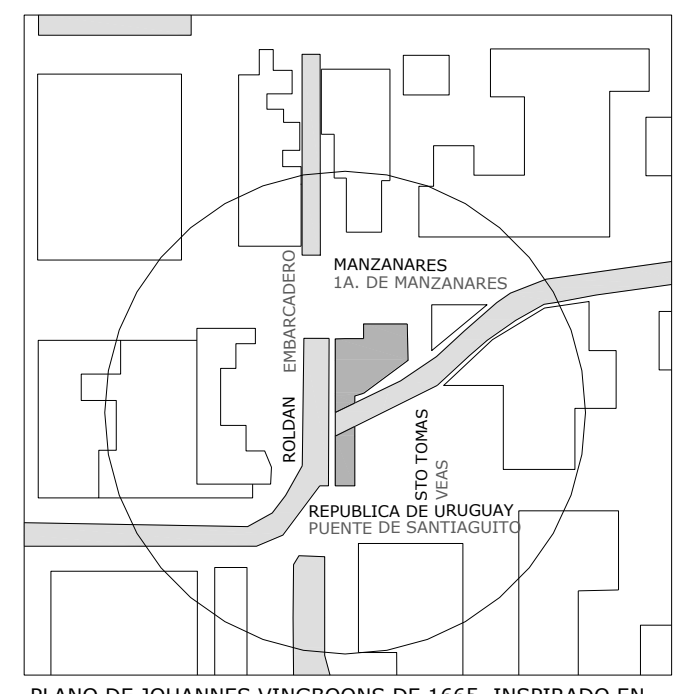

PLANO DE JOHANNES VINGBOONS DE 1665, INSPIRADO EN LA PERSPECTIVA DE 1628 DE JUAN GÓMEZ DE TRASMONTE.

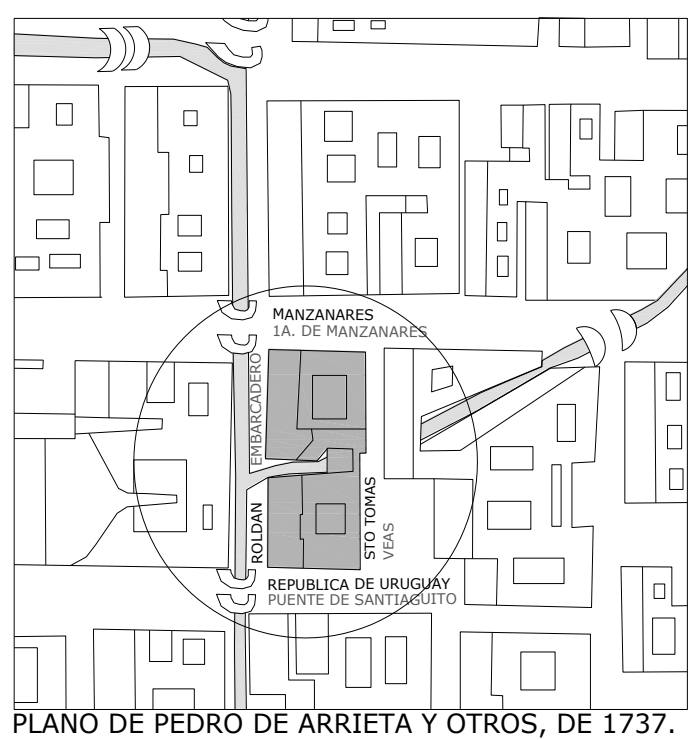

Manzana localizada en el cruce de la acequia de la Merced con la de Mexicaltzingo, dividida diagonalmente por la primera. Se puede observar que el tramo de la acequia cegada fue ocupado por dos nuevos lotes que siguen la forma del canal, en uno de ellos se ve un pequeño ancón que da hacia la acequia, y que probablemente haya sido un embarcadero con su correspondiente puerta falsa. Las casas 1 y 3 de Manzanares se ven modificadas en su partido arquitectónico, y es probable que junto con el número 7 de Manzanares hayan formado parte de un mismo inmueble con un gran patio en medio, como puede observarse en el plano de Pedro de Arrieta de 1737. En lo que respecta a los inmuebles del siglo XIX, todos estos presentan crujías que se ven alteradas en las colindancias con la acequia y los lotes colindantes con casas con acequia. Es probable que la casa de Roldán 28-30 date del siglo XVIII, y no del XIX como se indica en el catálogo de monumentos históricos de la ciudad de México, ya que aún a pesar de lo alterado del edificio pueden observarse en su partido arquitectónico restos del patio central, representados en el plano de Pedro de Arrieta de 1737. 


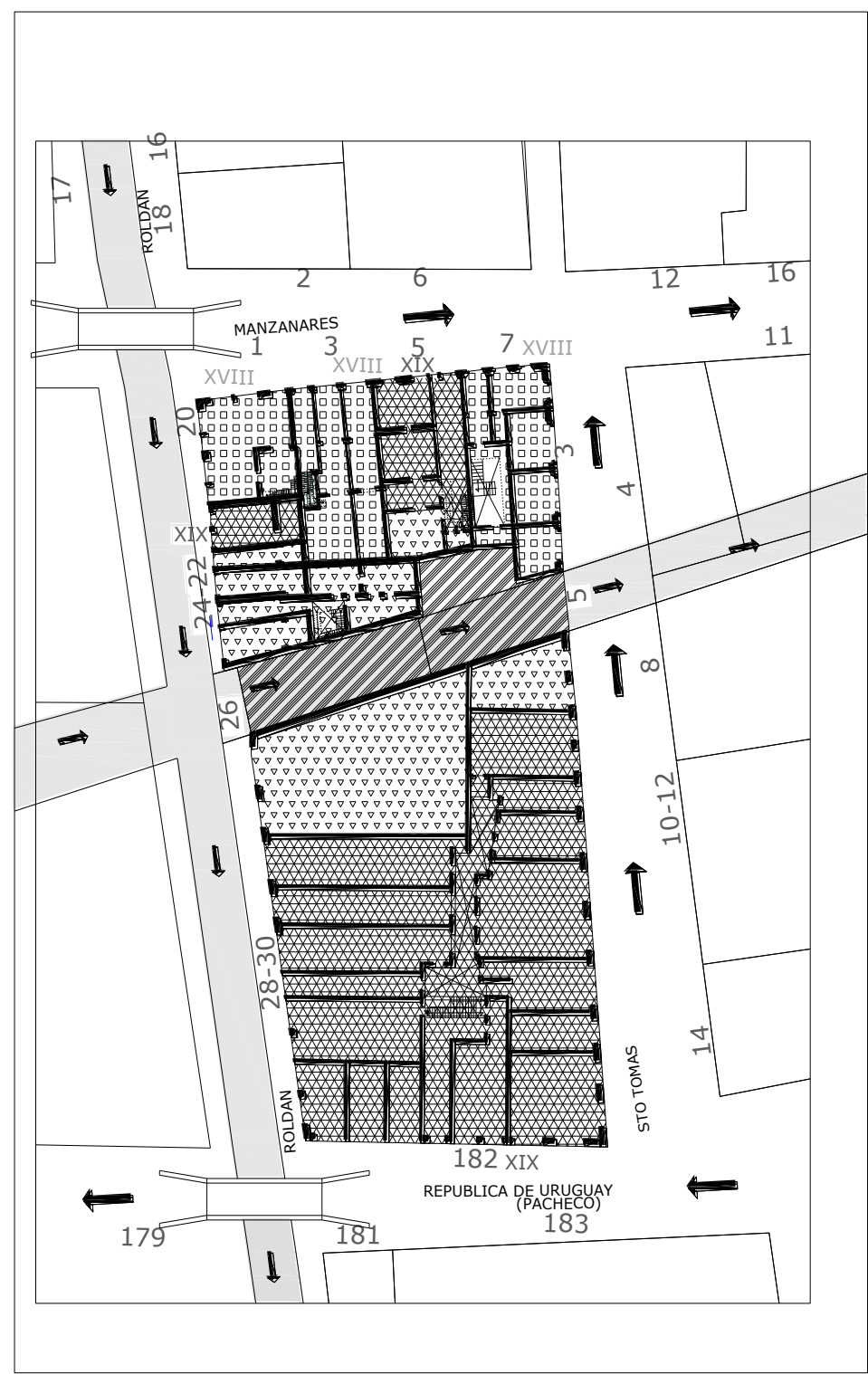

पTI Lotes en acequias cegadas.

Fag. Crujias sin afectación por la traza de los lotes en edificios del siglo XIX

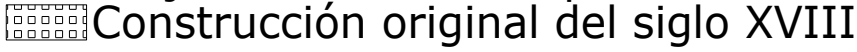




\section{2.- Núcleo 2}

Conformado por las casas ubicadas en:

1.- República del Salvador 29.

2.- República del Salvador 35-37.

3.- Bolívar 71.

4.- Bolívar 73.

5.- Bolívar 77.

6.- Bolívar 79.

7.- Aldaco 8-12.

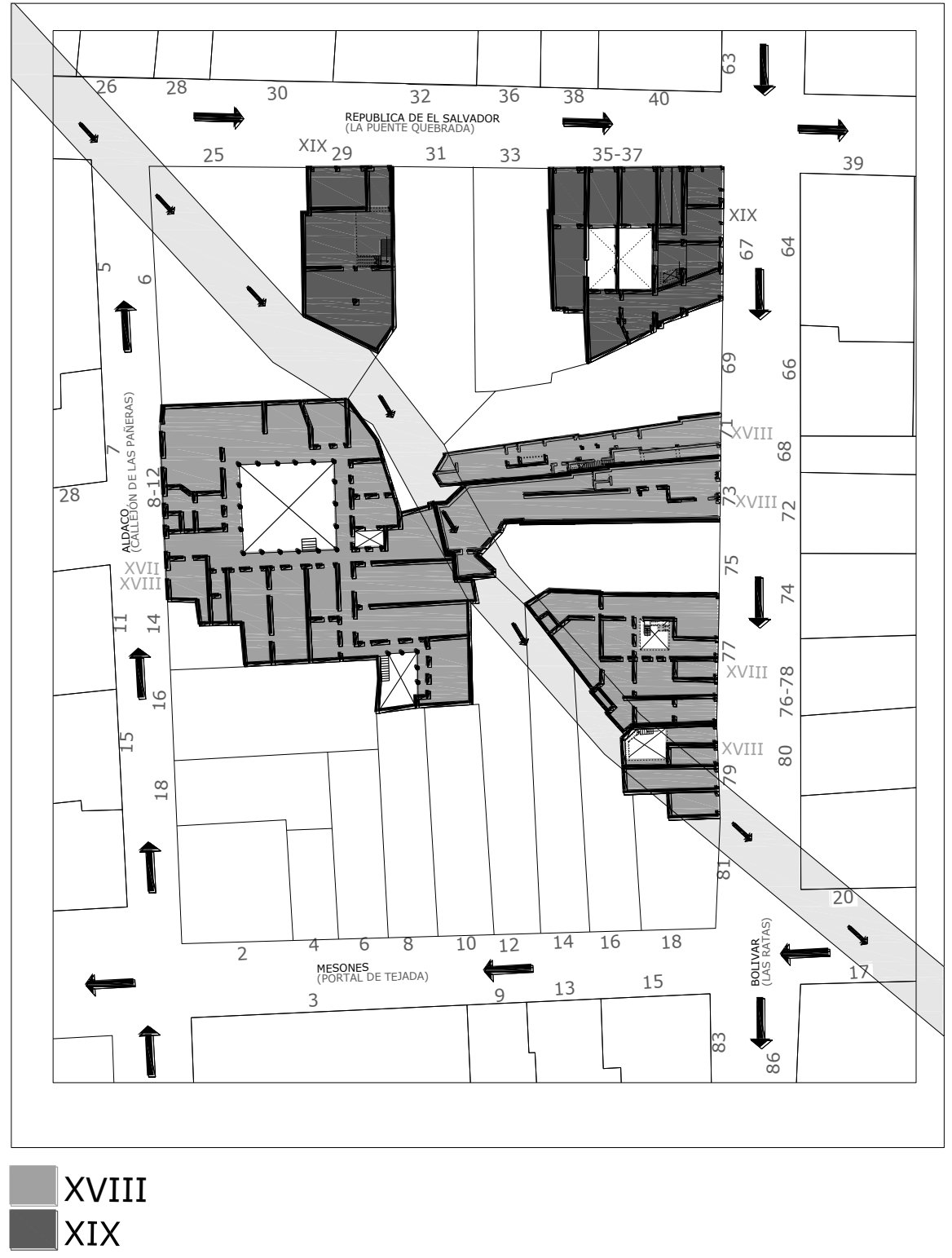




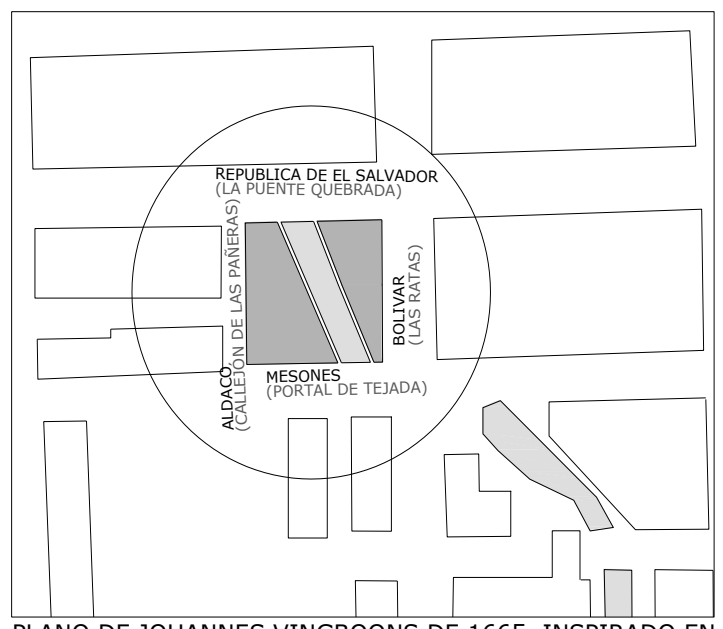

PLANO DE JOHANNES VINGBOONS DE 1665, INSPIRADO EN LA PERSPECTIVA DE 1628 DE JUAN GÓMEZ DE TRASMONTE.

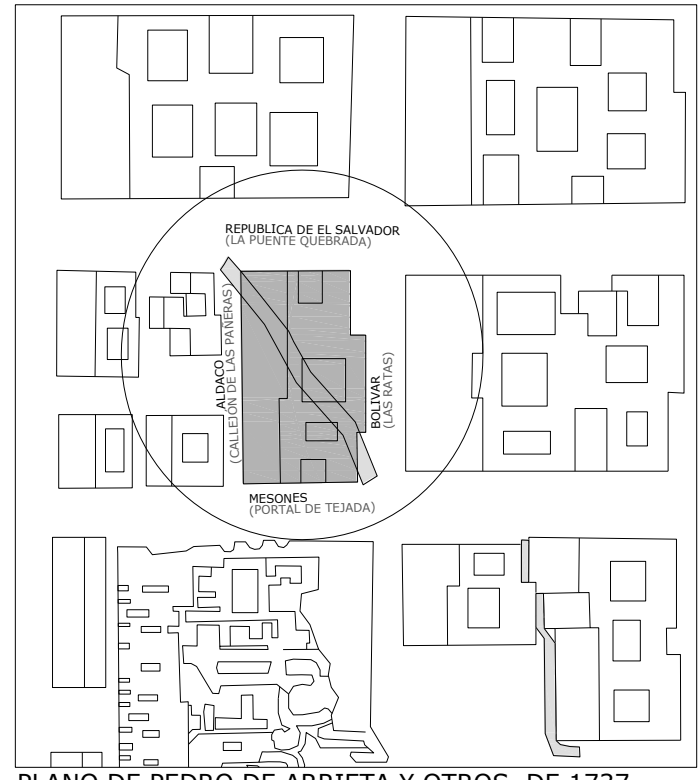

PLANO DE PEDRO DE ARRIETA Y OTROS, DE 1737.

Este núcleo se encuentra en el trayecto de la acequia de Monserrate, y fue el bañadero de caballos en el siglo XVI; ya durante el siglo XVIII había sido ocupado por casas, algunas en las esquinas con ancones en la actual calle de Bolívar, algunas de estas casas guardan en su partido arquitectónico restos de patios que pueden observarse en el plano de Pedro de Arrieta de 1737, patios que se sitúan a corta distancia de la acequia, y que es probable fueran embarcaderos y tuvieran localizadas puertas falsas en comunicación con el canal; las casas de Bolívar 71 y 73 se hallan muy modificadas en su partido arquitectónico, sin embargo, se puede ver parte de la construcción sobre la acequia y es probable que sean agregados. En lo que respecta a los inmuebles del siglo XIX, éstos se hallan afectados en el trazo de sus muros en las colindancias con lotes que limitan con la acequia, y en lo que respecta a los lotes, gran parte de éstos se ven afectados por la forma de ésta, adoptando sus curvaturas. 


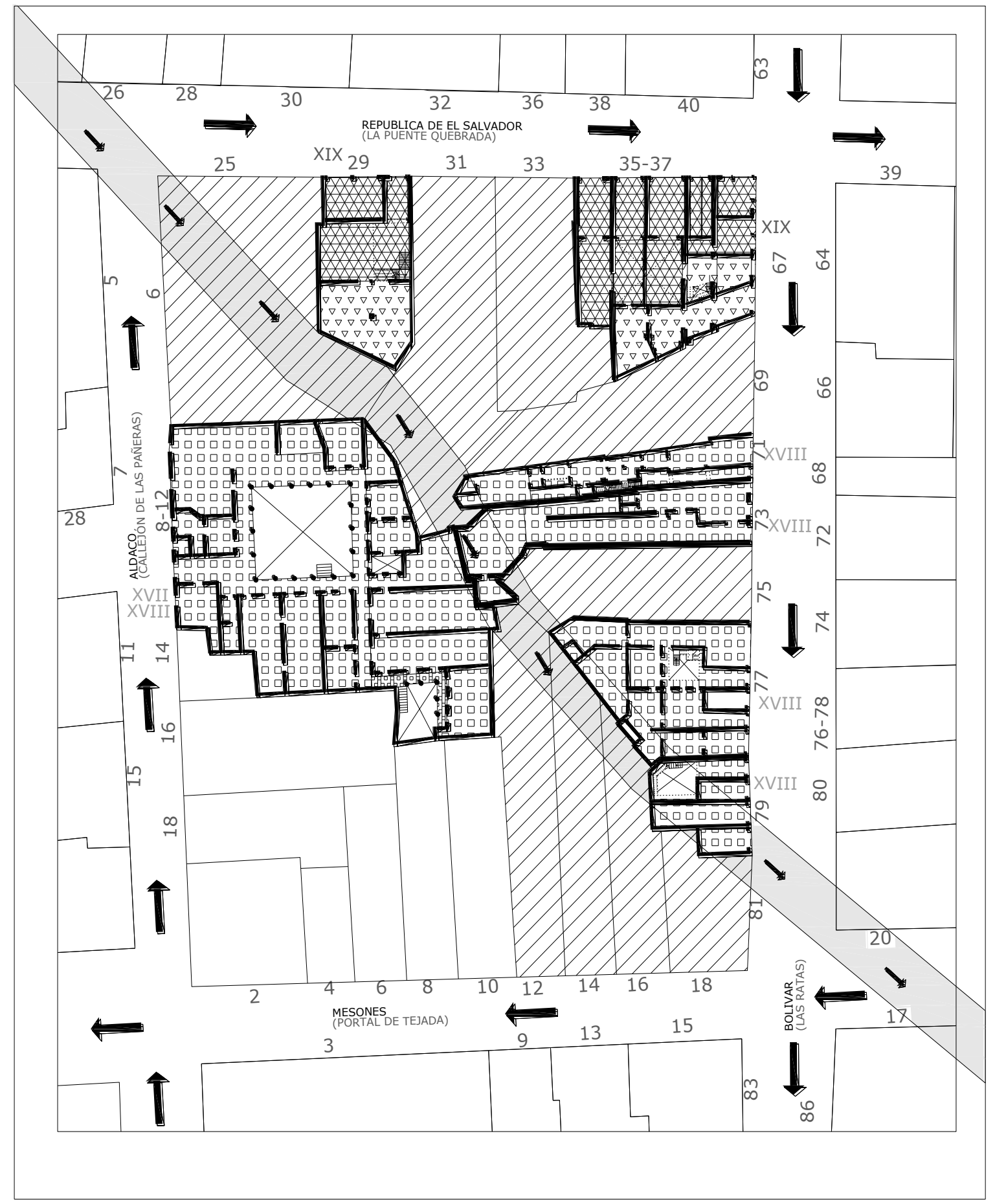

Afectación en la forma de los demas lotes.

F $\forall$ Crujias afectadas por la traza de los lotes en edificios del siglo XIX Crujias sin afectación por la traza de los lotes en edificios del siglo XIX

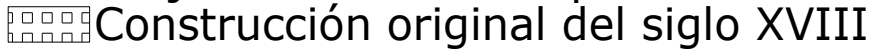




\section{Núcleo 3}

Conformado por las casas ubicadas en:

1.- Las Cruces 21.

2.- República del Salvador 164.

3.- República del Salvador 166.

4.- Jesús María 87-89.

5.- República de Uruguay 157.

6.- República de Uruguay 161.

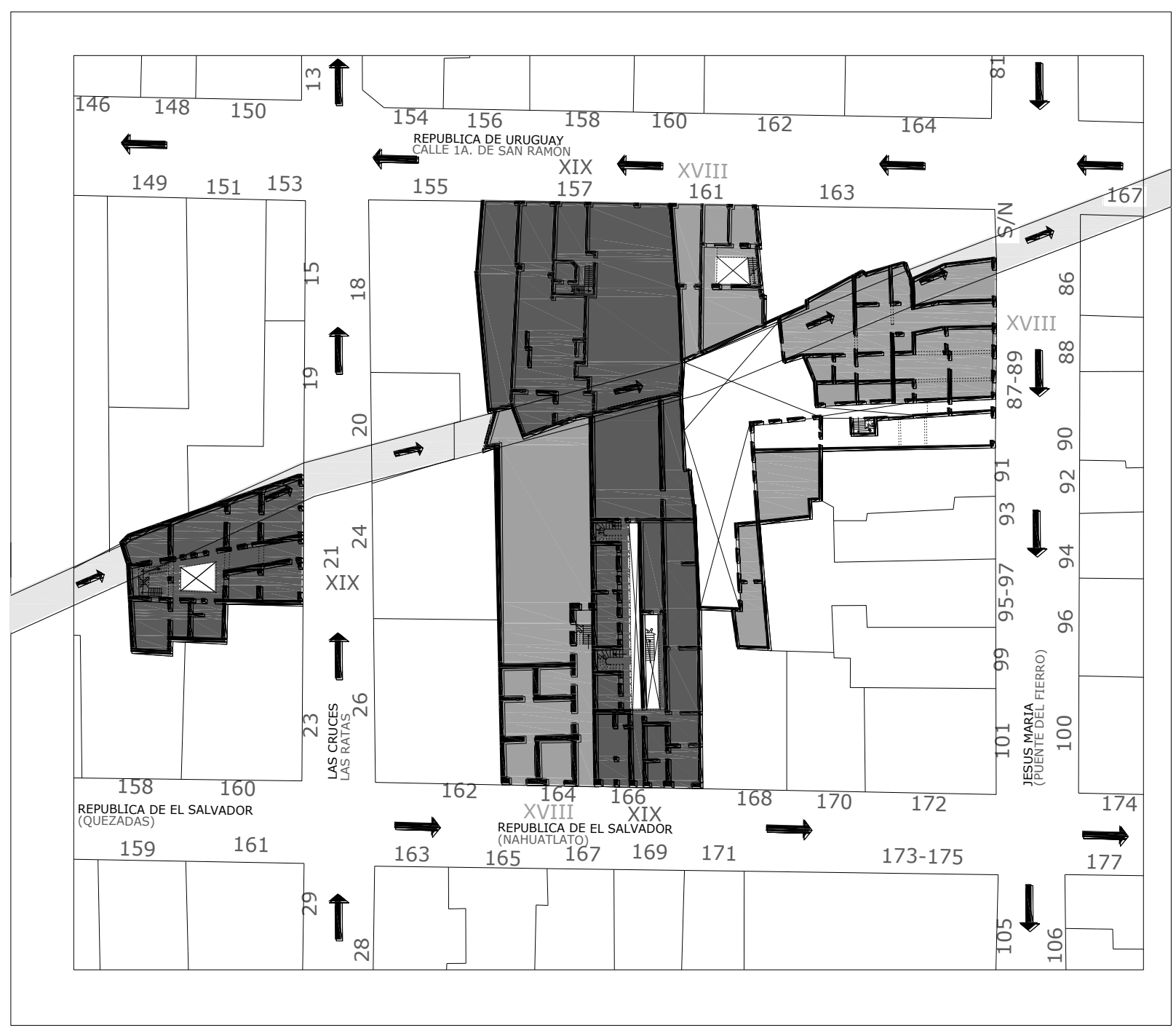

XVIII

XIX 


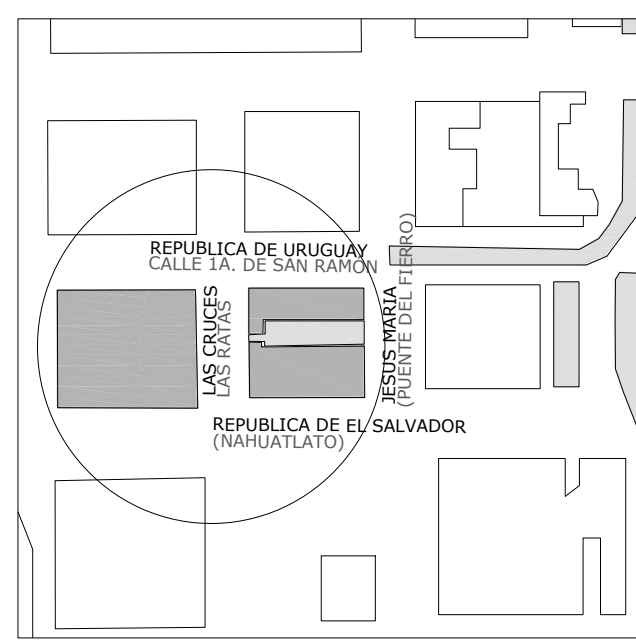

PLANO DE JOHANNES VINGBOONS DE 1665, INSPIRADO EN LA PERSPECTIVA DE 1628 DE JUAN GÓMEZ DE TRASMONTE.

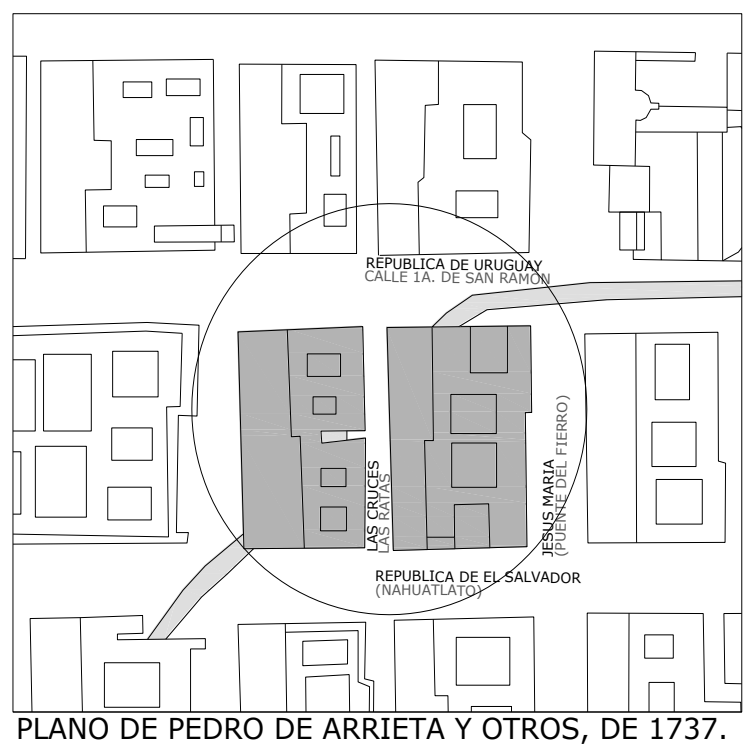

Núcleo localizado entre las calles de Las Cruces y Jesús María, entre República de Uruguay y República de Salvador; los inmuebles ubicados en esta zona siguen el trayecto de la acequia de la Merced; excesivamente modificados y mutilados fueron los edificios de República del Salvador 164 y 166, así como Jesús María 87-89. Se puede observar en ellos que las crujías colindantes con la acequia han sido demolidas para agrandar el área de bodegas de los comercios ubicados en las accesorias que dan hacia las calles; no obstante, es posible apreciar restos de la traza de la acequia, y la afectación en crujías limítrofes con el canal y con casas de acequia. En los inmuebles de Las Cruces 21 y Uruguay 161, puede verse restos de los patios, y en el caso de Las Cruces 21 la ampliación de construcción sobre la acequia cegada y la colindancia del patio con ella, siendo probable que éste haya servido como embarcadero y puerta falsa. Los lotes se ven afectados en su mayoría, siendo escasos los que siguen una forma regular. 


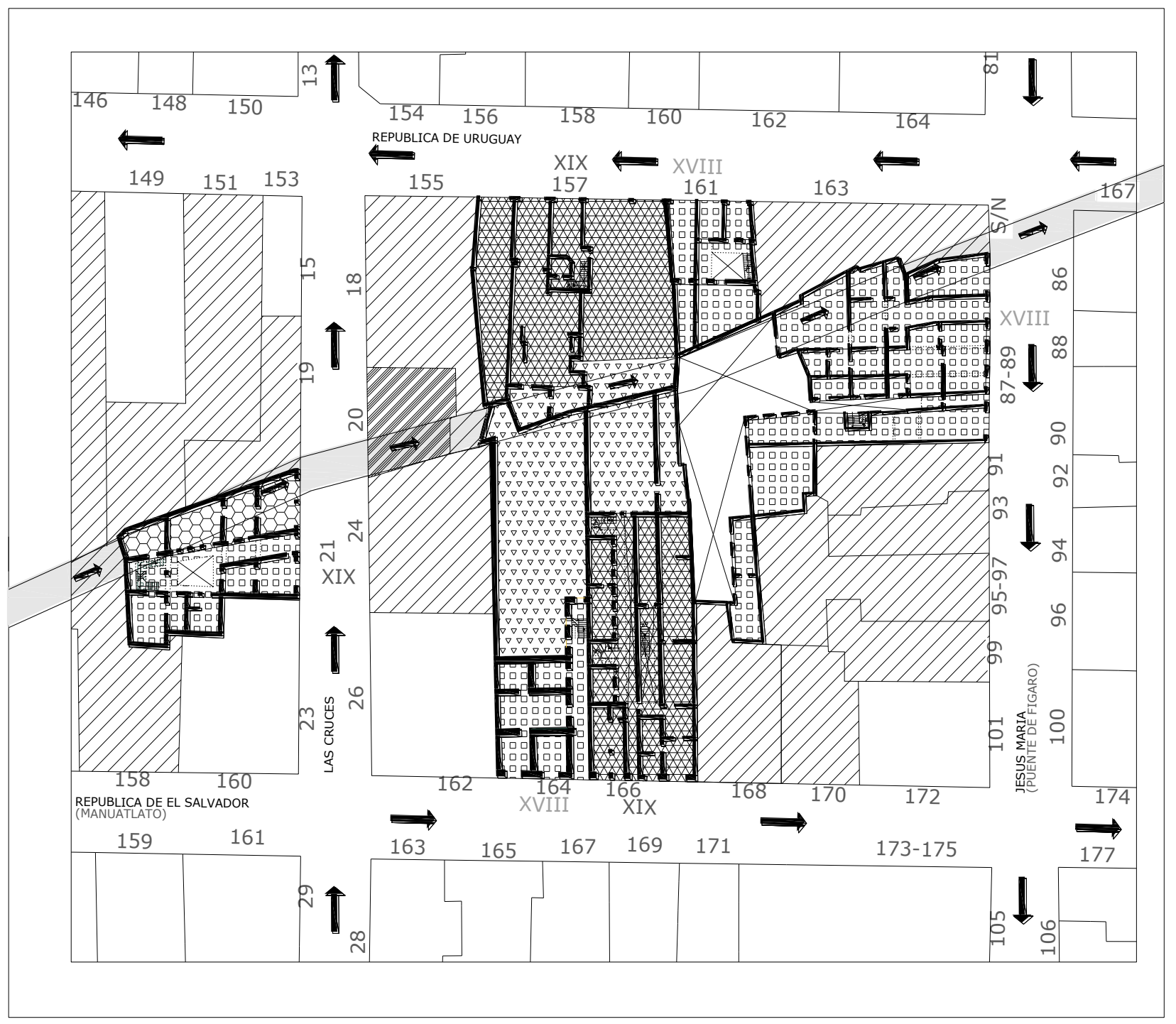

Z7AAfectación en la forma de los lotes colindantes con casas con acequia. Exy Ampliacion de Construcción sobre acequia cegada.

WMLotes en acequias cegadas.

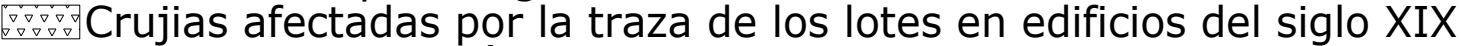
Crujias sin afectación por la traza de los lotes en edificios del siglo XIX 區践Construcción original del siglo XVIII 


\section{4.- Núcleo 4}

Conformado por las casas ubicadas en:

1.- Manzanares 11.

2.- Manzanares 15.

3.- Manzanares 17.

4.- Manzanares 19.

5.- Manzanares 21.

6.- Manzanares 25.

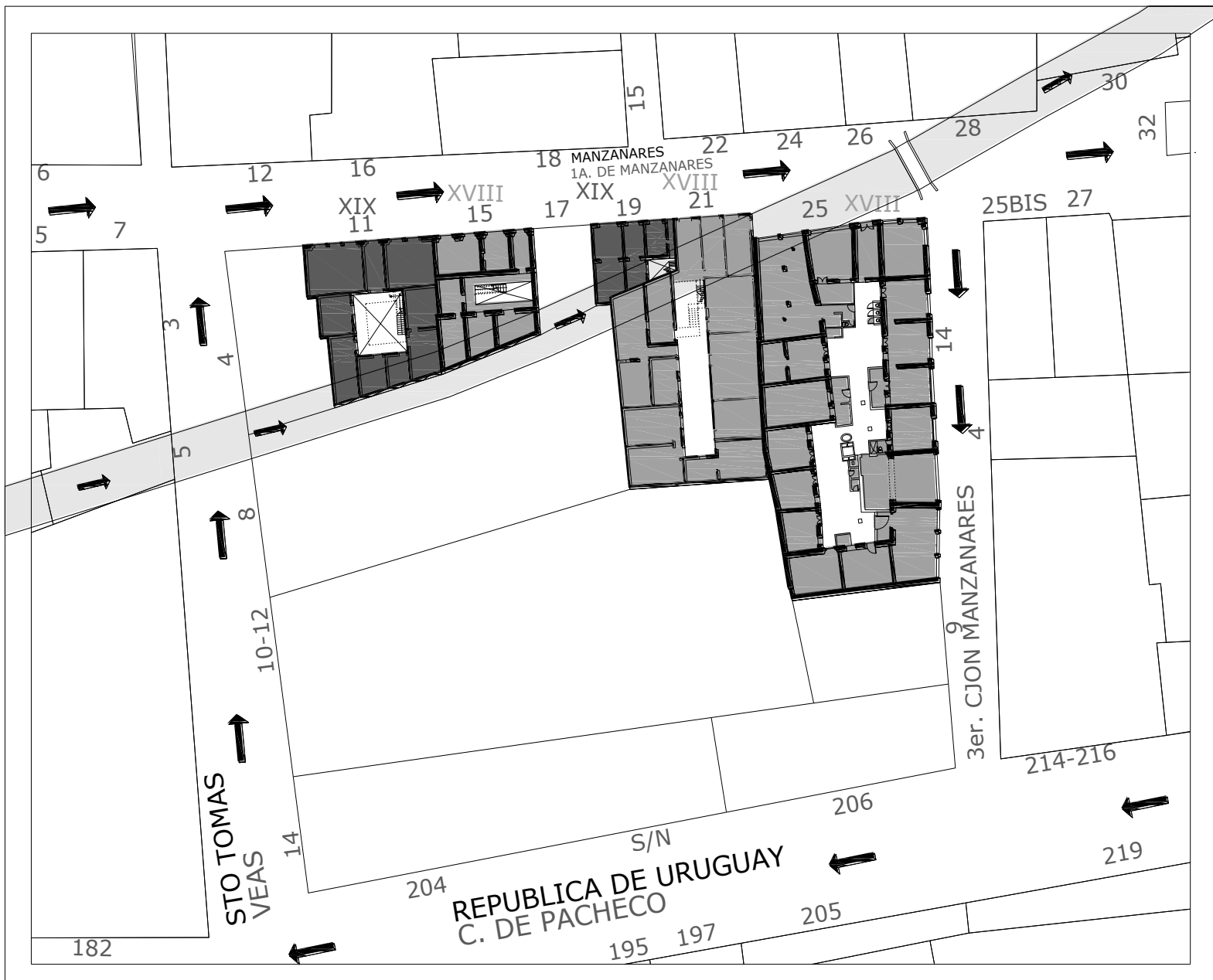

XVIII 
Al hacer una hipótesis de las edificaciones del siglo XVIII, después de quitar los posibles agregados que se encuentran sobre el canal, se puede observar una relación directa de los patios de las casas con respecto a la acequia, fungiendo de esta forma como posibles embarcaderos; en la casa de Manzanares 15 se pueden observar vanos de puertas que dan hacia la acequia, siendo probable que uno de estos vanos sirviera de puerta falsa; además, se encuentra en el sitio un pequeño ancón de forma triangular que se forma entre la acequia y la construcción de la casa. Es posible que tal elemento sirviera de embarcadero.

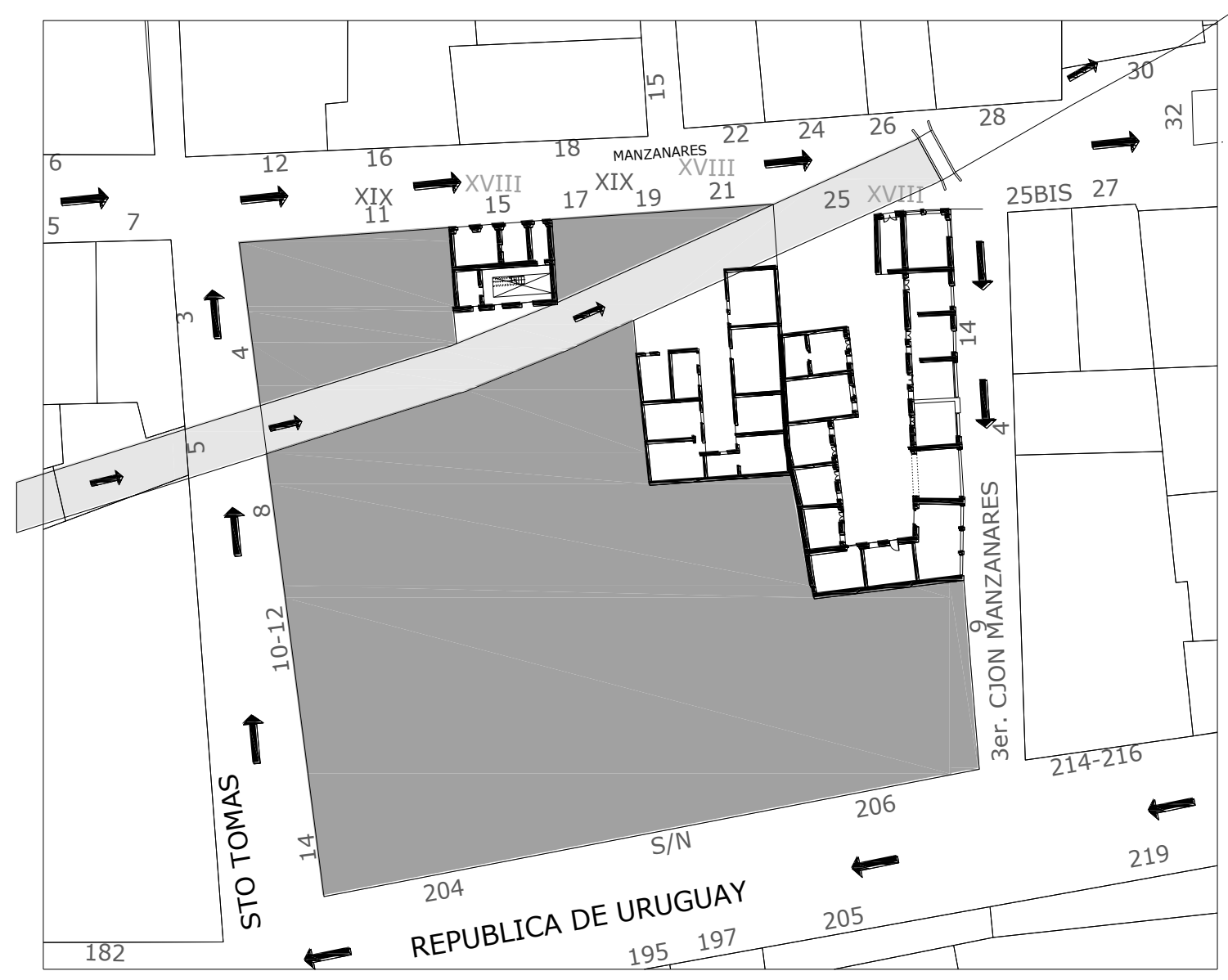

ÁREA PERDIDA DE CONSTRUCCIÓN DEL S. XVIII 


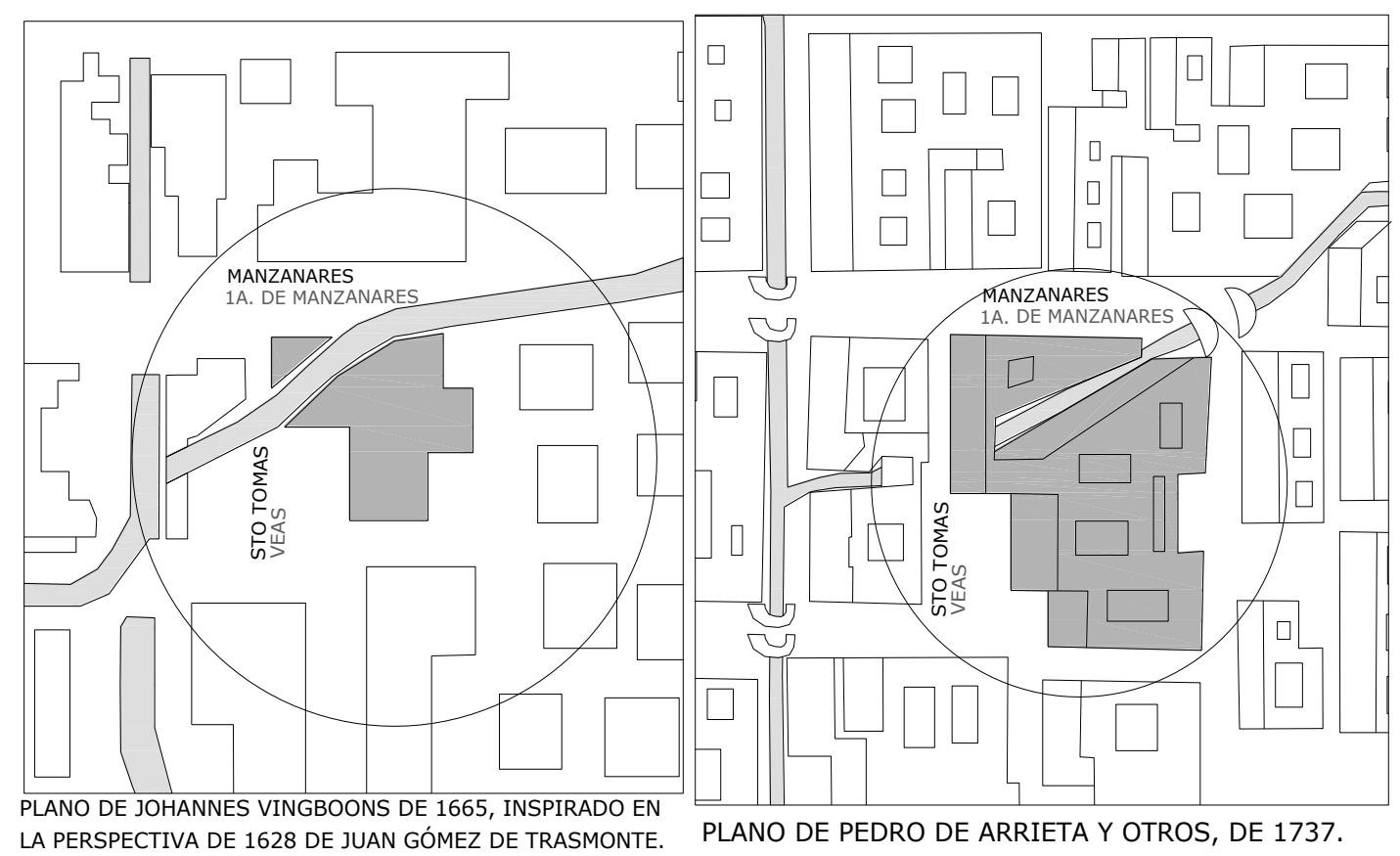

Núcleo localizado en la calle de Manzanares, cerca de la capilla del Señor de la Humildad. Las casas del siglo XVIII aparecen con agregados sobre la acequia de la Merced, estando los patios en relación directa con la acequia, siendo muy probable que estos sirvieran como embarcaderos y puertas falsas de los inmuebles; las casas del siglo XIX aparecen con afectaciones en las crujías limítrofes con la acequia, asimismo los lotes adoptan la forma de la curvatura del canal y de las colindancias con las casas con acequia. 


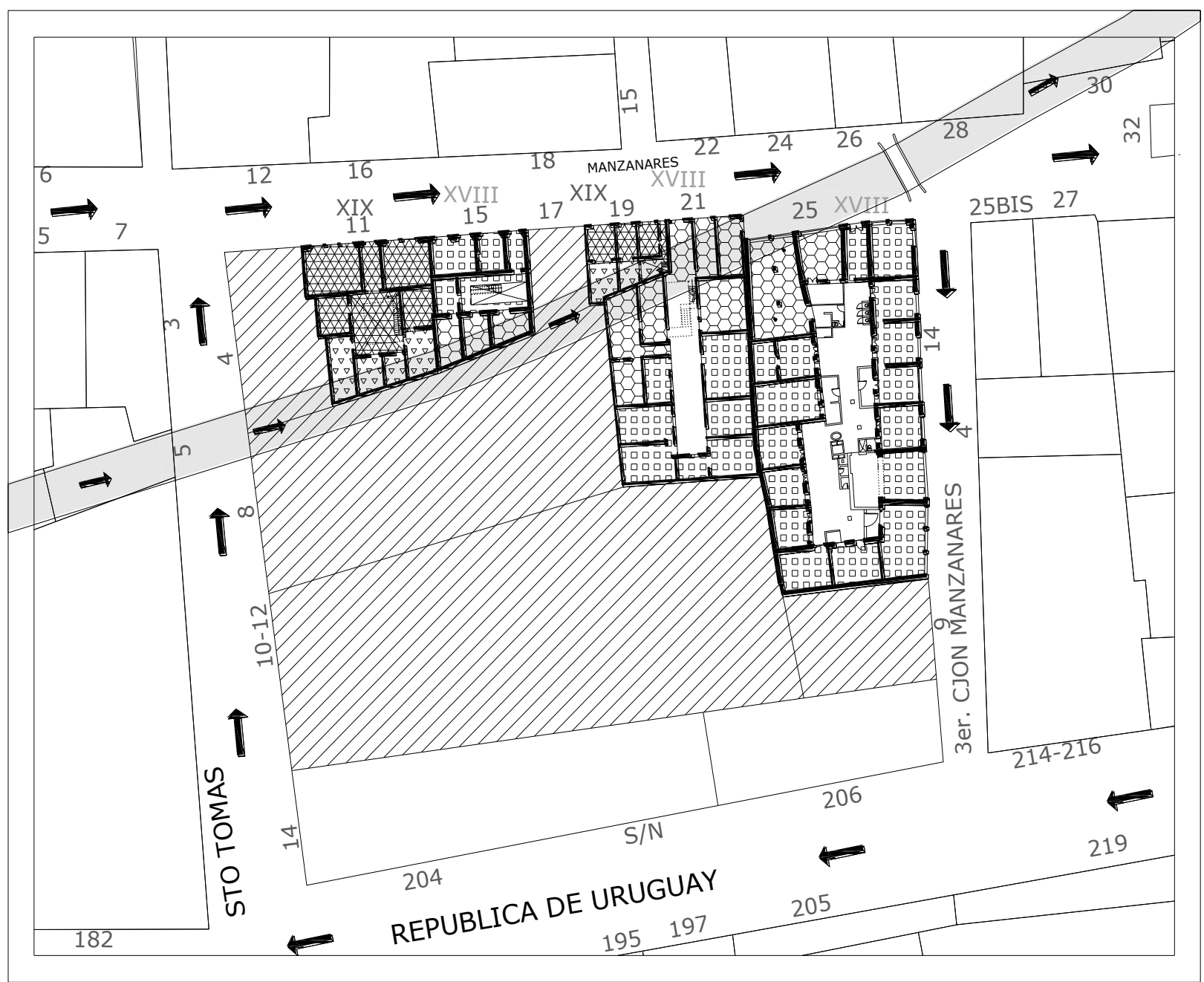

V//入Afectación en la forma de los demas lotes.

Ampliacion de Construcción sobre acequia cegada.

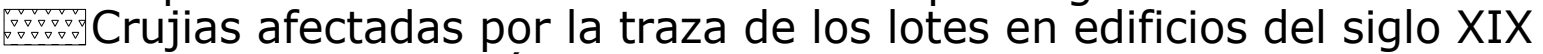
Crujias sin afectación por la traza de los lotes en edificios del siglo XIX 區品品嚾Construcción original del siglo XVIII 


\section{5.- Núcleo 5}

Conformado por las casas ubicadas en:

1.- San Jerónimo 28.

2.- San Jerónimo 34, Isabel la Católica 95.

3.- San Jerónimo 36, Isabel la Católica 97.

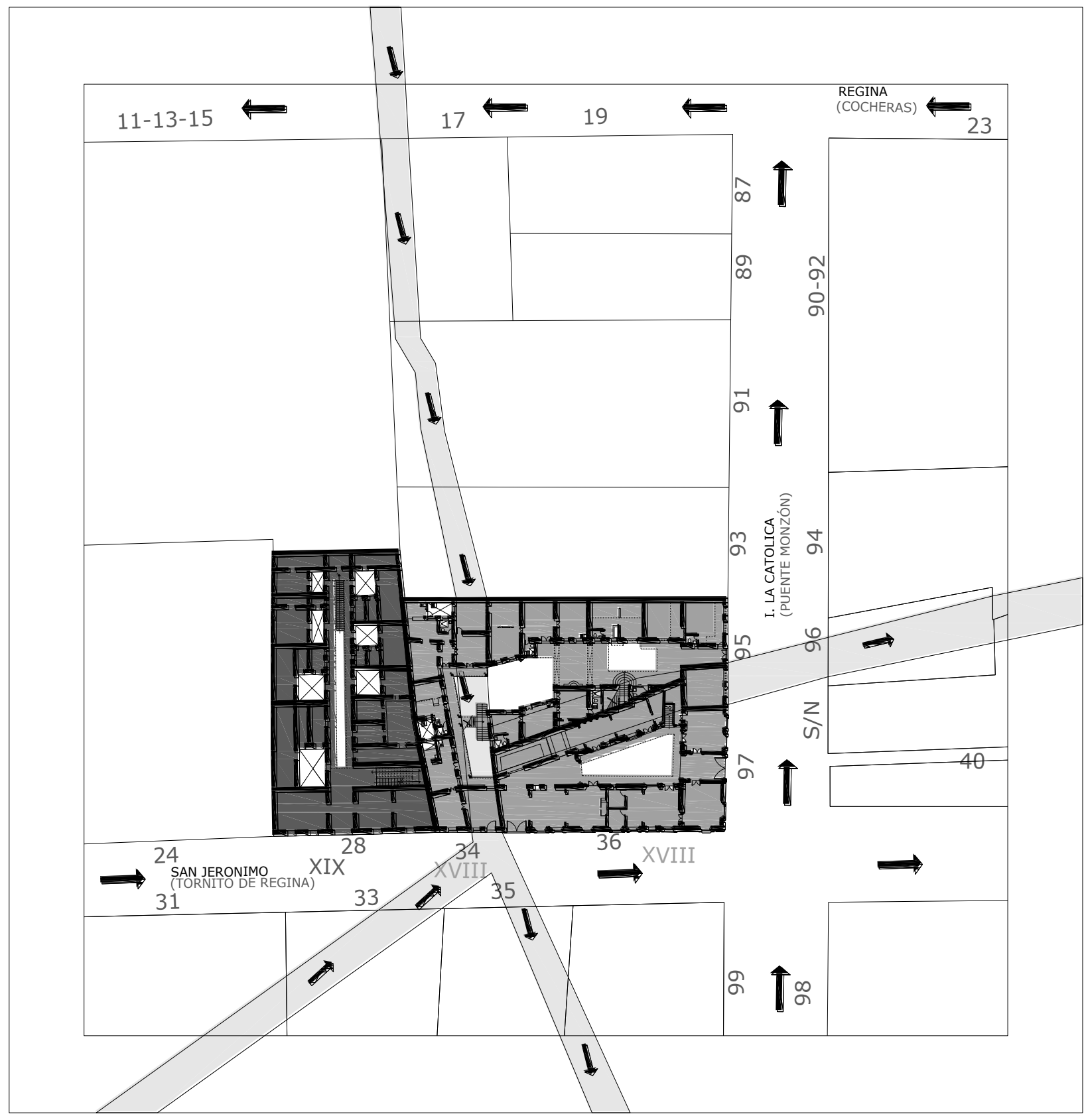

XVIII

XIX 
Al hacer una hipótesis de la casa de la acequia al quitar los agregados que se encuentran sobra el canal, se puede observar el cruce de la acequia de la Merced y de la acequia de Monserrate a través de toda la casa, en forma longitudinal y transversal, siendo probable que hayan existido puentes interiores para comunicar las distintas áreas del inmueble; la inclusión de puertas falsas en este caso específico no era necesaria, pues la comunicación de la acequia era directa en el interior del propio inmueble; el acceso hacia las dos calles se hacía por dos puertas, una principal localizada en Isabel la Católica, y otra de servicio localizada en San Jerónimo; las demás casas localizadas en el trayecto de la acequia de Monserrate ( $\mathrm{y}$ de las cuales no queda vestigio), es posible que hayan tenido puertas falsas en comunicación directa con el canal.

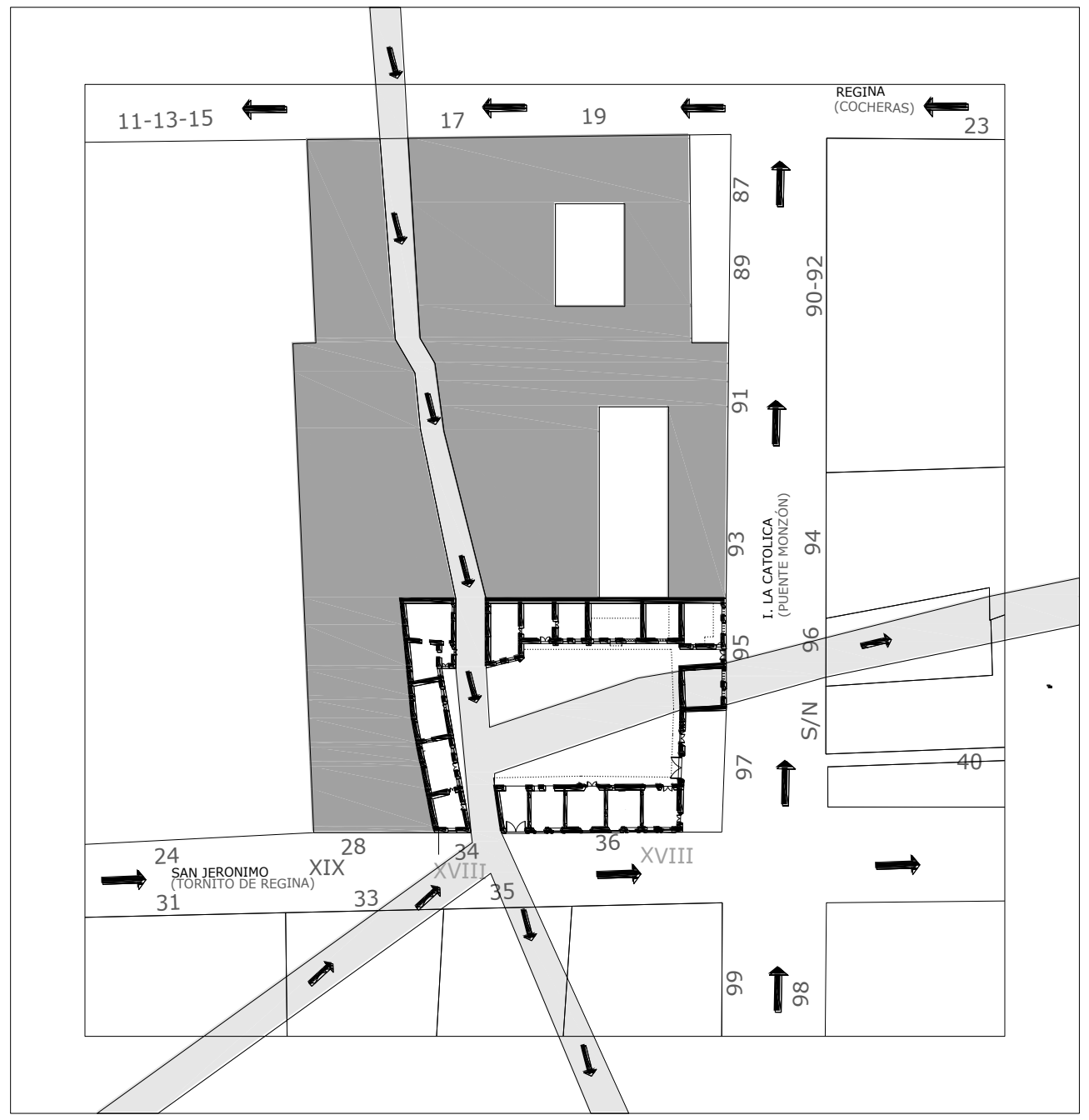

AREA PERDIDA DE CONSTRUCCIÓN DEL S. XVIII 


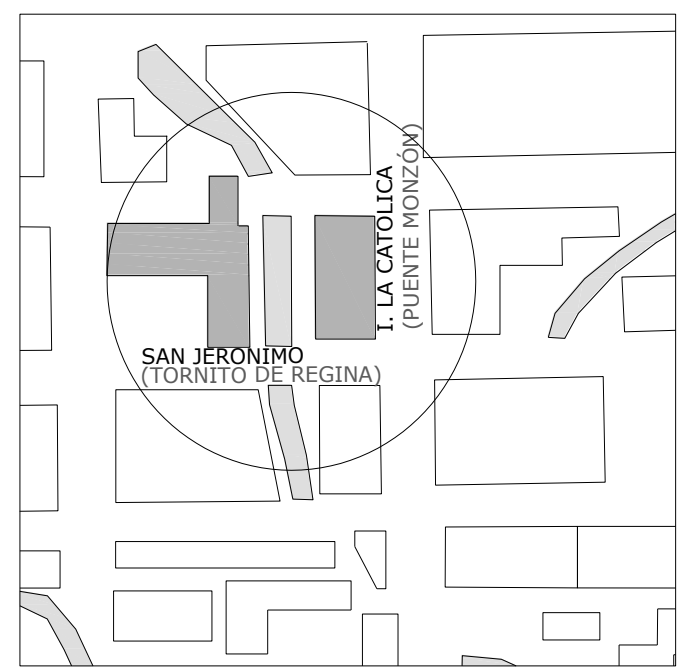

PLANO DE JOHANNES VINGBOONS DE 1665, INSPIRADO EN LA PERSPECTIVA DE 1628 DE JUAN GÓMEZ DE TRASMONTE.

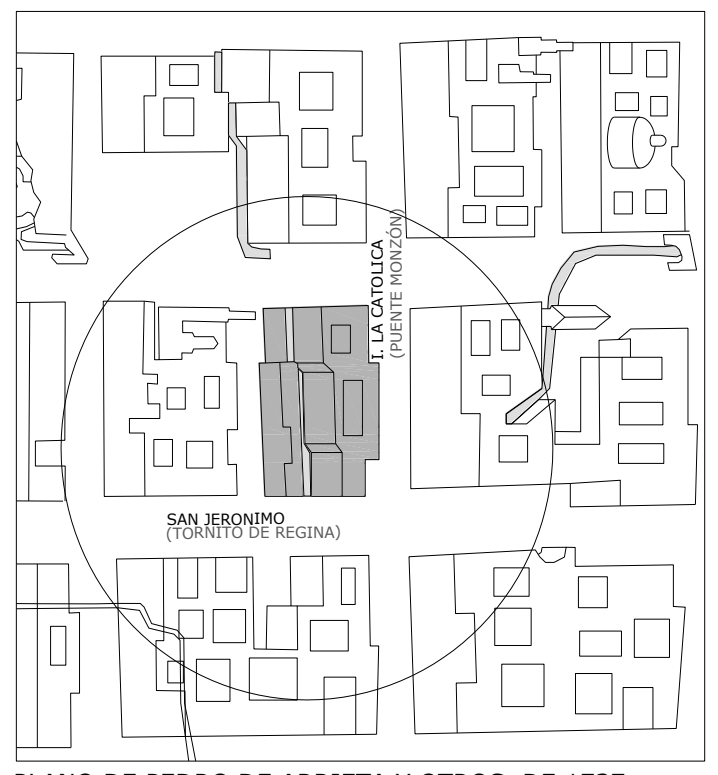

PLANO DE PEDRO DE ARRIETA Y OTROS, DE 1737.

Núcleo conformado por dos inmuebles del siglo XVIII en la esquina de Bolívar y San Jerónimo, además de la casa ubicada en San Jerónimo no. 28 del siglo XIX. Las dos casas del siglo XVIII se encuentran en el cruce de las acequias de Monserrate y de la Merced, estos dos inmuebles formaban un solo edificio por el cual atravesaba en su totalidad la acequia de la Merced. Al cegarse la acequia se dividieron, y el área libre fue ocupada por agregados en ambos lados de los inmuebles; asimismo se puede observar que los locales que colindan con la calle no tenían comunicación con la casa y probablemente fueran utilizados como accesorias de taza y plato, razón por la cual el gran patio de la casa tal vez fuese usado como embarcadero de abastecimiento para tales comercios. En lo que respecta a la casa del siglo XIX, sólo se ve afectada en el partido arquitectónico en la colindancia con la casa de la acequia; en cambio, los lotes colindantes con la acequia y la casa de la acequia conservan formas regulares. 


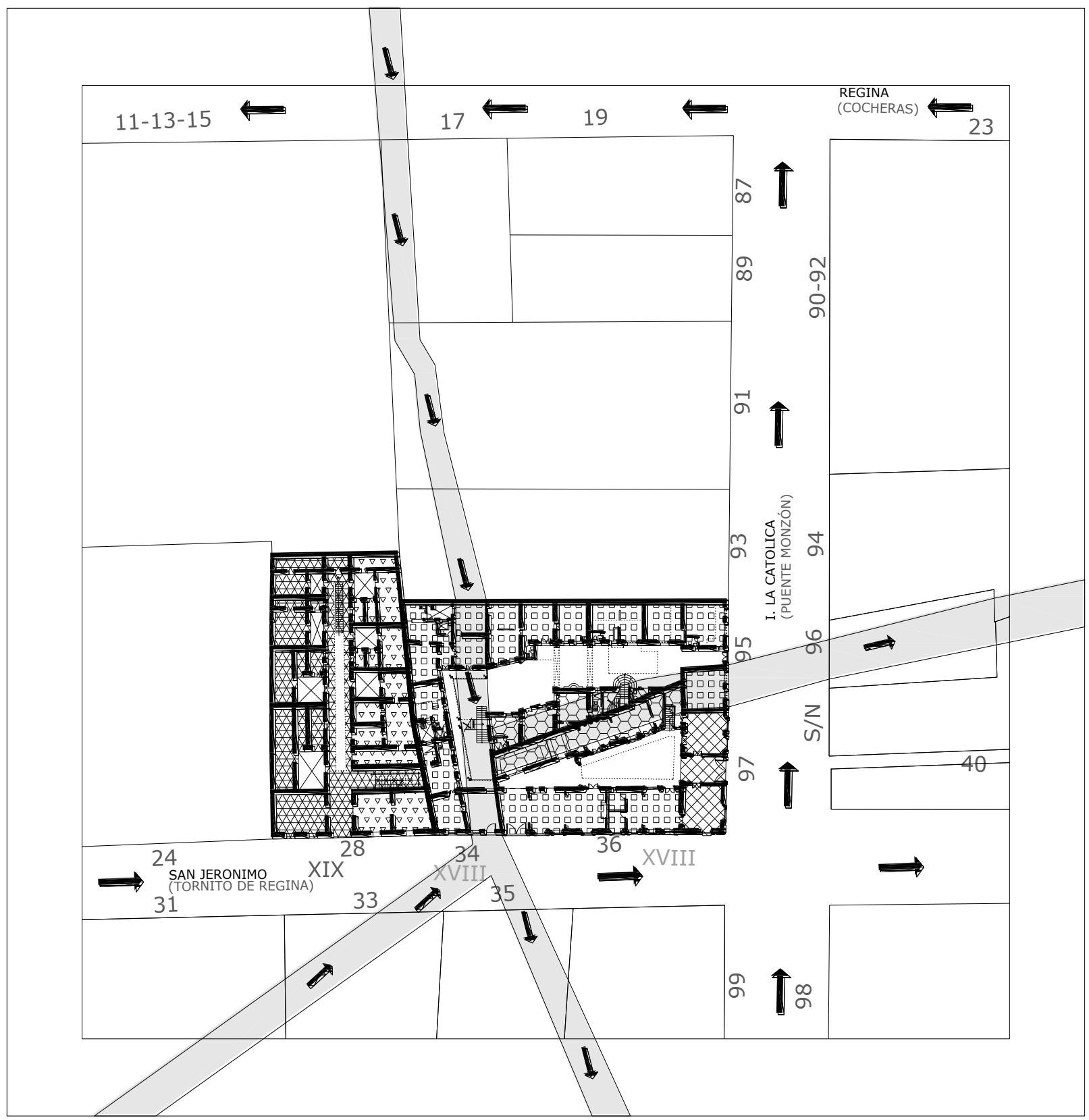

Ancones.

Empliacion de Construcción sobre acequia cegada.

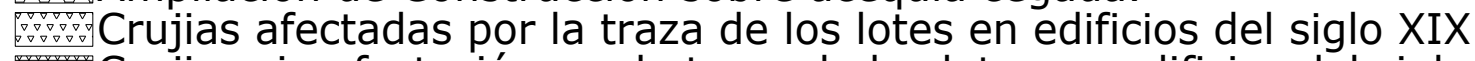
Crujias sin afectación por la traza de los lotes en edificios del siglo XIX 践 


\section{6.- Núcleo 6}

Conformado por las casas ubicadas en:

1.- Mesones 87.

2.- Mesones 91-93.

3.- Mesones 97.

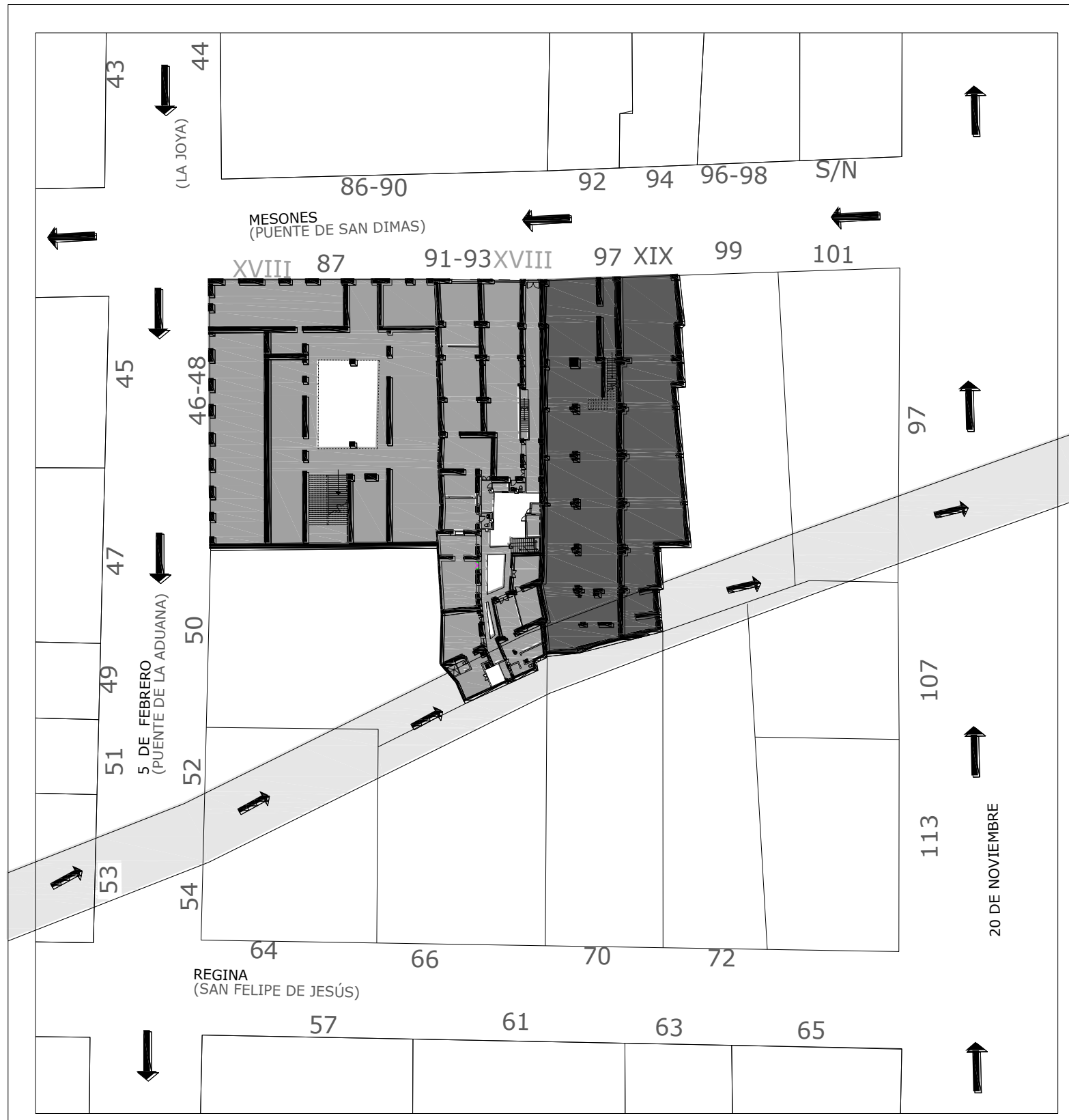

XVIII

XIX 
La comunicación directa de la casa de Mesones 91-93 con la acequia de la Merced se hacía por medio de una puerta falsa localizada en la parte posterior del inmueble; a la vez esta puerta se comunicaba con un patio localizado en la parte posterior de la casa. También se puede observar la probable existencia de agregados en la parte posterior de una etapa anterior en la que se cegó la acequia, que correspondería con el ancho asentado en documentos del Archivo Histórico del Distrito Federal, donde queda registrada la anchura de la acequia de la Merced en 13 varas $(10.85 \mathrm{mts})^{60}$. En lo que respecta a la casa de Mesones 97, ésta se halla demasiado modificada como para hacer una hipótesis; no obstante, existe un quiebre en los muros que dan hacia la zona de la acequia, que permiten ver que tal requiebre seguía el trayecto del canal. El inmueble de Mesones 87 no presenta alteraciones producto de la acequia.

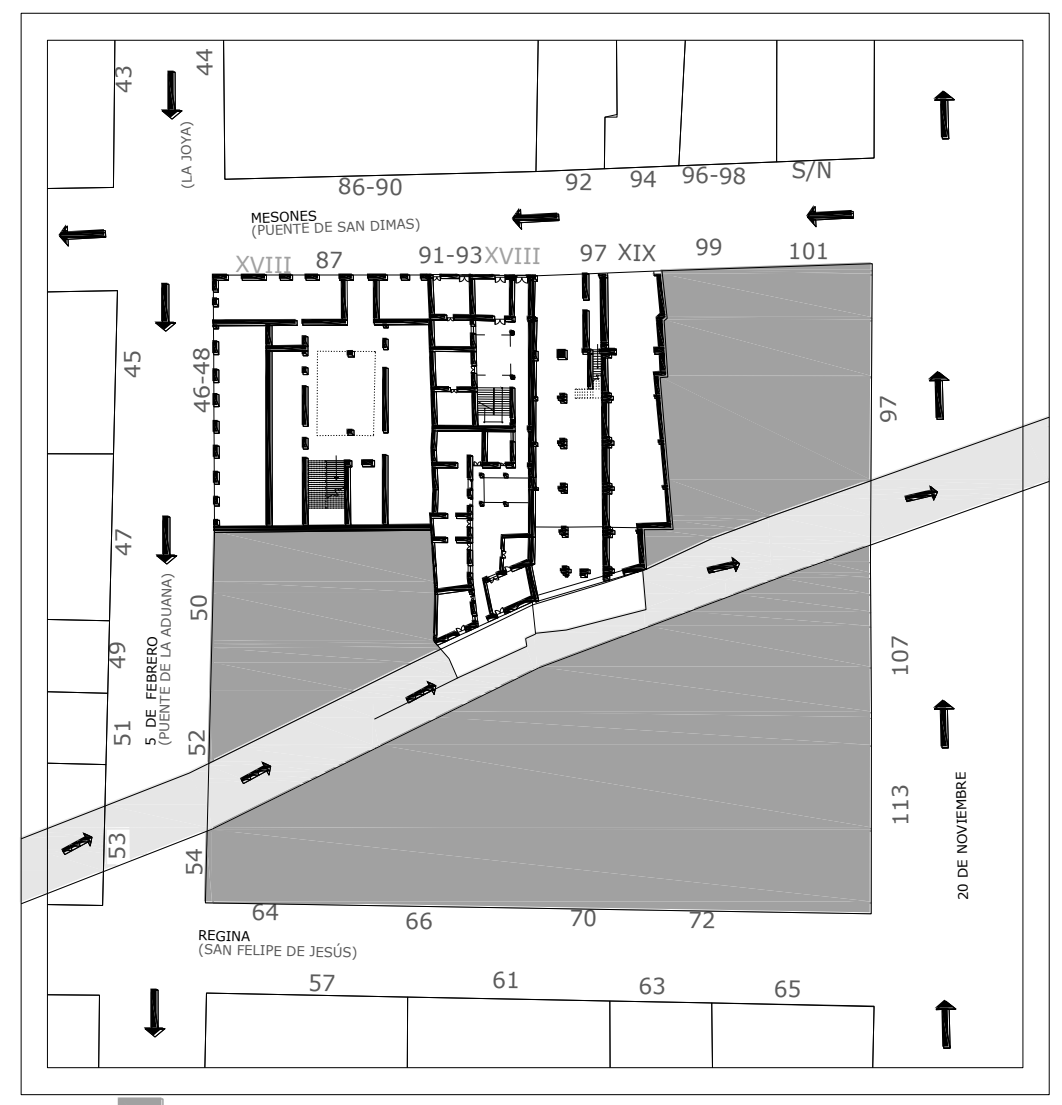

AREA PERDIDA DE CONSTRUCCIÓN DEL S. XVIII

${ }^{60}$ Exp. 36 Fecha 1773 Vol. 3716, Aytto. De la Cd. De Mex. Puentes.

Autos de prova del dulcísimo nombre de Jhs. De religiosos del señor San Agustín sobre la liberación que pretende de fabricar el puente que llaman de san Dimas. 


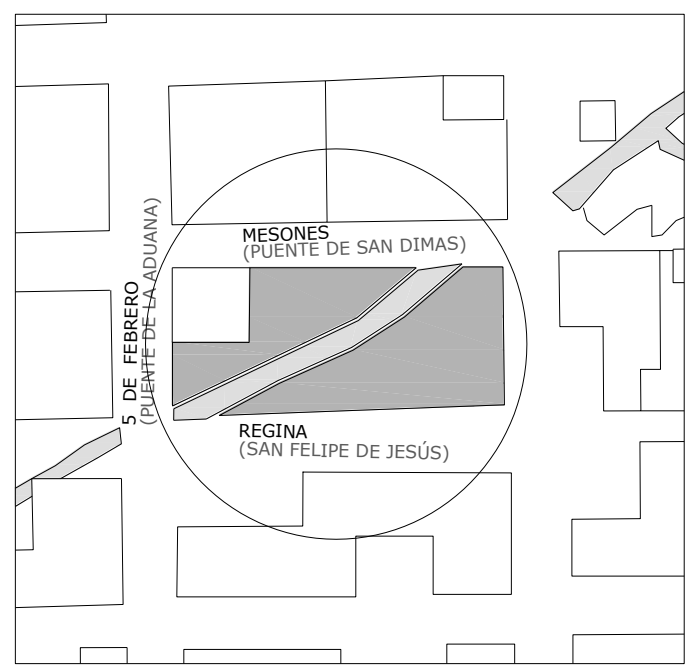

PLANO DE JOHANNES VINGBOONS DE 1665, INSPIRADO EN LA PERSPECTIVA DE 1628 DE JUAN GÓMEZ DE TRASMONTE.

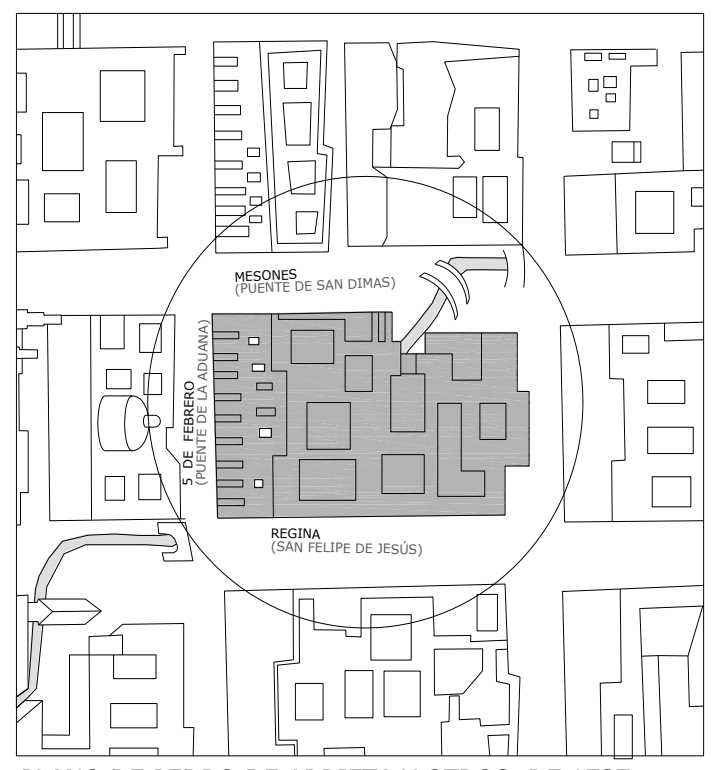

PLANO DE PEDRO DE ARRIETA Y OTROS, DE 1737.

Núcleo localizado en la calle de Mesones, en la antigua calle del puente de San Dimas. La afectación de los inmuebles históricos se ve solamente en la casa de Mesones 91-93 del siglo XVIII, y la casa de Mesones 97 del siglo XIX. La casa localizada en Mesones 87 no presenta ninguna afectación en el partido arquitectónico. La casa de Mesones 91-93 presenta, en el trazo de los muros, la desecación de la acequia de la Merced, así como su cegamiento, viéndose agregados que siguen la forma del canal. Se observa, en adición, una relación directa del patio posterior con la acequia y el espacio entre los agregados de la puerta falsa. La casa de Mesones 97 ha sido modificada notoriamente, viéndose que la mayoría de sus muros intermedios han sido demolidos; sin embargo, se puede observar el trazo de la acequia en su colindancia con ésta, así como restos de agregados, siendo probable que la construcción sea del siglo XVIII. En lo que respecta a los lotes, se aprecia que la mayoría sufren afectaciones en su trazado, en las colindancias con la acequia y con las casas con acequia. 


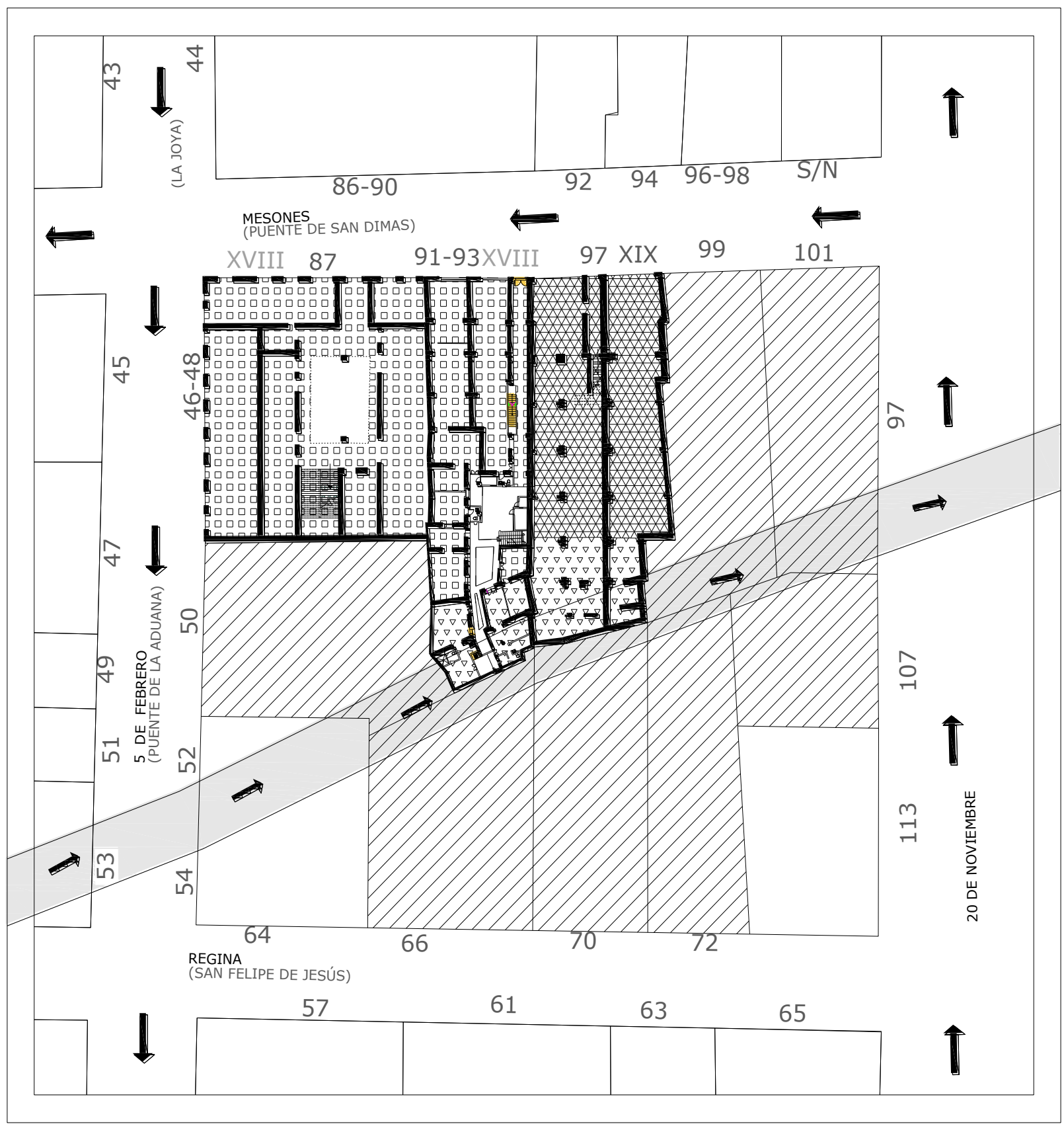

Q//AAfectación en la forma de los demas lotes.

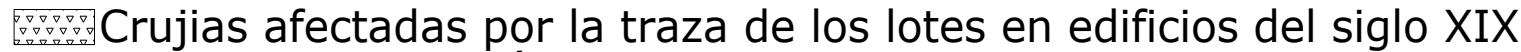
Crujias sin afectación por la traza de los lotes en edificios del siglo XIX

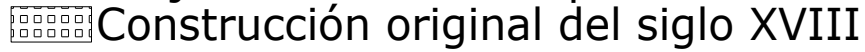




\section{La Casa de Mesones 91-93, una casa con acequia}

La casa de Mesones número 91-93, se ubica en el Centro Histórico de la Ciudad de México. Los antiguos nombres de esta calle fueron los de Puente de San Dimas, y del Venero, el primero por el puente del mismo nombre que se encontraba en la calle de Mesones y Pino Suárez (nombres actuales) ${ }^{61}$, y el segundo nombre por la casa del Capitán Pedro de Venero ${ }^{62}$, cuya casa se ubicó en el número uno de esta calle. El inmueble se sitúa en lo que fue la ribera de la acequia de la merced, notándose en su partido arquitectónico las diferentes fases de cegamiento de dicha vía de comunicación acuática.

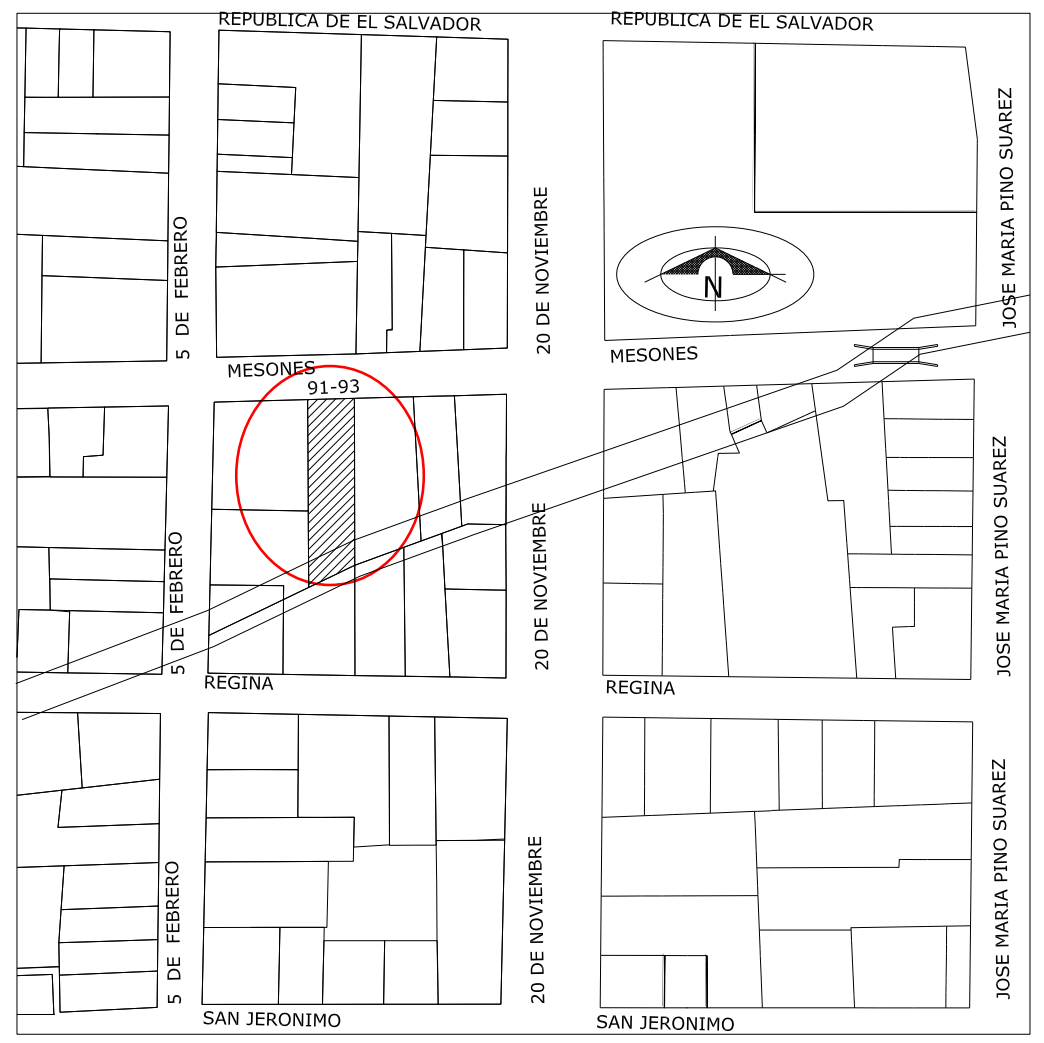

PLANO CATASTRAL ACTUAL.

Localización del inmueble en el plano catastral actual.

\section{Antecedentes históricos de la casa de Mesones 91-93}

Ubicada en un terreno localizado en el antiguo barrio mexica conocido como Huitzillan, el caso de estudio tiene sus antecedentes desde el siglo XVI, en que la propiedad del terreno donde se ubica el inmueble fue otorgada al conquistador

\footnotetext{
${ }^{61}$ NIETO GARCÍA, Raúl Candido, Restauración de una vivienda del siglo XVIII: Mesones 94, Tesis Maestría, UNAM.

${ }^{62}$ MARROQUI, José María, La Ciudad de México, Tomo II, México, 1969
} 
Juan de Cabra, el cual por sus aportes hechos a la Conquista en la Ciudad de México y de Pánuco, recibió las Mercedes del solar conocido como Mesones, además de recibir una encomienda en Mytepeque, y la explotación de minas en Michoacán y Zacatecas ${ }^{63}$. El plano más antiguo en el que se puede vislumbrar la localización del predio donde se ubica el caso de estudio, se refiere al plano de Upsala, ${ }^{64}$. Aquí se puede observar como baldía el área señalada en rojo, y se observa la ubicación de las acequias existentes, pasando por la zona del caso de estudio la acequia de la merced.

Durante el siglo XVIII no hay más datos que puedan dar seguimiento de la historia del terreno donde se ubica la casa, lo que se puede observar en planos y perspectivas del siglo XVII, entre los cuáles se puede mencionar el plano de 1665 de Johannes Vingboons, basado en la perspectiva de 1628 de Juan Gómez de Trasmonte, y el biombo de 1693 de Diego Correa, observándose aún baldía la zona donde se emplaza esta casa. Fray Agustín de Vetancourt ${ }^{65}$ proporciona datos de que en esta zona se ubicaba un pequeño manantial que provocaba que el terreno fuera lodoso o pantanoso, por lo tanto, dificultaba la construcción e hizo sumamente tardío el poblamiento de esta zona mientras que la mayoría de la ciudad ya se hallaba edificada.

\footnotetext{
${ }^{63}$ VALERO DE GARCÍA LASCURÁIN, Ana Rita, Solares y conquistadores: Orígenes de la propiedad en la ciudad de México, Ana Rita Valero de García Lascuráin,1991, El Colegio de México.

${ }^{64}$ BENITTEZ, Fernando, Historia de la Ciudad de México, Tomo 2, Editorial Salvat, México, 1984, p.36, p48.

${ }^{65}$ VETANCOURT, Agustín de; San Vicente, Juan Manuel de; Viera, Juan de; La Ciudad de México en el Siglo XVIII (16901780) Tres Crónicas, Dirección General de Publicaciones, CONACULTA, México, 1990.
} 


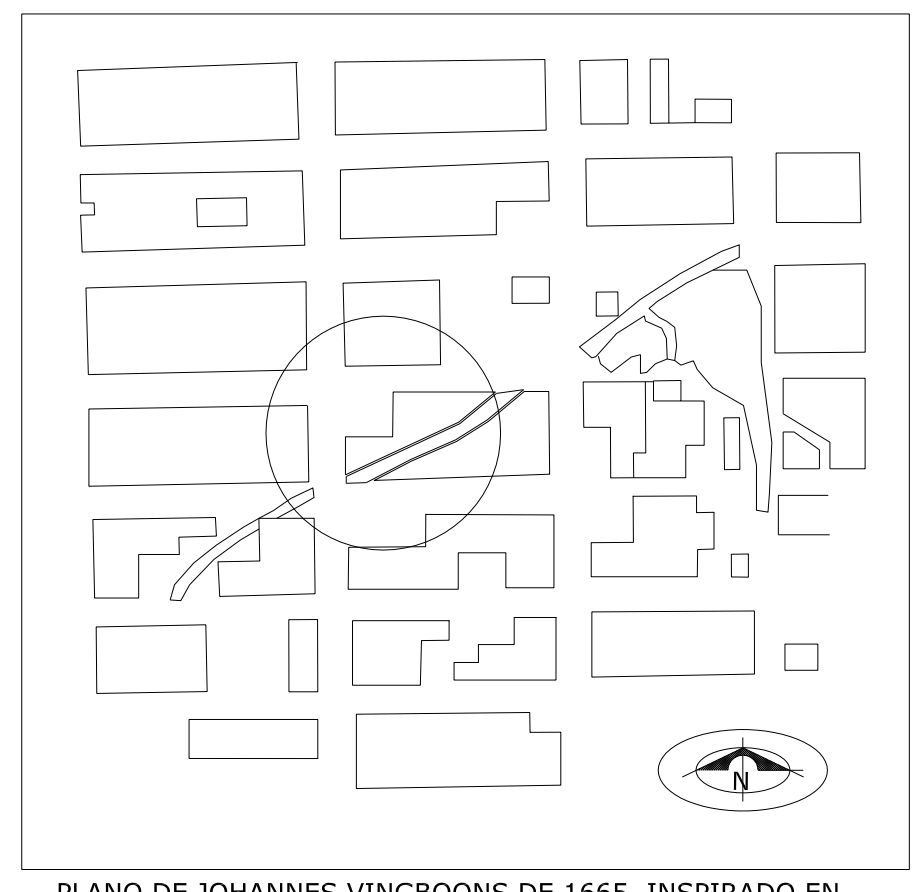

PLANO DE JOHANNES VINGBOONS DE 1665, INSPIRADO EN LA PERSPECTIVA DE 1628 DE JUAN GÓMEZ DE TRASMONTE.

Plano de 1665 de Johannes Vingboons, Ilustración 102, 500 planos de la Ciudad de México 1325-1933, Ethel Herrera Moreno, SAHOP, 1992. Como se ha mencionado, en el plano de Johannes Vingboons aún puede observarse como baldía la zona donde se ubica el inmueble objeto de la presente investigación.

En el siglo XVIII la acequia de la Merced comienza a verse cubierta por construcciones que pasan por encima de ella, como puede observarse en un pequeño fragmento de la perspectiva de $1760^{66}$, en el que aparece cubierta la parte de lo que serían las calles de 5 de Febrero y 20 de Noviembre, entre Regina y Mesones; así como en la zona entre Pino Suárez y Correo Mayor, entre Mesones y República del Salvador.

Ubicada en la antigua calle conocida como del Puente de San Dimas o del Venero, el primer nombre por el puente del mismo nombre que se encontraba en Mesones y Pino Suárez (nombres actuales) ${ }^{67}$, y el segundo nombre por la casa del Capitán Pedro de Venero ${ }^{68}$ cuya casa se ubicó en el número uno de ésta calle; los antecedentes más próximos de la casa acerca de los propietarios datan de los

\footnotetext{
66 HERRERA MORENO, Ethel, 500 planos de la Ciudad de México: 1325 -1933, México, SAHOP. 1992, llustración 125.

${ }^{67}$ NIETO GARCÍA, Raúl Cándido, Restauración de una vivienda del siglo XVIII: Mesones 94, Tesis Maestría, UNAM.

${ }^{68}$ MARROQUI, José María, La Ciudad de México, Tomo II, México, 1969.
} 
años 30's del siglo XX, siendo dueño en este período el señor Julio Beltrán; el siguiente dueño, en los años 40’s del mismo siglo, fue el señor Abel Kushner Etel, de origen judío; y el actual poseedor es el señor Miguel Kushner Schnur, hijo de la persona mencionada con antelación. Los datos más interesantes son del 5 de julio de 1944, en donde se menciona el cambio que sufrieron algunas ventanas de la fachada, las cuales se convirtieron en puertas, y el descubrimiento de una hornacina que se encontraba tapiada; los demás documentos son de permisos para anuncios y mantenimiento de fachada (pintura y limpieza), sin encontrarse licencias ni planos de las intervenciones mayores de que fue objeto el caso de estudio.

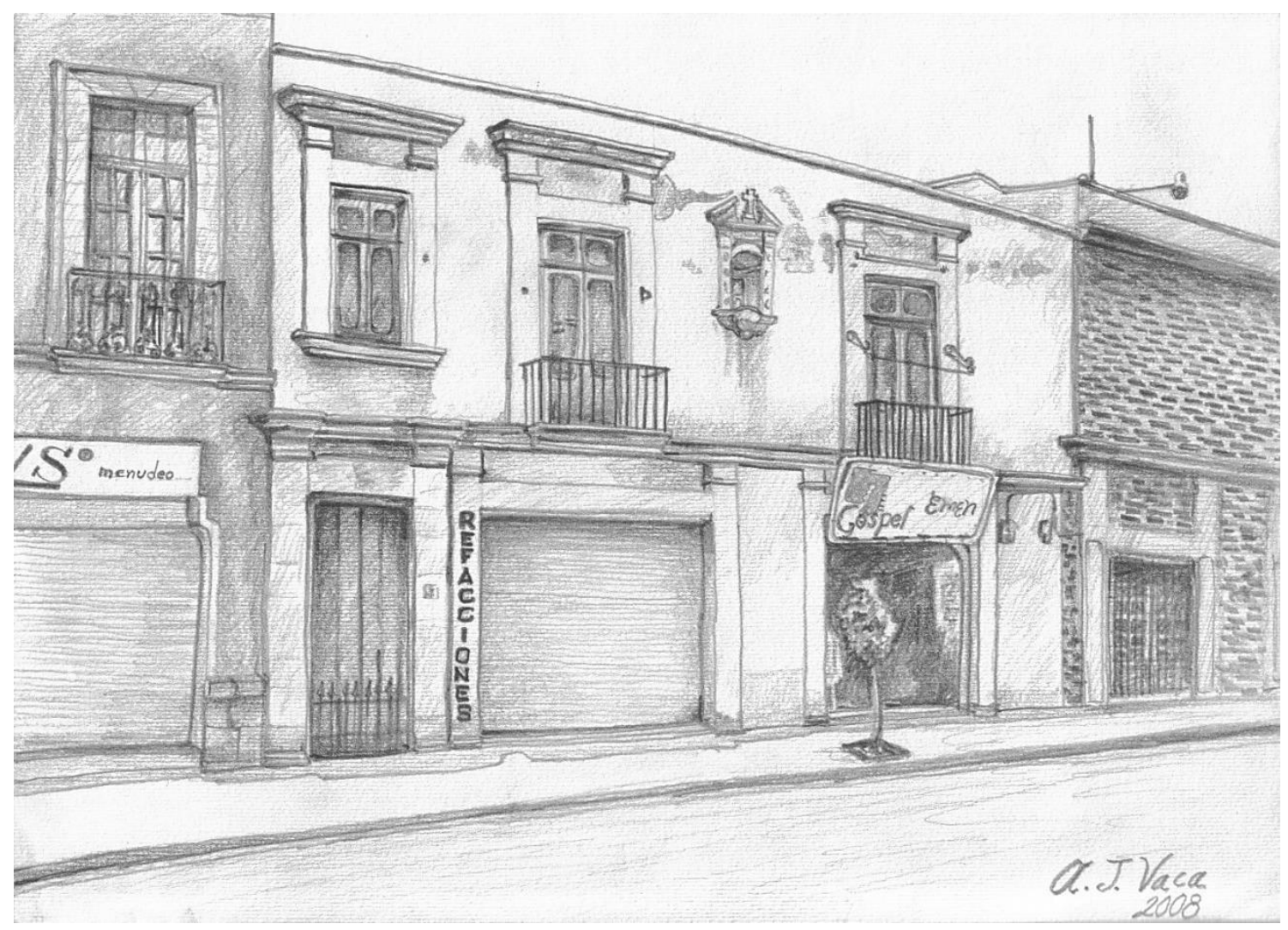

Aspecto de la fachada del inmueble en la actualidad. Dibujo: Alejandro Jiménez Vaca. 


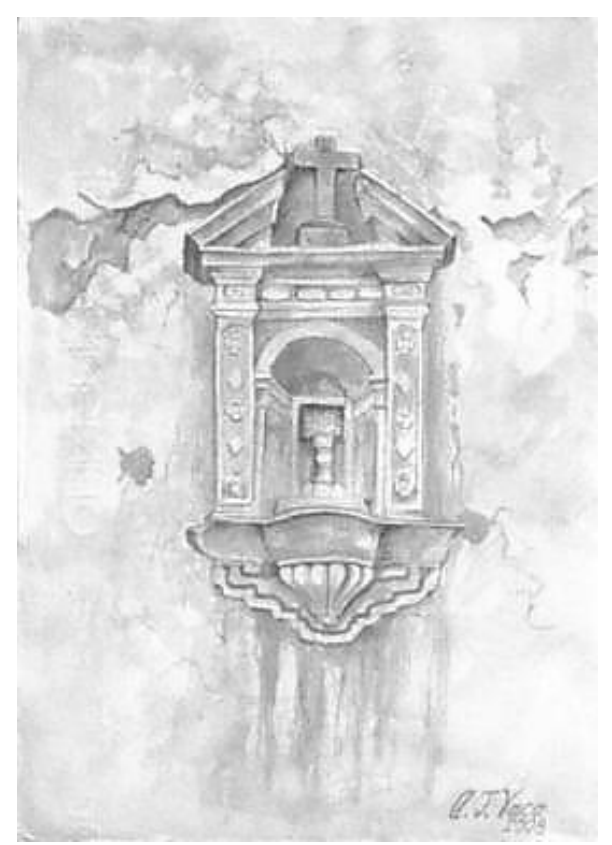

Hornacina encontrada en la fachada el 5 de julio de 1944. Acuarela: Alejandro Jiménez Vaca, 2008.

\section{Colindancias y el entorno Urbano}

La Casa de Mesones 91-93, se encuentra ubicada entre las calles de 20 de Noviembre y 5 de Febrero, a cuatro escasas calles de la Plaza de la Constitución y a una del corredor peatonal Regina (inaugurado en el año 2008). Los inmuebles con los que colinda son el número 97, catalogado como monumento histórico del siglo XIX; el otro inmueble es el número 87 , catalogado también como monumento histórico del siglo XVIII; enfrente existen edificios de departamentos con comercios en planta baja, y a unas cuantas casas, hacia 20 de Noviembre, se encuentra la casa número 94, la cual es también monumento histórico del siglo XVIII. Asimismo, en la esquina de 20 de Noviembre y Mesones, se encuentra el edificio del siglo XX del Hospital de Jesús, obra del Arquitecto José Villagrán. Respecto al estado físico de la calle, ésta se encuentra en regulares condiciones, aunque tiene tan sólo dos años y medio que se rehabilitó, encontrándose ya algunos botes de basura en malas condiciones, y el aspecto de la pintura de las fachadas de varias casas en considerable deterioro; los pavimentos de concreto estampado se ven en perfectas condiciones, sin que éstos hayan sido una opción adecuada para un Centro Histórico, en opinión de varios Arquitectos Restauradores 

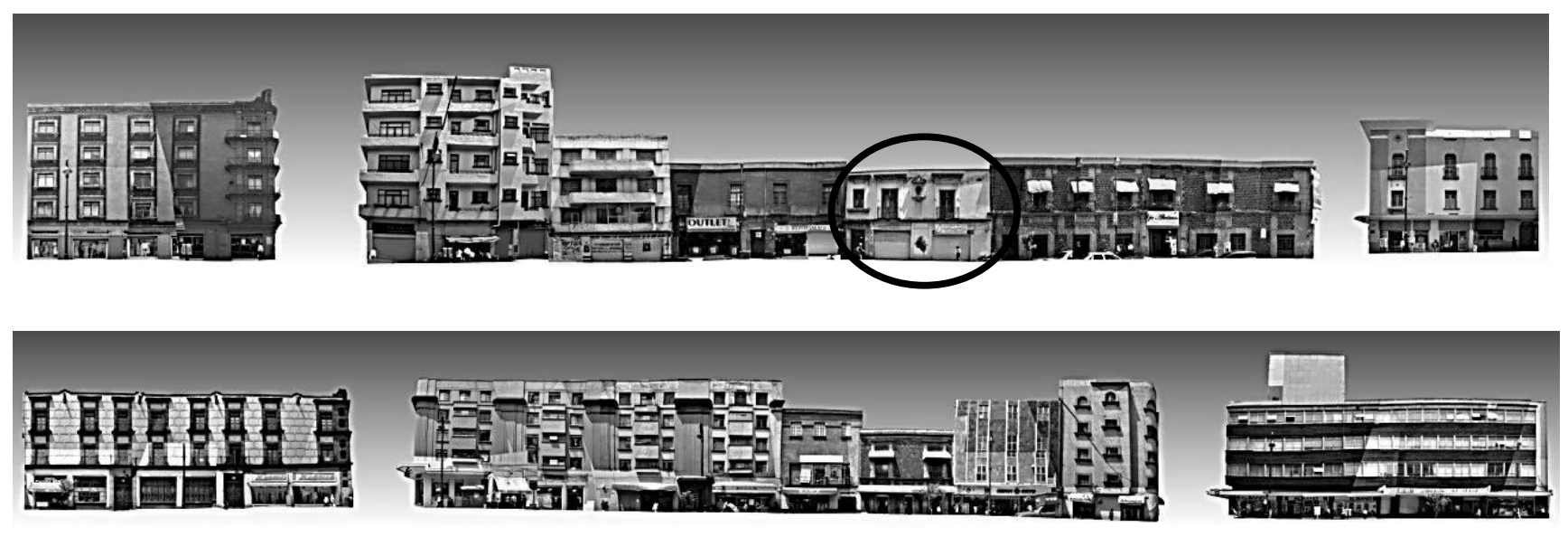

Larguillos fotográficos en donde se puede observar el caso de estudio en rojo, y el entorno en el que se ubica.

\section{Análisis espacial}

La Casa de Mesones 91-93 corresponde a la tipología de casa sola, con dos niveles. A continuación, la descripción de este tipo de casas:

Casa sola.

Estas viviendas correspondían a comerciantes y artesanos ricos. Se edificaban en terrenos pequeños, en uno o dos niveles, participando del espacio urbano.

Su partido se componía de planta baja, de accesorias y habitación anexa, con acceso directo de la calle.

Poseían una estructura arquitectónica con un espacio descubierto "patio principal", con el que se articulaban los espacios cerrados.

El espacio abierto constituía el centro de la vida familiar, aunque no se trate de un espacio central, ya que las habitaciones se ubicaban únicamente en tres de sus lados; en esta planta se encontraban los servicios. En planta alta se concentraban la zona habitacional y sus servicios.

La diferencia entre ésta y la señorial radica en la falta del salón del estrado y del dosel, así como ornamentación menos profusa. ${ }^{69}$

La diferencia que distingue a esta casa de otras de este tipo, es la de encontrarse en el trayecto de una acequia, específicamente la de la Merced, lo que le confiere características especiales, como la posible ubicación de una puerta falsa o puerta trasera que daba hacia la acequia, mientras que la principal se

${ }^{69}$ GONZÁLeZ AVELlANEdA, Albert, et. al. Manual Técnico de Procedimientos parta la Rehabilitación de Monumentos Históricos en el Distrito Federal, INAH, México, 1988 
encontraba en la calle de tierra; había una inclinación o pendiente del edificio que permitía el desagüe del agua recolectada de las cubiertas por medio de gárgolas hacia la misma acequia, y existía la adición de agregados visibles en el partido arquitectónico, en el que se ven las diversas etapas del cegamiento de esta vía de comunicación acuática.
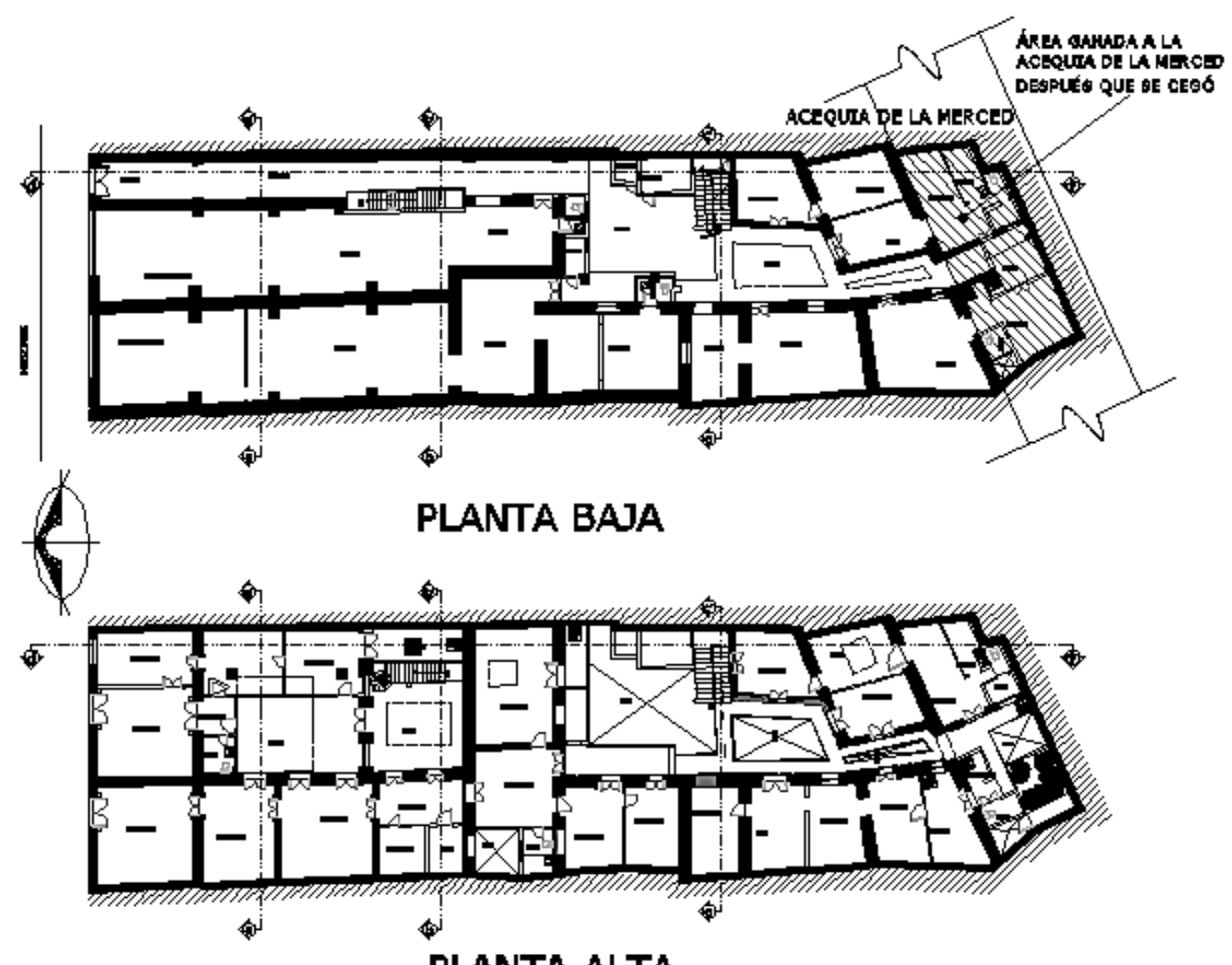

PLANTA ALTA

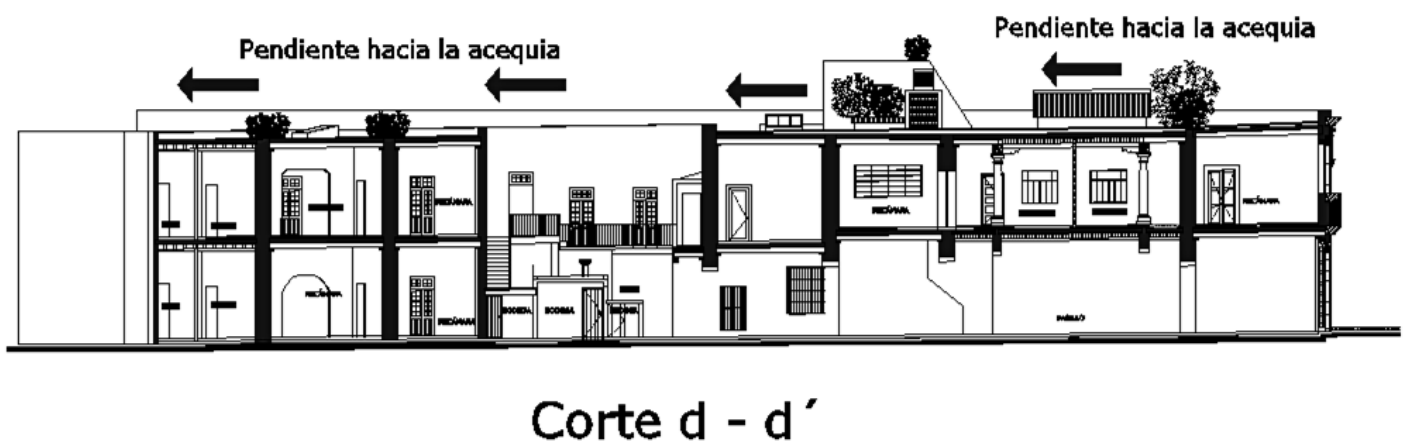

donde se ve el trazo de la acequia de la Merced, y Corte donde se observa la pendiente que tiene el inmueble, y que daba hacia la Acequia de la Merced. 


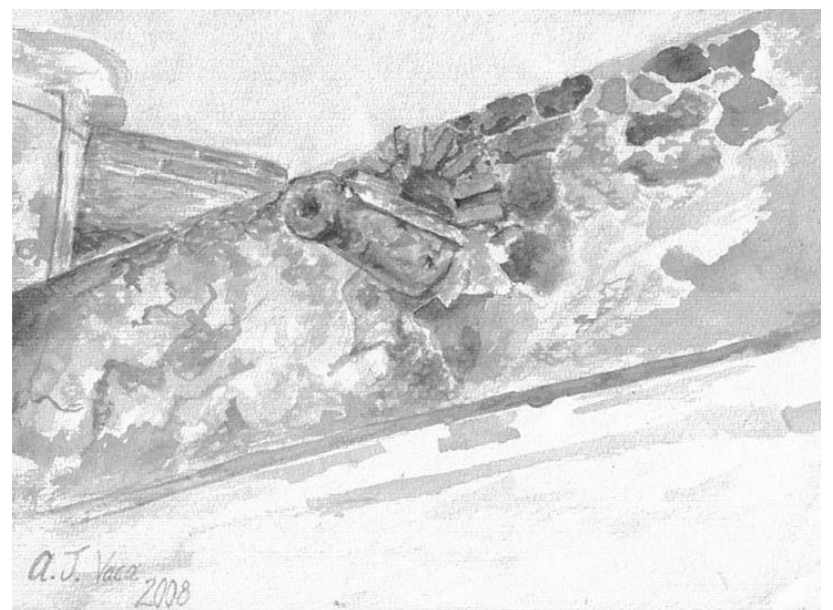

Gárgola encontrada en la parte posterior de la casa. Acuarela: Alejandro Jiménez Vaca, 2008.

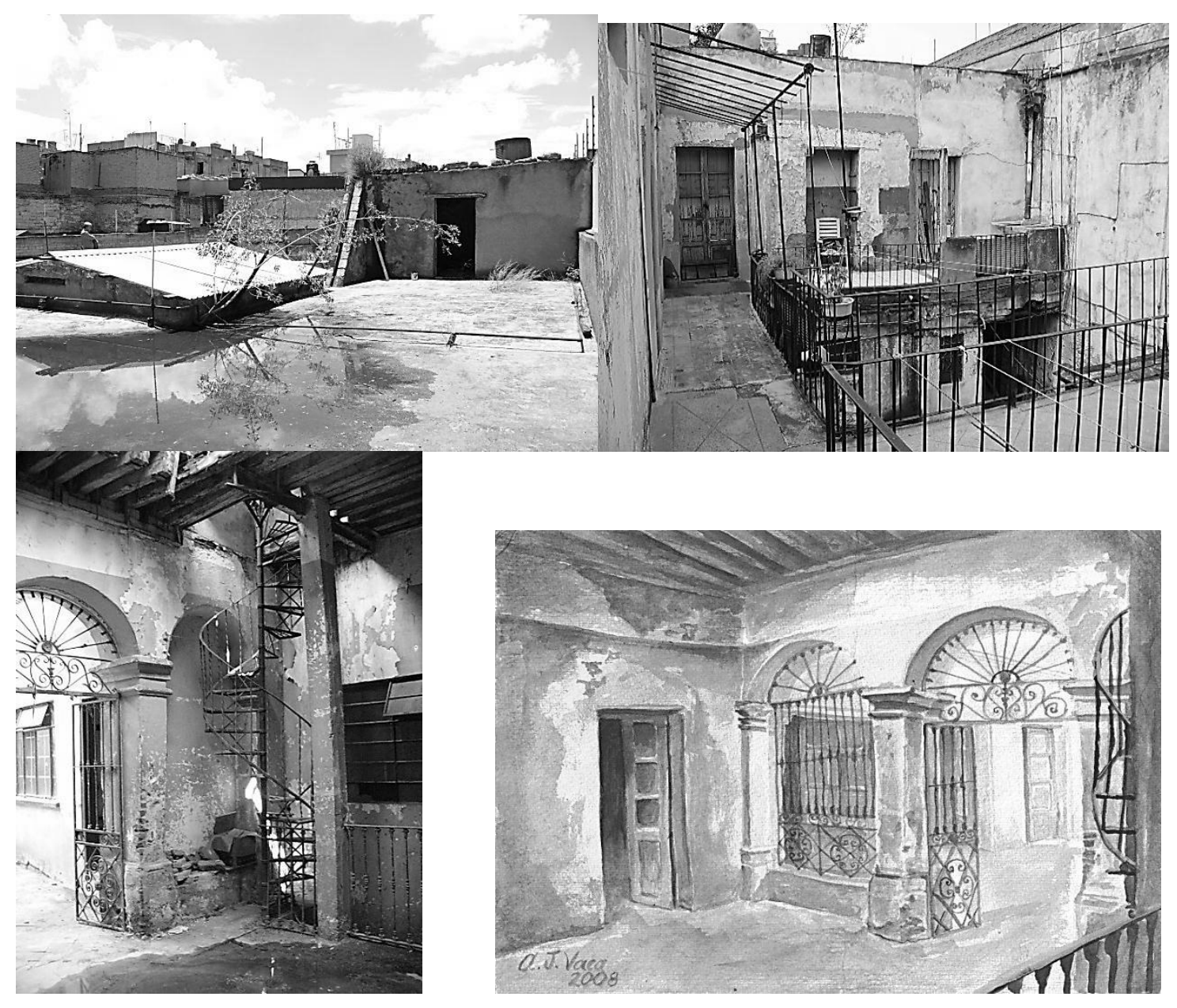

Fotografías de la azotea y patios del inmueble. Acuarela de la posible ubicación del cubo de escaleras, y vista del patio superior. Fotografías y acuarela de Alejandro Jiménez Vaca, 2008

El inmueble objeto de la presente investigación presenta distintos agregados, tanto del siglo XIX como del siglo XX. Realizando un análisis histórico 
y estético de los añadidos, se concluye que los pertenecientes al siglo XIX son indispensables para entender las modificaciones de que fue objeto el medio ambiente de la Ciudad de México y específicamente la zona donde se emplaza el monumento $^{70}$, a la vez de las transformaciones en el modo de vida y los servicios requeridos durante esta época, por lo que es necesario conservarlos como testimonio de dicho período histórico. Lo anteriormente expresado puede observarse en los planos de las plantas arquitectónicas, viéndose que existen varios agregados que siguen la forma diagonal de la ribera de la acequia de la Merced. En lo que se refiere a los agregados del siglo $\mathrm{XX}$, estos carecen de un valor estético, y sólo son añadidos provisionales, en los que no se cuidó la calidad de la mano de obra y de los materiales (lámina de asbesto, puertas de madera, bodegas y cuartos provisionales, descuadrados y sin trabes), por lo que se considera necesario su liberación, pues interfieren con la correcta lectura histórica y estética del monumento.

Eliminando los agregados y haciendo una comparativa con el programa arquitectónico de edificios análogos, se puede hacer un planteamiento hipotético del edificio, rescatándose los patios interiores, así como el cubo de las escaleras, además de la reconstrucción de un patio trasero y la ubicación de la puerta falsa en la parte posterior del inmueble. En lo referente a la fachada, subsisten vestigios en las cornisas de los arranques de las jambas, haciendo posible una reconstrucción de la apariencia de la fachada con los vanos originales. Además de una fotografía de 1935 del archivo fotográfico del INAH, que se reproduce en este documento, se puede observar uno de los vanos originales.

\footnotetext{
70 Se menciona en el libro "La Ciudad de México" de José María Marroquí, la existencia de un callejón interior entre las casas por donde pasaba la acequia de la Merced, éste fue ocupado por agregados de las diferentes edificaciones que seguían el trayecto de dicha acequia. (La Ciudad de México, Tomo Il, José María Marroquí, México, 1969).
} 


\section{CONCLUSIONES}

La gran cantidad de inmuebles con uso de vivienda existentes en el siglo XVIII (ya hayan sido palacios, casas, o vecindades) hace pensar en las particularidades del edificio estudiado en el presente trabajo. El analizar las características que pueden darle un valor adicional respecto a otros inmuebles de la misma época, así como examinar su ubicación cerca de una acequia, permite detenerse a reflexionar respecto a cuántos inmuebles comparten esta semejanza.

Un estudio que realicé en el Catálogo de Monumentos Históricos del Centro Histórico de la Ciudad de México, en el perímetro "A" (que por lo extenso no es posible incluir en este trabajo, del cual incluyo un plano como anexo) es síntesis de esta investigación. Y arroja como resultado que los inmuebles del siglo XVIII suman un total de 480 edificios (lo que representa casi un $40 \%$ del total de los inmuebles que son patrimonio monumental en la Ciudad de México). Este dato haría pensar que las casas de acequia representarían un número proporcionalmente similar en cantidad. Sin embargo, al hacer un análisis de la cantidad de edificios que se encuentran en las cercanías de una acequia, encontramos que el total de casas del siglo XVIII de esta clase es de 76; al hacer aún una depuración más extensa en estos inmuebles, en donde la acequia atraviesa parcial o totalmente la construcción, hallamos que el número decrece, siendo el total el de 19 casos. Aunque la disminución de casas no para ahí, ya que varias de ellas han sido modificadas o mutiladas drásticamente, al haberse demolido muros o crujías enteras que daban cuenta de los rastros de alguna acequia en el partido arquitectónico (siendo el total de una escasa decena las casas del siglo XVIII que no han sido modificadas o que conservan rastros de su partido arquitectónico original). Si se adicionan las del siglo XVII y unas pocas del siglo XIX, se obtendrían unas veinte casas con estas características, aproximadamente.

La trascendencia de este tipo de casas denominadas "de acequia" (las cuales guardan en la traza de sus muros el testimonio del pasado lacustre de la ciudad) permite determinar su conservación, respetando los aparentes errores en el trazado de los muros que no seguían un eje recto como otros inmuebles y 
donde, a diferencia de los demás, el desvío de muros era más notorio, formando ángulos que seguían el trazo de las antiguas vialidades prehispánicas. De este modo, parece apropiado adoptar el término de "casas de acequia" para este tipo de edificaciones, y abogar por su conservación respetando el trazo original de sus muros dejando la especulación inmobiliaria y comercial de lado; especulación que, por agrandar la bodega de algún comercio, ha hecho demoler muros que estaban "chuecos" sin ninguna razón aparente (por lo que se juzga necesario concientizar a los propietarios de la importancia de estas casas como parte de la historia de la ciudad, y del entorno acuático que imperaba en la misma).

La necesidad de continuar con las obras del desagüe de la Cuenca de México, trajo consigo un desequilibrio ecológico en el que el desecamiento paulatino era evidente; las obras del desagüe tenían como finalidad obtener un mayor control sobre los niveles de agua, y evitar de esta forma las inundaciones que habían asolado a la Ciudad de México. Tal decrecimiento hizo que la sociedad novohispana reconsiderara los métodos constructivos de la arquitectura hidráulica prehispánica, incorporando al sistema hidráulico virreinal los viejos diques o albarradones para contener y almacenar agua, y así poder continuar con el sistema productivo de las poblaciones periféricas a los lagos, así como a la misma ciudad. Contrariamente a lo que se cree, la sociedad virreinal no negó el entorno lacustre en el que estaba inmersa; tampoco intentó desecar los lagos; lo que buscó, mediante el desagüe, fue mantener un control en el nivel de ellos, y de esta forma asegurar la habitabilidad de la población por un período de tiempo permanente. Dicha continuidad se puede apreciar en la construcción de acequias durante el siglo XVIII y el siglo XIX, en la que los arquitectos de la llustración dieron seguimiento a este método de irrigación agrícola y de navegación.

La forma de las acequias hizo que el trazo de los lotes, en el trayecto de las mismas, se viera supeditado a la forma que iban adquiriendo en su transcurso, haciendo que tuvieran formas irregulares dependiendo de las curvaturas que las acequias tomaban, modificando tanto los lotes que estaban en las riberas de los canales, como los lotes que colindaban con éstos; asimismo, las particularidades de estos lotes no se limitaban a su morfología, sino también a la inclusión de 
elementos arquitectónicos de los que dotaban a los edificios, y que los hacían poseer características únicas (entre éstas se pueden mencionar las puertas falsas, los embarcaderos, y en algunas ocasiones los puentes).

En cuanto a los puntos pendientes que deja la presente investigación, se puede mencionar la búsqueda en archivos históricos de documentos que den cuenta, en el siglo XVIII, del cegamiento parcial de las acequias en cuanto al ancho de las mismas, pues como se puede corroborar a través de planos catastrales y de levantamientos arquitectónicos, existe el testimonio físico de este hecho, habiendo ocurrido, en el caso específico de la acequia de la Merced, una reducción en el ancho de la misma, siendo el ancho en el año de 1773 el de 13 varas (10.85 mts), ajustándose la misma a 8 varas $(6.68 \mathrm{mts})$, que corresponden al año de su cegamiento total en el año de 1788 (hecho que queda asentado en el trazo de los lotes en los planos catastrales).

La búsqueda de documentos aplica también al cegamiento parcial y total de algunas acequias principales, tanto como de las acequias secundarias en cuanto a su longitud (de lo cual no se cuenta con datos). En lo que corresponde a las líneas de investigación en otros períodos, es importante el del siglo XVI y XVII, pues como es sabido (y se puede constatar mediante planos de estos períodos) las acequias prehispánicas seguían el mismo trayecto que las del período virreinal; sin embargo, no es probable que los métodos de construcción de las mismas se hayan mantenido como en el período prehispánico (pues tal como consta en las crónicas de los conquistadores y de contemporáneos de esa época, las acequias fueron destruidas en el sitio a México Tenochtitlán, y reconstruidas durante el nuevo régimen, siendo muy probable que las acequias de la Ciudad de México en el período novohispano hayan sido construidas híbridamente, tanto con métodos de los naturales como con métodos europeos).

En lo respectivo al período que corresponde al siglo XIX, es importante la investigación acerca de las acequias y canales que se construyeron durante entonces, pues algunos de estos elementos fueron de gran magnitud; por ejemplo, los ubicados en la zona sur de la cuenca, que buscaban entre otros objetivos el desagüe por el sur de la Cuenca de México, a la par que disminuir distancias en 
las rutas de navegación del vapor México-Chalco. Entre dichos canales se pueden mencionar el canal de Garay y precisamente el canal de Chalco, además de incluir en este apartado los construidos en la zona norte de la ciudad, donde se continuaban obras de desagües y de diques para contener el agua de los lagos y dar continuidad al sistema productivo de la cuenca (además de brindar obras de canalización para irrigación agrícola y otras actividades productivas).

Muy extenso es el estudio que queda por realizar en lo que respecta a las acequias en el resto del país, de las cuales sobreviven algunas en regiones apartadas o marginadas, en donde la falta de acceso a nuevas tecnologías hace que continúen con este sistema de riego (muy probablemente el uso de éstas se haya mantenido desde el período prehispánico, cambiando los materiales con que se han edificado, aunque manteniendo su trazo original).

Se encuentra en este apartado una gran tarea, pues no hay datos que den testimonio de las acequias en el período virreinal de la zona centro y sur del país, a diferencia de las acequias del norte donde, gracias al interés de los estadunidenses por este tipo de construcciones, se han realizado estudios que dan cuenta de su uso y edificación, provocando investigaciones simultáneas del lado mexicano -no de la cantidad y del detalle que las realizadas por el gobierno de Estados Unidos, pero que por lo menos dan cuenta de este tipo de construcciones en una región determinada de México-. Así, queda pendiente hacer una revisión de estos estudios para ver qué puntos faltan por tocar en dicho apartado. 


\section{ANEXOS}




\section{ANEXO 1}

PLANO DE LA CIUDAD DE MÉXICO CON LOS 480 INMUEBLES DEL SIGLO

XVIII CON USO DE VIVIENDA Y CASAS CON ACEQUIA DEL SIGLO XVIII.

\section{FUENTE: CATÁLOGO DE MONUMENTOS HISTÓRICOS DEL DISTRITO}

FEDERAL, PERÍMETRO “A”, INAH.

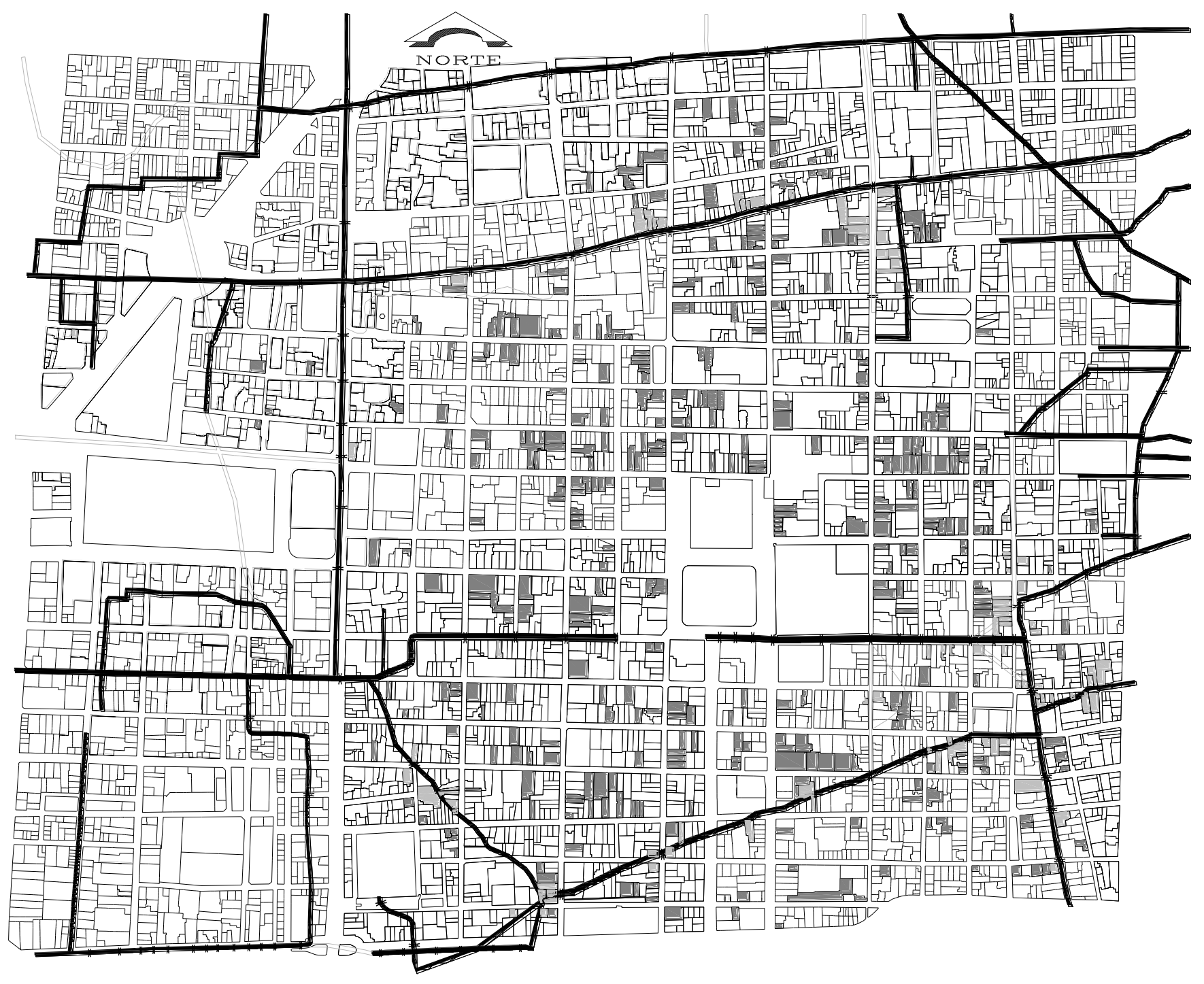

CASAS DEL SIGLO XVIII CON USO DE VIVENDA

CASAS CON ACEQUIA 


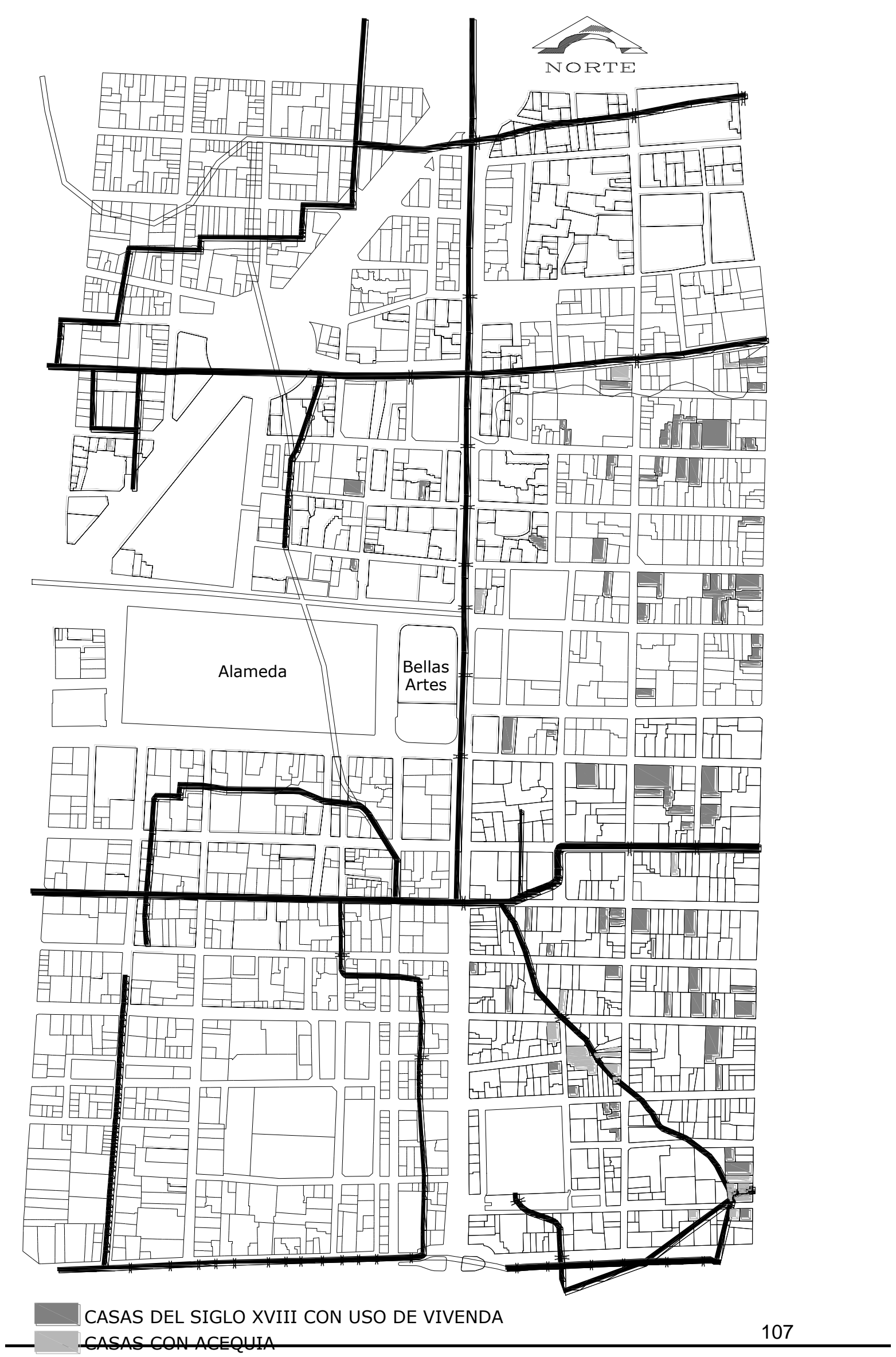




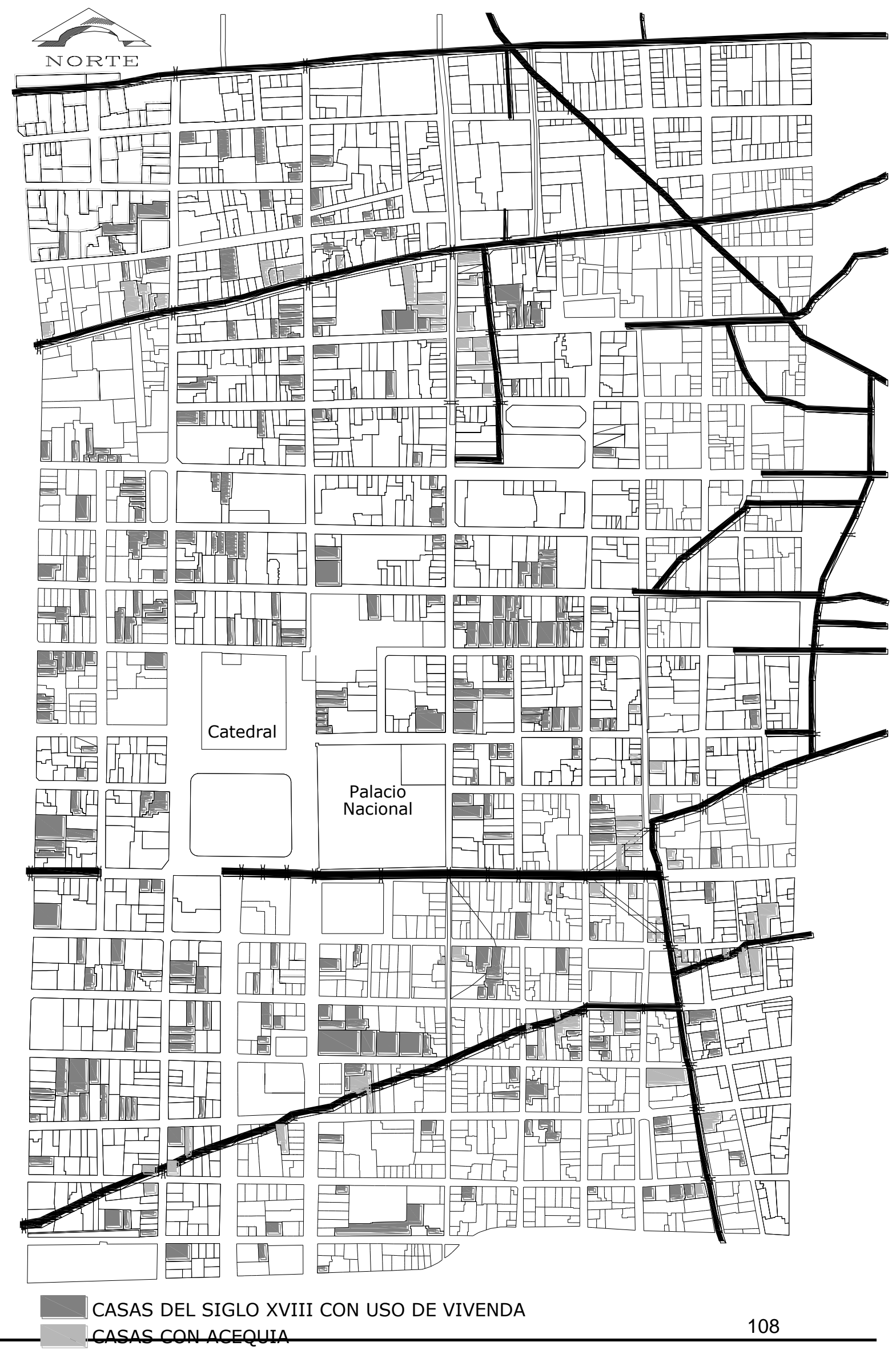




\section{ANEXO 2}

\section{Plano de puentes en la ciudad de México.}

Información basada en los siguientes planos: Plano de Pedro de Arrieta y los Maestros de la Arquitectura de 1737, Plano de José Antonio Alzate de 1772, Plano de Juan Manuel de Villavicencio de 1782, Plano de Diego García Conde de 1793, y Plano de Antonio García Cubas de 1881.

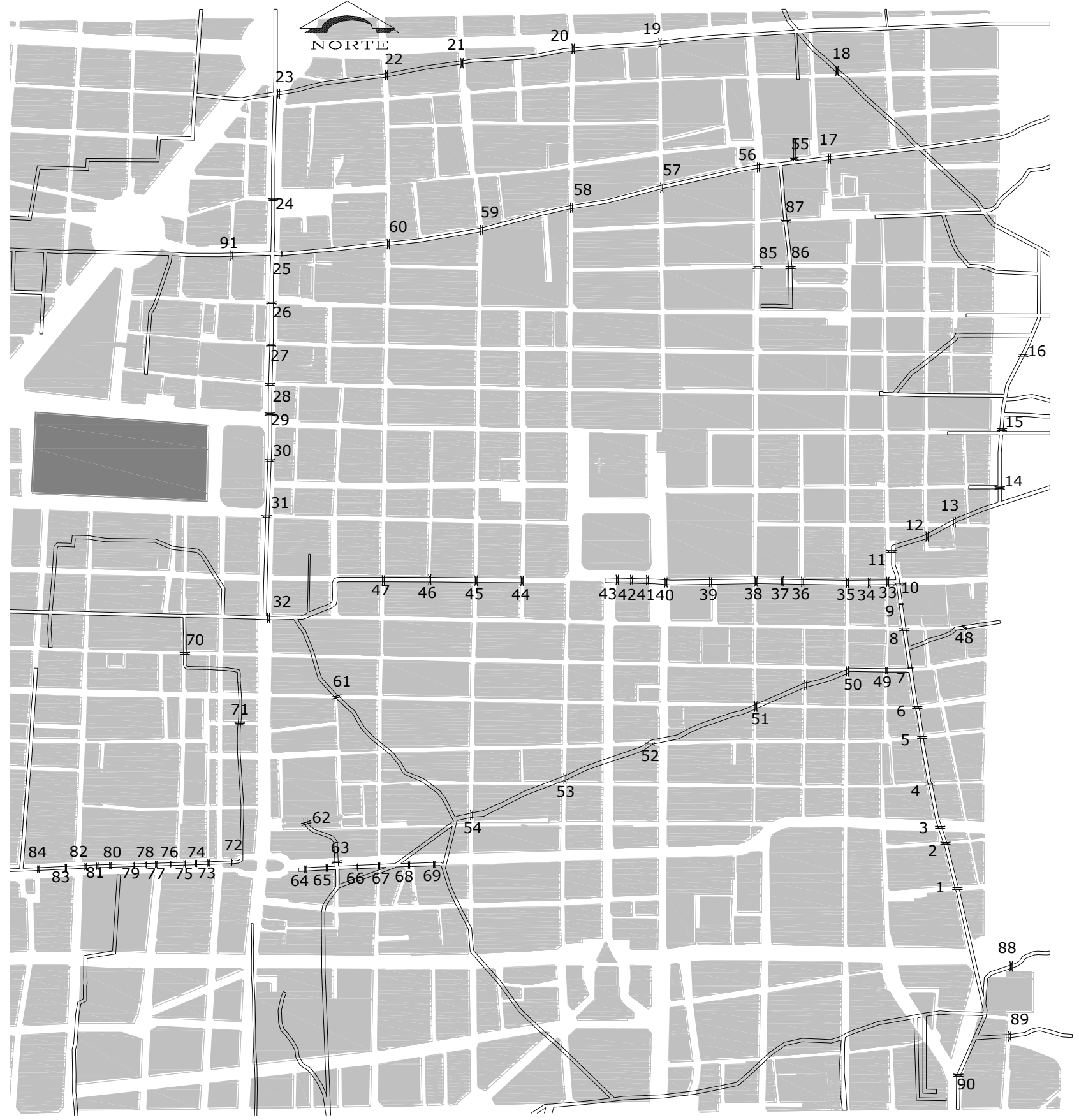


A continuación, se enlistan los puentes localizados en el mapa presentado con anterioridad, con el nombre del puente, su ubicación con nombres de calles en planos del siglo XVIII, y entre paréntesis la ubicación en calles con nomenclatura actual:

1.- Puente de San Pablo o de Santo Tomás, en la calle del Puente de San Pablo y calle de Santa Bárbara (Calle del Puente de Santo Tomás y Roldán)

2.- Puente de la Higuera, calle del Puente de la Higuera y calle de Santa Bárbara (Carretones y Roldán).

3.- Puente en la Calle de la Higuera, calle de la Higuera y calle del Olvido (San Pablo y Roldán).

4.- Puente de los Curtidores, calle del Puente de los Curtidores y calle del Olvido (calle de Misioneros y Roldán).

5.- Puente del Blanquillo, calle del Puente del Blanquillo y calle del Olvido (calle Ramón Corona y Roldán).

6.- Puente Colorado, calle del Puente Colorado y calle del Embarcadero (calle de República del Salvador y Roldán).

7.- Puente de Santiaguito, calle del Puente de Santiaguito y calle del Embarcadero (calle de República de Uruguay y Roldán).

8.- Puente de la Merced, calle del Puente de la Merced y calle del Embarcadero, (calle de Manzanares y Roldán).

9.- Puente sin nombre en la calle del embarcadero, entre la calle del Puente de la Merced y la calle del Puente de la Leña, (frente a la casa de la calle de Roldán No. 7-9-11).

10.- Puente de la Leña, calle del Puente de la Leña y calle del Embarcadero (Corregidora y Roldán). 
11.- Puente de la Alhóndiga o de la Casa del Diezmo, calle de la Alhóndiga o 1․ calle de la Santísima, frente a la casa del Diezmo (calle de la Alhóndiga, frente a la casa del Diezmo).

12.- Puente de Solano en la calle de Alegría y Pajaritos (Soledad y Margil).

13.- Puente de la Soledad en la calle de Santa Cruz y Pacheco (Soledad y San Marcos).

14.- Puente sin nombre en la calle de Calavera y calle sin nombre (Emiliano Zapata y Eje 1 Ote.)

15.- Puente de San Lázaro, calle de San Marcos y calle sin nombre (República de Guatemala y Eje 1 Ote.).

16.- Puente de San Antonio Tomatlán, calle del Puente de San Antonio Tomatlán y calle sin nombre (San Antonio Tomatlán y Eje 1 Ote.).

17.- Puente en la calle de Cantaritos (Florida y Manuel de la Peña y Peña)

18.- Puente en la calle de la espalda de los Cántaros, una calle al oriente de la calle de los Cantaritos, y continuación hacia el oriente de la calle de Basquez (República de Costa Rica, entre Florida y González Ortega, probablemente en el terreno de la casa de República de Costa Rica No. 78).

19.- Puente Blanco, en la $7^{a}$ del Relox y Acequia de Tezontlale (Argentina y Eje 1 Norte).

20.- Puente de Tezontlale, en la calle del Puente de Tezontlale y Acequia de Tezontlale (Brasil y Eje 1 Norte).

21.- Puente en el callejón del Carrizo y la Acequia de Tezontlale (Ignacio Comonfort y Panamá).

22.- Puente del Clérigo, en la calle del Puente de la Misericordia y Acequia de Tezontlale (Allende y Órgano).

23.- Puente de las Guerras, Calle de las Rejas de la Concepción o Calzada de Santa María o Calle del Puente de las Guerras y Acequia de Tezontlale (Eje Central Lázaro Cárdenas y Moctezuma).

24.- Puente en la calle de Santa María y Calle del Puente de las Guerras (Pedro Moreno y Eje Central Lázaro Cárdenas). 
25.- Puente del Zacate, en la calle del Puente del Zacate y Calle de la Cerca de San Lorenzo (República de Perú y Eje Central Lázaro Cárdenas).

26.- Puente de Villamil, en la calle del Puente de Villamil y Calle de las Rejas de la Concepción (Villamil y Eje Central Lázaro Cárdenas).

27.- Puente de San José Carbonero, en la calle de San José Carbonero y Calle de las Rejas de la Concepción (Pensador Mexicano y Eje Central Lázaro Cárdenas).

28.- Puente de los Gallos, en la calle del Puente de los Gallos y Calle de las Rejas de la Concepción (Santa Veracruz y Eje Central Lázaro Cárdenas).

29.- Puente de la Mariscala, en la calle del Puente de la Mariscala y Calle de las Rejas de la Concepción (Av. Hidalgo y Eje Central Lázaro Cárdenas).

30.- Puente de Santa Isabel, en el Callejón de Santa Isabel y Calle de Santa Isabel (Eje Central Lázaro Cárdenas frente al Palacio de Bellas Artes).

31.- Puente de San Francisco, en el Callejón de San Francisco o Calle del Puente de San Francisco y Calle de Santa Isabel (Madero y Eje Central Lázaro Cárdenas).

32.- Puente del Hospital Real, en la calle del Hospital Real y Zuleta (Eje Central Lázaro Cárdenas y Venustiano Carranza).

33.- Puente de Santa Ifigenia, en el callejón de Santa Ifigenia y Calle del Puente de la Leña (Alhóndiga y Corregidora).

34.- Puente sin nombre, en la calle del Puente de la Leña entre el callejón de Santa Ifigenia y Puente de Jesús María (Probablemente frente a la casa de Corregidora No. 62).

35.- Puente de Jesús María, en la calle del Puente de Jesús María y Calle del Puente de la Leña (Jesús María y Corregidora).

36.- Puente de Chiquis, Calle de Chiquis y Calle del Colegio de Santos o Calle de la Estampa de Jesús María (Academia y Corregidora).

37.- Puente sin nombre, en la calle de Calle del Colegio de Santos o Calle de la Estampa de Jesús María (Probablemente frente a la casa de Corregidora No. 22). 
38.- Puente del Correo Mayor o Puente del Indio Triste, en la calle del Puente del Correo Mayor y Calle de los Meleros (Correo Mayor y Corregidora).

39.- Puente del Real Palacio, en la calle de Meleros y calle de Real Palacio, en el costado sur del Palacio Virreinal (Corregidora, costado sur de Palacio Nacional).

40.- Puente sin nombre en la esquina sur-poniente del Palacio Virreinal, calle de Meleros y calle del Real Palacio, frente a la plaza del Volador, (Corregidora y Pino Suárez).

41, 42, 43.- Tres Puentes sin nombre, frente al portal de las flores, calle del Portal de las Flores, en la parte sur de la Plaza de Palacio (Edificio Oriente del Ayuntamiento en la parte sur de la Plaza de la Constitución).

44.- Puente de la Palma, en la calle de la Palma y calle de los Tlapaleros (Palma y 16 de septiembre).

45.- Puente del Espíritu Santo, en la calle del Espíritu Santo y calle de los Tlapaleros (Isabel la Católica y 16 de septiembre).

46.- Puente en el Callejón del Espíritu Santo, en el Callejón del Espíritu Santo y calle del Coliseo Viejo (Motolinía y 16 de septiembre).

47.- Puente en la calle del Coliseo, en la calle del Coliseo y calle del Coliseo Viejo (Bolívar y 16 de septiembre).

48.-Puente de Manzanares, en la $2^{a}$. Calle de Manzanares, frente a la capilla del Señor de la Humildad (calle de Manzanares y callejón de Manzanares).

49.- Puente en la calle de la Puerta Falsa de la Merced, en la calle de la Puerta de la Merced y Talavera (República de Uruguay y Talavera).

50.- Puente del Fierro, en la calle del Puente del Fierro y calle de la Puerta Falsa de la Merced (Jesús María y Uruguay).

51.- Puente de Balvanera, en calle del Puente de Balvanera y Quezadas (Correo Mayor y República del Salvador).

52.- Puente de San Dimas o Puente de Jesús, en la calle del Puente de San Dimas y calle del Puente de Jesús (Mesones y Pino Suárez).

53.- Puente de la Aduana Vieja, 1a․ Calle de la Aduana y calle de San Felipe de Jesús (5 de febrero y Regina). 
54.- Puente de Monzón, en la calle del Puente de Monzón y San Gerónimo (Isabel la Católica y San Jerónimo).

55.- Puente sin nombre, en la Plaza del Carmen, una calle al oriente de la calle del Carmen (Plaza del Estudiante, Apartado casi esquina con 2ํ. Callejón de Girón).

56.- Puente sin nombre, en la calle del Carmen y Apartado (Carmen y Apartado).

57.- Puente de Leguisamo, en la calle del Puente de Leguisamo y calle del Apartado (Argentina y Apartado).

58.- Puente de Santo Domingo, en la calle del Puente de Santo Domingo y calle de la Pulquería de Celaya (Brasil y República de Perú).

59.- Puente en la calle $2^{a}$. de la Pila Seca, calle $2^{a}$. de la Pila Seca y calle de la Estampa de la Misericordia (República de Chile y República de Perú).

60.- Puente de la Misericordia, en la calle del Puente de la Misericordia y calle de la Estampa de la Misericordia (Allende y República de Perú).

61.-Puente Quebrado o Puente la Quebrada, en la calle de Puente la Quebrada y callejón de las Pañeras (República del Salvador y Aldaco).

62.- Puente sin nombre, en la Plaza de las Vizcaínas, en la parte sur del Colegio de las Vizcaínas (Plaza de las Vizcaínas).

63.- Puente sin nombre, en la calle Verde, entre la calle de la Tecpan de San Juan y Calle $2^{-a}$ de la Estampa de Regina (José María Izazaga, entre Eje Central Lázaro Cárdenas y Bolívar, probablemente frente a la casa de Izazaga No. 32).

64, 65.- Dos Puentes sin nombre, en la calle Verde entre Calzada de la Piedad y calle sin nombre (José María Izazaga, entre Eje Central Lázaro Cárdenas e lgualdad).

66.- Puente $\sin$ nombre, en la calle Verde, entre calle $\sin$ nombre y calle $2^{\underline{a}}$ de la Estampa de Regina (José María Izazaga, entre Igualdad y Bolívar).

67.- Puente sin nombre, en la calle Verde y calle $2^{\underline{a}}$ de la Estampa de Regina (José María Izazaga y Bolívar). 
68.- Puente sin nombre, en la calle Verde, entre calle $2^{\underline{a}}$ de la Estampa de Regina y calle sin nombre (José María Izazaga, entre Bolívar y Callejón Nezahualcóyotl).

69.- Puente sin nombre, en la calle Verde, entre calle sin nombre y calle del Chapitel de Monserrate (José María Izazaga, entre callejón Nezahualcóyotl e Isabel la Católica).

70.- Puente del Santísimo, en la calle del Puente del Santísimo y calle de la Victoria (Dolores y Victoria).

|71.- Puente de Peredo, en la calle del Puente de Peredo entre el callejón de San Pedro y la calle del Tecpan de San Juan (Puente Peredo entre López y Eje Central Lázaro Cárdenas).

72.- Puente del Salto del Agua, en la calle del Salto del Agua, entre el callejón de San Pedro y la calle del Tecpan de San Juan (Arcos de Belem, entre López y Eje Central Lázaro Cárdenas).

73.- Puente sin nombre, en la calle de Aranda y calle del Salto del Agua (Aranda y Arcos de Belem)

74, 75.- Dos Puentes sin nombre, en la calle del Salto del agua, entre la calle de Aranda y la calle de la Chiquigüitera (Arcos de Belem, entre Aranda y Buentono).

76, 77, 78, 79, 80, 81, 82.- Siete puentes sin nombre, en la calle de la Quemada, entre la calle de la Chiquigüitera y callejón de la Ancha (Arcos de Belem, entre Buentono y Luis Moya).

83, 84.- Dos Puentes sin nombre, en la calle del Colegio de San Miguel de Belem, entre callejón de la Ancha y callejón de los Reyes (Arcos de Belem, entre Luis Moya y Revillagigedo).

85.- Puente del Carmen, en la calle del Puente del Carmen y calle del Puente del Cuervo (Carmen y República de Colombia).

86.- Puente del Cuervo, en la calle del Puente del Cuervo y calle sin nombre (República de Colombia y 1er callejón de Girón).

87.- Puente de San Sebastián, en la calle del Puente de San Sebastián y calle sin nombre (República de Bolivia y $2^{\circ}$ callejón de Girón). 
88.- Puente sin nombre, cerca de la compuerta nueva de la Acequia Real y de la Capilla de San Diego (Fray Servando Teresa de Mier, entre Calzada de la Canal e Ixnahualtongo).

89.- Puente de Garavito, cerca de la compuerta nueva de la Acequia Real (calle del Canal y Cuitláhuac).

90.- Puente del Pipis, cerca de la compuerta nueva de la Acequia Real (Calzada del Canal y Calzada de la Viga).

91.- Puente sin nombre, en el sureste del templo de Santa María la Redonda, calle de Obispo y calle sin nombre (Violeta y Rivapalacio). 


\section{ANEXO 3}

OBRAS HIDRÁULICAS EN LA CUENCA DE MÉXICO EN EL SIGLO XVIII.

FUENTE: ÁNGEL PALERM, Obras hidráulicas prehispánicas en el sistema lacustre del Valle de México, SEP, INAH, México 1973, p 233.

\section{I.- En los lagos meridionales de agua dulce (Chalco-Xochimilco)}

\section{A. Calzadas-dique, acueductos, albarradones.}

1.- México-Xochimilco, calzada-dique.

2.- Coyoacán-Culhuacán, calzada-dique.

3.- Tláhuac calzada-dique.

4.- San Agustín de las Cuevas-México, acueducto.

B.- Acequias, canales, puertos y ríos canalizados.

5.- Xochimilco, San Agustín de las Cuevas, Tlalmanalco, Tepolula, Sierra Nevada, (manantiales, ríos y avenidas que alimentan las lagunas de Chalco y Xochimilco, algunos de ellos canalizados).

6.- Chalco-Xochimilco-México, acequia navegable.

7.- Amecameca y Tepolula, (cambio del curso del río hacia Chimalhuacán, por medio de represas.

\section{C.- Otros rasgos hidráulicos (chinampas, etc.)}

8.- Xochimilco, chinampas.

9.- Mexicalcingo, compuertas por las que vierten al lago de Texcoco el agua de los lagos de Chalco y Xochimilco.

II.- En los lagos centrales de agua salobre (Texcoco-México).

\section{A.- Calzadas-diques, acueductos, albarradones.}

10.- Tepeyac-San Lázaro-San Antón (albarradón de Ahuízotl, rodeando la ciudad en forma semicircular).

11.- Ecatepec-Chiconautla (Acalhuacan), calzada-dique.

12.- Albarradón de Nezahualcóyotl, (paralelo al de Ahuízotl).

13.- Tepeyac-Tlatelolco, calzada-dique.

14.- Coyoacán-calzada México-Ixtapalapa, calzada-dique.

15.- México-Ixtapalapa, calzada dique. 
16.- Chapultepec-México, calzada dique.

17.- Acolman, dique sobre el río de San Juan Teotihuacán, formando una laguna artificial.

18.- Tacuba-México, calzada dique.

19.- Azcapotzalco-México, calzada-dique.

20.- Churubusco-México, acueducto sobre calzada.

21.- Pantitlán, albarrada.

22.- México-Tenayuca.

23.- México-La Piedad, calzada-dique.

\section{B.- Acequias, canales, puertos y ríos canalizados.}

24.- Los Remedios-Azcapotzalco, Tlalnepantla, San Mateo y Guadalupe (ríos canalizados que vierten en la laguna de México por el norte; desaguan al lago de Texcoco por el puente de Guadalupe).

25.- Coyoacán, Cuajimalpa, Mixcoac, Tacubaya, (ríos canalizados que vierten en la laguna por el este, al final de la calzada de San Antón, parte del albarradón de Ahuízotl.

26.- Sanctorum (Tecamachalco) y Morales (arroyos canalizados que riegan el ejido de Chapultepec y desaguan en el lago de Texcoco).

27.- San Juan Teotihuacán, Otumba, Apan, Calpulalpan, Los Jardines, Papalotla, Texcoco, (ríos y arroyos algunos de ellos canalizados, que vierten en el Lago de Texcoco).

28.- México, siete acequias navegables que rodean la ciudad: la que pasa frente al Palacio, la que pasa frente al convento del Carmen, la de la Merced, la del Chapitel, la del Tezontlal, la que pasa frente a la ermita de Santa Ana y la que viene de Mexicaltzingo.

29.- Chapultepec-San Antón-Pantitlán, acequia navegable.

30.- Mexicalcingo-Pantitlán, acequia.

\section{C.- Otros rasgos hidráulicos (chinampas, etc.).}

31.- Calzada Tepeyac-San Antón (albarradón de Ahuízotl, siete compuertas para desaguar las siete acequias navegables que rodean la ciudad).

32.- México, chinampas (camellones de tierra portátil, huertas y arboledas). 
33.- Tacuba, chinampas, (huertas).

34.- Pantitlán, sumidero escalonado.

35.- Pantitlán, compuerta controlada por buzos.

\section{En los lagos septentrionales de agua dulce (Citlaltépetl, Zumpango, Jaltocan, Ecatepec).}

\section{A.- Calzadas-diques, acueductos, albarradones.}

36.- Zumpango, calzada-dique (al sur de la laguna).

37.- Acolman. Dique sobre el río de San Juan Teotihuacán, formando una laguna artificial.

38.- Tizayuca, dique sobre las avenidas de Pachuca, formando una laguna artificial con salida hacia Zumpango .

39.- Zumpango, calzada-dique separando la laguna de Zumpango de la de Citlaltépetl.

\section{B.- Acequias, canales, puertos y ríos canalizados.}

40.- Tepotzotlán, San Miguel, Cuautitlán, avenidas de Pachuca y Real del Monte, (ríos, algunos de ellos canalizados, que vierten en la laguna de Zumpango y luego en la de Ecatepec).

41.- Desagüe de Huehuetoca. 


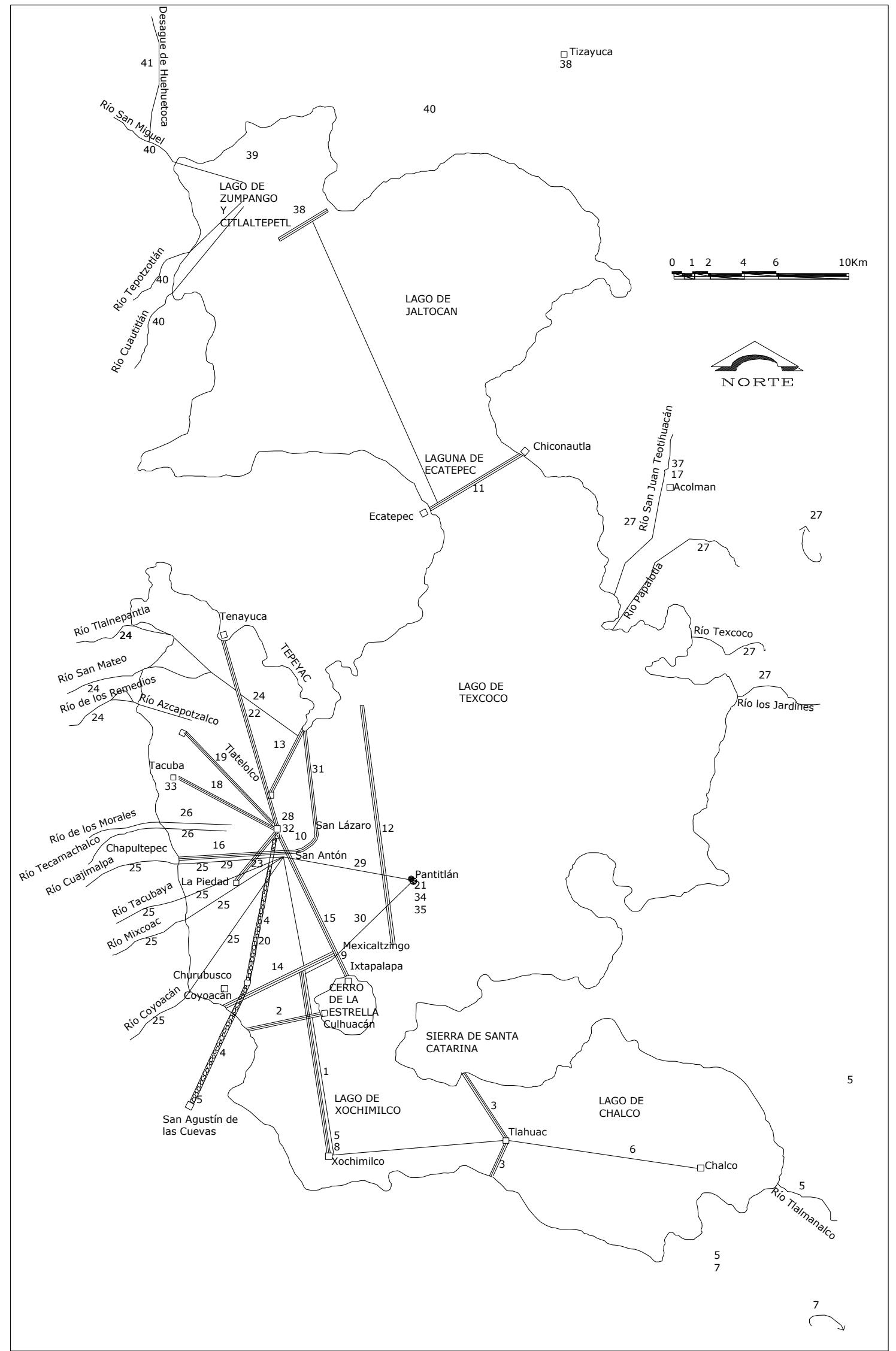




\section{Glosario}

Acalli. (del nahua Atl: Agua, Calli: Casa) Canoa de fondo plano sin vela ni timón, con grandes remos o pértigas que se acomodaban en el fondo, o con paletas en aguas profundas. (BHNCM)

Acalote. (Del nahua: Atl-agua, calli-casa, otli, camino). (LCMPT) Canal de gran dimensión que servía como vía de comunicación primaria en toda la cuenca de México. (NA)

Acequia. (Del ár. hisp. assáqya, y este del ár. clás. sāqiyah, irrigadora). Zanja o canal por donde se conducen las aguas para regar y para otros fines. (DRAE)

Acueducto. Del lat. aquaeductus). Conducto artificial por donde va el agua a lugar determinado, y especialmente el que tiene por objeto abastecer de aguas a una población. (DRAE). Este conducto puede ser subterráneo, superficial o aéreo. (NA).

Ahuejote. (Del nahua ahuexotl, sauce de agua). Nombre genérico de varios árboles de la familia de las Salicáceas. (DRAE). Árbol con silueta espigada que crece en las riberas de lagos y canales de la cuenca de México.

Alarife. (Del ár. hisp. al'aríf, y este del ár. clás. 'arîf, experto). Arquitecto o maestro de obras. (DRAE), conocedor de las artes de la construcción. (DAU)

Albarradón. (Del ár. al-barrada) Pared de piedras secas, sin mortero. En la ciudad de México del siglo XVI, designación de los diques construidos, para contener el agua de los lagos en la cuenca y evitar las inundaciones. (NA)

Alcabala. (Del ár. hisp. alqabála). Tributo del tanto por ciento del precio que pagaba al fisco el vendedor en el contrato de compraventa y ambos contratantes en el de permuta. Tributo que pagaba el forastero por los géneros que vendía. (DRAE)

Apantle. (Del nahua atl, agua, y pantli, hilera, fila). Acequia para regar. (DRAE) Canales que, en la cuenca de México, servían para conducir las corrientes de las aguas de los lagos y para la navegación, a la vez servían para el riego chinampas. (NA) 
Atlazompa. (Del nahua: Atl: Agua, Tzompa: cabeza) Chinampas atlazompa: Cultivos concentrados en pequeños núcleos, intercomunicados internamente y entre ellos por medio de pequeños canales. (NA)

Atarjea. (Del ár. hisp. attašyí', y este del ár. clás. tašyī', acompañamiento). Caja de ladrillo con que se visten las cañerías para su defensa. Conducto o encañado por donde las aguas de la casa van al sumidero. Méx. Canal pequeño de mampostería, a nivel del suelo o sobre arcos, que sirve para conducir agua. (DRAE)

Azud. (Del ár. hisp. assúdd, y este del ár. clás. sudd). Máquina con que se saca agua de los ríos para regar los campos. Es una gran rueda afianzada por el eje en dos fuertes pilares, y la cual, movida por el impulso de la corriente, da vueltas y arroja el agua fuera. Presa hecha en los ríos a fin de tomar agua para regar y para otros usos. (DRAE)

Canal. (Del lat. Canalis, is, tubo, caño, conducto de agua, canal cubierto o no). Cauce artificial para conducir el agua tanto de riego como de uso urbano. Talla o vaciado en forma de medio cilindro o tubo, practicado en cualquier elemento. (DAU).

Canoa. (De or. taíno). Embarcación de remo muy estrecha, ordinariamente de una pieza, sin quilla y sin diferencia de forma entre proa y popa. Canal de madera u otra materia para conducir el agua. (DRAE)

Chinampa. Chinampa: del náhuatl chinámitl que quiere decir reja o seto de cañas. Armazón hecho con cuerdas de ixtle y con troncos delgados de árbol, sobre los cuales se ponían transversalmente cañas más delgadas y una capa gruesa de tierra vegetal. (LCMPT)

Compuerta. Plancha fuerte de madera o de hierro, que se desliza por carriles o correderas, y se coloca en los canales, diques, etc., para graduar o cortar el paso del agua. (DRAE)

Cuenca. (Del lat. concha). Territorio rodeado de alturas. Territorio cuyas aguas afluyen todas a un mismo río, lago o mar. (DRAE) Tipos: Una cuenca endorreica se caracteriza 
porque todas sus aguas son descargadas hacia un cuerpo de agua interior, también se le denomina cuenca cerrada. En la cuenca exorreica, los escurrimientos confluyen y desembocan en el mar o en un sistema lagunar costero. Una cuenca arreica no tiene salida hacia el mar ni tampoco drena hacia un cuerpo de agua colector observable. (DCHM)

Data. Data'. (Del lat. tardío [charta] data, propiamente 'documento dado', es decir, extendido, otorgado, palabra que en las escrituras latinas precede a la indicación del lugar y la fecha).Abertura para desviar de un embalse o de una corriente de agua parte de su caudal. (DRAE) Esta abertura puede ser rectangular o circular, con cierta medida para dejar pasar determinadas cantidades de agua (NA).

Desembarcadero. Lugar destinado o que se elige para desembarcar. (DRAE)

Dique. (Del neerl. dijk). Muro o construcción para contener las aguas. (DRAE)

Embarcadero. Lugar acondicionado para embarcar mercancías o gente. (DRAE)

Garita. (Del fr. ant. garite, hoy guérite). Torre pequeña de fábrica o de madera fuerte, con ventanillas largas y estrechas, que se coloca en los puntos salientes de las fortificaciones para abrigo y defensa de los centinelas. Casilla pequeña, para abrigo y comodidad de centinelas, vigilantes, guardafrenos, etc. Cuarto pequeño que suelen tener los porteros en el portal para poder ver quién entra y sale. Méx. Entrada de la ciudad. (DRAE)

Gárgola. (Del b. lat. gargŭla). Parte final, por lo común vistosamente adornada, del caño o canal por donde se vierte el agua de los tejados o de las fuentes. (DRAE)

Inmundicia. (Del lat. immunditia). suciedad (cosa que ensucia). (DRAE)

Lebrillo. (De or. inc.). Vasija de barro vidriado, de plata u otro metal, más ancha por el borde que por el fondo, y que sirve para lavar ropa, para baños de pies y otros usos. (DRAE) 
Otate. (Del nahua otlatl, clase de carrizo, bastón). Tallo de esta planta. (DRAE) Caña maciza muy dura que se da cerca de los ríos. Vara que puede ser obtenida del carrizo, de ramas o tallos de plantas y árboles de espesor similar, ya secas se utilizan para hacer muros o enramadas para cubiertas (NA).

Puente. (Del lat. pons, pontis). Construcción de piedra, ladrillo, madera, hierro, hormigón, etc., que se construye y forma sobre los ríos, fosos y otros sitios, para poder pasarlos. Suelo que se hace poniendo tablas sobre barcas, odres u otros cuerpos flotantes, para pasar un río. (DRAE)

Riba. (Del lat. ripa). Porción de tierra con alguna elevación y declive. Tierra cercana a los ríos. Margen y orilla del mar o río. (DRAE)

Sifón. (Del lat. sipho, -ōnis, y este del gr. oí $\varphi \omega v$ ). Tubo encorvado que sirve para sacar líquidos del vaso que los contiene, haciéndolos pasar por un punto superior a su nivel. Tubo doblemente acodado, en que el agua detenida dentro de él impide la salida de los gases de las cañerías al exterior. Arq. Canal cerrado o tubo que sirve para hacer pasar el agua por un punto inferior a sus dos extremos. (DRAE)

Tajo. (De tajar). Corte hecho con instrumento adecuado. Filo o corte. Escarpa alta y cortada casi a plomo. (DRAE)

Trajinera. (De Trajinar, llevar una carga de un lado a otro). Embarcación utilizada para transportar carga en los lagos del Valle de México. (DRAE).

Trinchera. (Del it. trincera). Zanja defensiva que permite disparar a cubierto del enemigo. Desmonte hecho en el terreno para una vía de comunicación, con taludes por ambos lados. (DRAE)

Zanja. (De zanjar). Excavación larga y estrecha que se hace en la tierra para echar los cimientos, conducir las aguas, defender los sembrados o cosas semejantes. (DRAE) 


\section{Fuentes:}

DRAE. Diccionario de la Real Academia Española. www.rae.es/

DAU. CAMACHO CARDONA, Mario, Diccionario de Arquitectura y Urbanismo, Editorial Trillas, México, 1998.

DCHM. INEGI-INE-CONAGUA, 2007. Documento técnico del mapa de Cuencas hidrográficas de México (escala 1: 250 000). "Delimitación de las Cuencas Hidrográficas de México", elaborada por Priego A.G., Isunza E., Luna N. y Pérez J.L

LCMPT. VALERO DE GARCíA LASCURÁIN, Ana Rita, "La ciudad de México Tenochtitlán, su primera traza 1524-1534”, Editorial Jus, México, 1992.

BHNCM. SIERRA, Carlos Justo, "Breve Historia de la Navegación en la Ciudad de México", Departamento del Distrito Federal, 1973,

NA. Nota del Autor. (Alejandro Jiménez Vaca).

\section{FUENTES DE INFORMACIÓN}

\section{LIBROS}

APENES, Ola, SEFI (Sociedad de exalumnos de la Facultad de Ingeniería de la Universidad Nacional Autónoma de México), Mapas Antiguos del Valle de México, UNAM, México 1984.

BARRIO LORENZOT, Juan Francisco del, El trabajo en México durante la época colonial: ordenanzas de gremios de la Nueva España, Secretaría. De Gobernación, México 1920.

BENÍTEZ, Fernando, Historia de la Ciudad de México, Tomo 2, Editorial Salvat, 1984

CAMACHO CARDONA, Mario, Diccionario de Arquitectura y Urbanismo, Editorial Trillas, México, 1998.

CERVANTES DE SALAZAR, Francisco, México en 1554, UNAM, México, 2007. 
CUEVAS AGUIRRE Y ESPINOSA, Francisco de, Extracto de las diligencias y reconocimiento de los Ríos, Lagunas y desagües de la capital de México y su valle: de los caminos para su comunicación y su comercio, México SEFI, 1979.

DE LA TORRE VILLALPANDO, Guadalupe, Los muros de agua. El resguardo de la Ciudad de México, siglo XVIII, coedición INAH, GDF, México. 1999.

ERSKINE INGLIS, Frances La vida en México durante una residencia de dos años en ese país, Editorial Noriega, Madrid, España, 2009.

ESPINOZA LÓPEZ, Enrique, Ciudad de México, Compendio Cronológico de su Desarrollo Urbano, 1521-1980, México 1991.

GARCÍA SALGADO, Tomás, Conferencias del bicentenario de la fundación de la Escuela de Pintura, Escultura y Arquitectura, UNAM, México, 1984.

GALVÁN RIVERA, Mariano, Ordenanzas de tierras y aguas, Registro Agrario Nacional: Centro de Investigaciones y Estudios Superiores en Antropología Social, México,1998.

GONZÁLEZ AVELLANEDA, Albert y/otros, Manual Técnico de Procedimientos para la Rehabilitación de Monumentos Históricos en el Distrito Federal, INAH, México.

GONZÁLEZ LICÓN, Héctor Javier, Glosario de Términos Técnico Arquitectónicos, Universidad Michoacana de San Nicolas de Hidalgo, 1994.

HERNÁNDEZ FRANYUTI, Regina Ignacio de Castera, Arquitecto y urbanista de la Ciudad de México, 1777-1811, Instituto Mora, México, 1997.

HERRERA MORENO, Ethel, 500 planos de la Ciudad de México: 1325 -1933, México, SAHOP. 1992

LENZ, Hans, México-Tenochtitlán, Ciudad Lacustre, Según el relato de sus cronistas, Porrúa, México, 1969

MARROQUI, José María, La Ciudad de México, Tomo I, II, III, J. Medina, México, 1969.

MUSSET, Alain, El Agua en el Valle de México, siglos XVI-XVIII, Pórtico de la Ciudad de México, México, 1992.

NOVO, Salvador, Los paseos de México, Fondo de Cultura Económica, México, 1974

PALERM, Ángel, Obras hidráulicas prehispánicas en el sistema lacustre del Valle de México, SEP, INAH, México 1973.

PINEDA MENDOZA, Raquel, Origen, vida y muerte del acueducto de Santa Fe, Instituto de Investigaciones Estéticas, UNAM, México, 2000.

RIVERA CAMBAS, Manuel, México pintoresco, artístico y monumental, 1840-1917, Editorial del Valle de México, México, 1974. 
ROJAS, Pedro, La casa de los mascarones, UNAM, Instituto de Investigaciones Estéticas, México, 1985.

ROJAS, Pedro, Historia General del Arte Mexicano, Época Colonial, Editorial Hermes S.A. 1963.

ROJAS RABIELA, Teresa; Strauss K.; Rafael A., Lameiras, José, Nuevas noticias sobre las obras hidráulicas prehispánicas y coloniales en el Valle de México, Instituto Nacional de Antropología e Historia, México, 1974.

ROJAS RABIELA, Teresa, Sanders, William T., Historia de la Agricultura, Época prehispánica siglo XVI, Tomo II, Instituto Nacional de Antropología e Historia, México, 1989.

ROMERO DE TERREROS, Manuel, Residencias Coloniales de México, Monografías Mexicanas de Arte, publicadas por la Dirección General de Bellas Artes y dirigida por Jorge Enciso, Inspector General de Monumentos Artísticos, México, 1918.

SIERRA, Carlos Justo, Historia de la navegación en la Ciudad de México, Departamento del Distrito Federal México, 1973.

TOUSSAINT, Manuel, Planos de la Ciudad de México, Siglos XVI y XVII, UNAM, México, 1990.

TOUSSAINT, Manuel, Arte Colonial en México, UNAM, México, 1990.

TOVAR DE TERESA, Guillermo, México Barroco, SAHOP, México, 1981.

TOVAR DE TERESA, Guillermo, La Ciudad de los Palacios; Crónica de un Patrimonio Perdido, Edit. Vuelta, México, 1992. Clasificación:

TRUEBLOOD, Beatrice, La Ciudad Antigua de México, Siglos XVI-XX, Bancomer, México, 1990.

TURRIANO, Juanelo, Los Veintiún Libros de los Ingenios y Máquinas de Juanelo Turriano, Tomos I, II y V, Biblioteca Nacional. Madrid, Ministerio de Cultura, Fundación Juanelo Turriano y Ediciones Doce Calles, España, 1996.

VALERO DE GARCÍA LASCURÁIN, Ana Rita, Solares y conquistadores: Orígenes de la propiedad en la ciudad de México, El Colegio de México, 1991

VALERO DE GARCÍA LASCURÁIN, Ana Rita, La ciudad de México-Tenochtitlán su primera traza 1524-1534, Editorial Jus, México, 1992.

VETANCOURT, Agustín de; San Vicente, Juan Manuel de; Viera, Juan de; La Ciudad de México en el Siglo XVIII (1690-1780) Tres Crónicas, Dirección General de Publicaciones, CONACULTA, México, 1990.

\section{TESIS}


BRAVO GUERRERO, Sandra Cynthia, Mesones y Ventas en la Nueva España, Arquitectura de Hospedaje, Tesis de Maestría, Facultad de Arquitectura, Restauración de Monumentos, UNAM, 2006

HERNÁNDEZ PONS, Elsa Cristina, La Acequia Real: Historia de un Canal de Navegación, Tesis de Doctorado en Estudios Mesoamericanos, Facultad de Filosofía y Letras, UNAM, 2002.

HORZ BALBÁS, Elena, La vivienda media de la Ciudad de México, época colonial, Tesis Maestría, Historia del Arte 1980, UNAM

LÓPEZ BARRERA, Sergio, Restauración y reutilización de una casa del siglo XVIII, en el antiguo barrio de San Sebastián Atzacoalco, Tesis de Maestría, Facultad de Arquitectura, Restauración de Monumentos, UNAM, 2008.

NIETO GARCÍA, Raúl Cándido, Restauración de una vivienda del siglo XVIII: Mesones 94, Tesis de Maestría, Restauración de Monumentos, Facultad de Arquitectura, Restauración de Monumentos, UNAM.

PASTRANA SALCEDO, Tarsicio, Agua y Arquitectura, Ingeniería Hidráulica Virreinal, Tesis de Doctorado, Facultad de Arquitectura, UNAM, 2008.

VELOZ LEIJA, Claudia Liliana, Las casas de renta de la orden de los Agustinos en la Ciudad de México, Tesis de Maestría, Facultad de Arquitectura, Restauración de Monumentos, UNAM 2008.

\section{REVISTAS:}

Acequias, Universidad Iberoamericana Laguna, Torreón Coahuila, Núm. 1.

Arqueología Mexicana, "Lagos del Valle de México", Vol. XII, Núm. 68, p, 31 y 32.

SANDRE OSORIO, Israel, Boletín del Archivo Histórico del Agua, SEMARNAT, CONAGUA, México, Año 12, No. 35, enero-abril, 2007, p. 46 a 49. 
